\title{
Task 10 - Technology Development Integration
}

\author{
Semi-Annual Report
}

April 1 - September 30, 1996

By

John G. Hendrikson

Daniel J. Daly

Work Performed Under Contract No.: DE-FC21-94MC31388

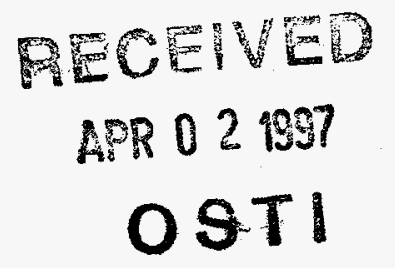

For

U.S. Department of Energy

Office of Environmental Management Office of Technology Development Washington, DC
U.S. Department of Energy Office of Fossil Energy Morgantown Energy Technology Center Morgantown, West Virginia
By

Energy and Environmental Research Center Grand Forks, North Dakota
Ht

DISTRIBUTION OF THIS DOCUMENT IS UNLIMITED 


\section{Disclaimer}

This report was prepared as an account of work sponsored by an agency of the United States Government. Neither the United States Government nor any agency thereof, nor any of their employees, makes any warranty, express or implied, or assumes any legal liability or responsibility for the accuracy, completeness, or usefulness of any information, apparatus, product, or process disclosed, or represents that its use would not infringe privately owned rights. Reference herein to any specific commercial product, process, or service by trade name, trademark, manufacturer, or otherwise does not necessarily constitute or imply its endorsement, recommendation, or favoring by the United States Government or any agency thereof. The views and opinions of authors expressed herein do not necessarily state or reflect those of the United States Government or any agency thereof. 


\section{DISCLAMIER}

Portions of this document may be illegible in electronic image products. Images are produced from the best available original document. 


\title{
Task 10 - Technology Development Integration
}

\author{
Semi-Annual Report \\ April 1 - September 30, 1996
}

\author{
By \\ John G. Hendrikson \\ Daniel J. Daly
}

Work Performed Under Contract No.: DE-FC21-94MC31388

For

U.S. Department of Energy

Office of Environmental Management

Office of Technology Development

1000 Independence Avenue

Washington, DC 20585
U.S. Department of Energy

Office of Fossil Energy

Morgantown Energy Technology Center

P.O. Box 880

Morgantown, West Virginia 26507-0880

\section{By}

Energy and Environmental Research Center

University of North Dakota

P. O. Box 9018

Grand Forks, North Dakota 58202-9018 


\section{DISCLAIMER}

This semiannual report was prepared as an account of work sponsored by an agency of the United States Government. Neither the United States Government, nor any agency thereof, nor any of their employees makes any warranty, express or implied, or assumes any legal liability or responsibility for the accuracy, completeness, or usefulness of any information, apparatus, product, or process disclosed or represents that its use would not infringe privately owned rights. Reference herein to any specific commercial product, process, or service by trade name, trademark, manufacturer, or otherwise does not necessarily constitute or imply its endorsement, recommendation, or favoring by the United States Government or any agency thereof. The views and opinions of authors expressed herein do not necessarily state or reflect those of the United States Government or any agency thereof.

\section{EERC DISCLAIMER}

This semiannual report was prepared by the Energy \& Environmental Research Center (EERC), an agency of the University of North Dakota, as an account of work sponsored by the U.S. Department of Energy, Morgantown Energy Technology Center. Because of the research nature of the work performed, neither the EERC nor any of its employees makes any warranty, express or implied, or assumes any legal liability or responsibility for the accuracy, completeness, or usefulness of any information, apparatus, product, or process disclosed or represents that its use would not infringe privately owned rights. Reference herein to any specific commercial product, process, or service by trade name, trademark, manufacturer, or otherwise does not necessarily constitute or imply its endorsement or recommendation by the EERC.

\section{ACKNOWLEDGMENT}

This semiannual report was prepared with the support of the U.S. Department of Energy (DOE) Morgantown Energy Technology Center Cooperative Agreement No. DE-FC2194MC31388. However, any opinions, findings, conclusions, or recommendations expressed herein are those of the author(s) and do not necessarily reflect the views of DOE. 


\section{TABLE OF CONTENTS}

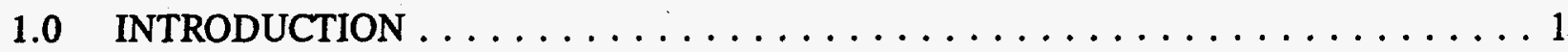

2.0 OBJECTIVES AND ACTIVITIES $\ldots \ldots \ldots \ldots \ldots \ldots \ldots \ldots \ldots \ldots \ldots \ldots$

3.0 ACCOMPLISHMENTS/WORK PERFORMED $\ldots \ldots \ldots \ldots \ldots \ldots \ldots$

4.0 WORK PLANNED FOR NEXT 6 MONTHS $\ldots \ldots \ldots \ldots \ldots \ldots \ldots$

Waste Policy Institute Monthly Report to the EERC, April 1996 . . . . . . . . . . . Appendix A

Waste Policy Institute Monthly Report to the EERC, May 1996 . . . . . . . . . . . Appendix B

Waste Policy Institute Monthly Report to the EERC, June 1996 . . . . . . . . . . Appendix C

Waste Policy Institute Monthly Report to the EERC, July 1996 . . . . . . . . . . . . Appendix D

Waste Policy Institute Monthly Report to the EERC, August 1996 . . . . . . . . . . . Appendix E

Waste Policy Institute Monthly Report to the EERC, September 1996 . . . . . . . . . Appendix F 


\section{TASK 10 - TECHNOLOGY DEVELOPMENT INTEGRATION}

\subsection{INTRODUCTION}

The Energy \& Environmental Research Center (EERC) in conjunction with the Waste Policy Institute (WPI) will identify and integrate new technologies to meet site-specific environmental management (EM) requirements at contaminated sites appropriate to U.S. Department of Energy (DOE) interests. EM technologies offered by developers will be evaluated to determine their complementary contribution to new cleanup systems focused on particular characterization and remediation problems at specific EM sites. The technology clusters identified will provide EM cleanup capabilities that are significantly faster, better, safer, and cheaper than systems that are currently available. Work will be performed under the DOE-EERC EM Cooperative Agreement (EMCA), which includes provisions "to develop, demonstrate, and commercialize technologies that address environmental management needs of contaminated sites 'together with' management activities which accelerate transfer of technologies." The effort began July 1, 1995.

\subsection{OBJECTIVES AND ACTIVTTIES}

This task will develop new approaches for evaluating technology focus areas and other research and development technical programs and activities. This includes creating technology development scenarios and formulating streamlined technical approaches that will expedite technology focus area initiatives, other technical programs, and projects. In addition, this task is designed to validate technologies and systems through all phases of research, development, demonstration, testing, and evaluation and ensure public involvement during the development process.

The work is divided into three activities. In Task 10.1, Technology Management, activity, technical reviews of requirements, needs, and assessments related to waste characterization, containment, in situ and ex situ treatment, waste storage, disposal, robotics handling, monitoring, laboratory analysis, and site characterization and remediation will be performed. The activities include but are not limited to the following: development of systems, experimental design, and plans; verification of technology performance; establishing regulatory documentation and intermediate products required for testing, demonstration, and validation; and preparation of review documentation. In addition, studies will be performed in various focus areas to facilitate rapid deployment of waste management technologies to the specific DOE sites and transfer to the private sector.

In Task 10.2, Project Management, the participants will conduct reviews and analyze and develop strategies for program management systems to integrate and control programs, projects, tasks, and documentation. This includes financial and technical management systems; decision analysis tools and program-planning software; and cost or schedule variance analysis and related software. In addition, the following activities will be carried out: conduct project reviews, public hearings, meetings, and public briefings; develop technical briefings; prepare related materials; plan for the transportation of hazardous waste, including acting as a liaison with the public on routes, safety, and preparedness; provide emergency management plans, training, and exercises for 
facility and transportation preparedness; and develop protocols for collecting, handling, analyzing, and shipping environmental samples.

As part of the Task 10.3, Technology Integration, activities to the private sector, criteria for identifying risks to public health and safety posed by conditions at weapons complex facilities will be established; the extent of these risks will be evaluated; the urgency and priorities for eliminating or minimizing the risks will be determined; and the cost of activities required to meet applicable compliance agreements will be assessed.

\subsection{ACCOMPLISHMENTS/WORK PERFORMED}

Activities over the reporting period have focused on providing logistical and administrative support.

- The EERC provided technical assistance to the mixed waste focus area with respect to the evaluation of treatment technologies. The work was done at Idaho National Engineering Laboratory in several intervals from June through the end of the reporting period.

- Van Ness Feldmann prepared a report for the EERC on the land tech program.

- The EERC provided Administrative support for the WPI subcontract. Activities under this subcontract are dealt with in detail for the reporting period in the WPI monthly reports contained in Appendices A through $\mathrm{F}$.

- Materials were prepared for an EERC presentation at the Western Governors' Association meeting in Pheonix, Arizona, in May. The presentation profiled the EMCA program.

- Industrial Partnerships to Deploy Environmental Technology Meeting at the Morgantown Energy Technology Center (METC), October 1996. The EERC prepared a slide presentation and a proceedings paper profiling EMCA technology development, demonstration, and commercialization activities. The paper abstract and slides were submitted at the end of September, and the paper was in draft final form at that time.

- Sixth SPECTRUM International Conference on Hazardous Waste Management, Seattle, Washington, August 18-23, 1996. The EERC had a display booth and gave a slide presentation (p. 1452 of meeting proceedings). The presentation profiled the EMCA model for facilitating the rapid commercialization of innovative EM technologies.

- METC-EERC EM Cooperative Agreement Program Review Meeting, June 5, 1996, at METC. A package of presentation materials was prepared and distributed at the meeting. 


\subsection{WORK PLANNED FOR NEXT 6 MONTHS}

Funding for WPI's efforts under this task will be exhausted in November, and no further funding is anticipated for the WPI subcontract. The EERC will continue to identify technologies to DOE for integration into the EM program. 
WASTE POLICY INSTITUTE MONTHLY REPORT TO THE EERC, APRIL 1996

APPENDIX A 


\section{UNIVERSITY OF NORTH DAKOTA ENERGY AND ENVIRONMENTAL RESEARCH CENTER}

\section{Monthly Report}

April, 1996

\section{TECHNOLOGY DEVELOPMENT INTEGRATION WPI SUBCONTRACT NUMBER 359636}

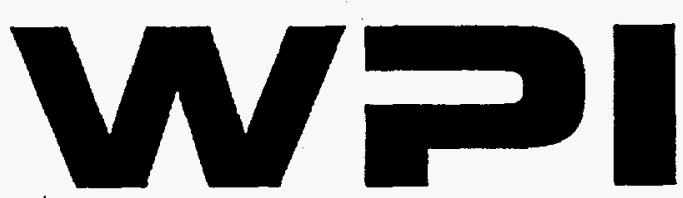


May 15,1996

Mr. John G. Hendrikson

Assistant to the Director

Energy and Environmental Research Center

University of North Dakota

15 North 23rd Street

Grand Forks, ND 58203

Subject: UNDEERC Fund No. 4624-0936, Technology Development Integration

WPI Subcontract No. 359636

Dear Mr. Hendrikson:

The Waste Policy Institute (WPI) is pleased to submit the enclosed report of activities conducted during the period of April 1, 1996 through April 30,1996, in compliance with Article VI and Appendix A of Subcontract Number 359636. A list of products developed during this period is provided as Attachment A to the activities report.

Through April 30, WPI has expended $\$ 9,297,843$. Our monthly cost and labor report provides the details of our costs to date. Although the current contract period extends through December 1, 1996, it should be noted that we anticipate the subcontract ceiling will be reached on or about September 30, 1996. This expenditure rate is consistent with our proposal for the new budget period.

Please do not hesitate to call me if you have any questions or require additional information.

Sincerely,

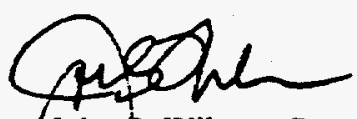

John S. Wilson, Program Manager

Waste Policy Institute

ce: L.

L. D. Eyman

G. Carter 
SUBCONTRACT NUMBER: 359636

Report Period: 4/1/96-4/30/96

CONTRACTOR NAME: Waste Policy Institute

555 Quince Orchard Road

Suite 600

Gaithersburg, MD 20878-1437

CONTRACT PERIOD: $\quad$ 6/28/95 -12/01/96

\section{SUBCONTRACT DELIVERABLES:}

This report is submitted in fulfillment of requirements specified for the University of North Dakota Energy and Environmental Research Center (UNDEERC)

Subcontract Number 359636. A list of products developed under this subcontract is provided as Attachment $\mathrm{A}$.

\section{SUMMARY OF ACTIVITIES:}

The team expended major effort in all focus areas to support the IRB preparation and presentations. Support to the business review was another major activity. The preparation of the "rainbow books" is nearing completion for each focus area.

\section{TASK A-TECHNOLOGY ASSESSMENT}

\section{TANKS FOCUS AREA (TFA)}

Staff provided notes/feedback on the Midyear Technical Review and Breakout Sessions to DOE-RL and received a "job well done" commendation from MACTEC, the DOERL/AMT Division's GSSC, for the quality, completeness, and frankness in the reports.

Members of the team attended the Characterization, Monitoring and Sensor Technology (CMST) Midyear Program Review meeting held in Gaithersburg, Maryland, where CMST-funded tasks that are relevant to TFA needs were evaluated. The evaluation efforts included comments on maturity level, implementation and commercialization of the technology and the applicability of the technology to meet end user needs. The review and comments were relayed to CMST program managers for discussion with the respective Principal Investigators (PI) and to DOE-RL. The WPI team is working with DOE-HQ to inquire about the dispositioning of the materials.

Staff assisted the TFA in compiling information on work from other DOE sites on tank closure activities. This data is critical in supporting planning for the Hanford Tank Initiative and will be used by the TFA in a technical briefing to the EM-30 and EM-50 Deputy Assistant Secretaries in early May. 
Information needs were discussed with the Colorado Center of Environmental Management (CCEM). The WPI staff prepared a packet of information related to tank closure activities across the DOE Complex and mailed it to CCEM in reply to this discussion.

Members of the team began development of a Tanks Focus Area "Success Book". The book will present problems that have been addressed by new technologies, and explain the technologies.

Staff worked with DOE program managers, engineers at Hanford, and graphic artists to begin developing a poster and public outreach material for the Hanford Tank Initiative. This is a project to deploy new technologies in Hanford Tanks, and work with the regulators to clean and close two tanks in the next four years.

The WPI team staffed the Tanks Focus Area exhibit at Science and Technology Week at EPCOT Center in Orlando, Florida. The exhibit includes posters of several TFA technologies, and a stereoscopic playback system, which plays a three-dimensional video taken inside a Hanford tank in October, 1995. The audience of the Science and Technology Week presentations was the general public vacationing in Florida. Many commented that the tanks problem is "scary as hell" but that they are glad DOE is "doing something about it".

Team members attended the Efficient Separations and Processing Midyear Review, April 16-18 in Gaithersburg, MD. Many of the ESP projects coordinate closely with those of the Tanks Focus Area.

\section{SUBSURFACE CONTAMINANTS FOCUS AREA (SCFA)}

The team drafted the FY98 Risk Data Sheet (RDS) Submittal for the Subsurface Contamination Focus Area. RDS will be used as a management tool to properly prioritize technology systems, based upon the systems' ability to reduce human, environmental and programmatic risk.

The team assisted in generating life cycle cost estimates for various technologies in the IRB workpackages from the beginning of their development until the time of deployment.

Staff members assisted in the preparation of the Plumes Focus Areas 1995 technology summary book. This publication provides a one or two page summary of the technology's progress over the last year. In addition, it includes the benefits and needs satisfied by the fully developed system. This book is written for a wide ranging non-technical audience to include stakeholders, government officials, employees of DOE and other federal agencies.

WPI team members provided input to an exhibit presented at the meeting of the Association of Western Governors, April 29-30. This exhibit showcases the accomplishments of 
Subsurface Contamination and provides a platform for Subsurface Contamination representatives to present the program.

A matrix was developed updating the deployment schedule for Plumes and Landfill Focus Areas EMAB technologies. The matrix was used by DOE-SR to determine if the technologies that were detailed in the EMAB report are on schedule for deployment, and if not, why not.

Members of the team submitted a technical review of TTP RL3-6-PL-21 Milestone 3A1 Report to DOE-SR on Governing Factors for Passive Soil Vapor Extraction. Staff also provided high level summary of findings and commented on PSVE recommendations as appropriate. The report was used by DOE-SR to evaluate technical progress of PSVE.

A technical review of relevant Efficient Separations and Processing Focus Area (ESP) technologies presented at the Mid-Year Review Meeting held April 11-18 was provided. A technology for Technetium removal was identified as supporting the demonstrations of Subsurface Contaminants' technologies at Paducah. Relevant technical information was identified, researched, collected, and distributed to DOE-SR team members. This information will be utilized by DOE-SR to leverage SCFA planned demonstrations at Paducah.

\section{DECONTAMINATION AND DECOMMISSIONING (D\&D) FOCUS AREA}

Members of the team completed a technical evaluation of the focus area program activities to recycle radioactively-contaminated scrap metal (RSM), and the available commercial capacity to recycle RSM. The briefing was presented by DOE-METC to EM-30, 40, and 60 to integrate the commercialization phase of these technologies.

A member of the staff participated in the technology screening and selection process for the Fernald Plant 1 Large-Scale Demonstration Project and attended an IC Team meeting on April 11, 1996 at Fernald Environmental Management Project. The IC Team considered the screening results of the second group of technologies for demonstration at this project.

The WPI team participated in the kick-off meeting of the Technology Screening and Assessment Team for the 105C-Reactor Cocooning Large Scale Demonstration Project at Richland, Washington on April 25 and 26, 1996. The team organized into sub-teams by discipline area to develop project requirements and select candidate technologies for further consideration. A meeting record is in preparation.

An Issue Paper on the Free-release of Volumetrically Contaminated Metals was developed and delivered to support decision-making processes at the top levels of OST management. 
Staff members attended the CMST mid-year review. In addition to reviewing $D \& D / C M S T$ projects for applicability and viability, project costs and schedule data were evaluated. Inputs were provided to the CMST program to support the FY97 decision-making process.

A draft summary report on the status of depleted uranium hexafluoride as reflected in reports from the Offices of Nuclear Energy and Environmental Management was prepared, including the EM Programmatic Environmental Impact Statement, and its possible disposition in the DOE Complex.

Staff members revised the technical write-up with costs matrix on the contribution of D\&D costs to the Baseline Environmental Management Report (BEMR). This technical input will be provided to $\mathrm{DOE}$ headquarters as supporting documentation for the numbers reflected in the BEMR.

Technical information to the US Army Corps of Engineers on the Hanford "C" reactor D\&D Large Scale Demonstration including data on the demo cost estimate of \$18 million was provided in support of METC.

\section{MIXED WASTE FOCUS AREA (MWFA)}

Team members evaluated the performance of refractories at MWFA-funded plasma and vitrification projects. Refractory life was estimated as a function of melt temperature, $\mathrm{pH}$, number of thermal cycles, and operating procedures.

After receiving comments on draft Site Regulatory Summaries from representatives of the respective Site Technical Coordination Groups, the staff commenced incorporating comments into the Site Regulatory Summaries and adding new information that was gathered.

WPI team members assisted the Technical Editor of The Mixed Waste Characterization, Treatment, and Disposal Focus Area Technology Summary Book by collecting original photographs and graphics.

Staff continued to develop draft language for MWFA Technology Development Requirements Documents (TDRD) Team members submitted final drafts to MWFA for the following TDRDs: Russian Projects, Mercury Monitors, Heavy Metal Monitors, Volatile Organic Compounds Monitors, and Alpha Monitors.

The Russian Workshop Proceedings were received and distributed.

Members of the team assisted DOE-ID with development of the Waste Forms Initiative. Tasks including: literature review of various topics related to Waste Forms; development of a Waste Forms bibliography; attendance at a Waste Forms Initiative teleconference 
call; preparation of meeting minutes; and developing the Waste Forms Performance Specifications (TDRDs).

The Continuous Emissions Monitors Test Plan for a demonstration of four CEMs at Research Triangle Park was reviewed.

A draft outline for a proposed study entitled: Evaluation of Non-Thermal Technologies was reviewed and comments were prepared. This document will be used to recommend specific technologies for MWFA funding in FY97.

Staff members collected, reviewed, and compiled information for Final Waste Forms. This information will be evaluated, and integrated with site selection and waste acceptance criteria to choose an optimal low level mixed waste form(s).

\section{TASK B-PROJECT ASSESSMENT}

\section{TANKS FOCUS AREA (TFA)}

The WPI Team submitted the final draft of the TFA Rainbow Book to our Editor on March 29, 1996. Comments are being dispositioned on an as-needed basis. At the editor's request, the team provided a names and address points-of-contact list for all of the Principal Investigators and Technical Integration Managers.

Staff reviewed and provided comments to DOE-RL including recommended disposition of the following TTPs:
AL16WT21-00
LANL Safety
AL16WT41-00
LANL Pretreatment
AL26WT51-01
SNL Retrieval \& Closure
CH26WT31-00
ANL Immobilization
CH26WT41-00
ANL Pretreatment
ID76WT21-01 INEL
Characterization/Technical Integration-Characterization
ID76WT41-01INEL Pretreatment
ID76WT51-01 INEL Retrieval \& Closure
OR16WT41-02
MMES Pretreatment
OR16WT5 -01
MMES Retrieval \& Closure
RL36WT11-02
TFA Technical Implementation Team
RL36WT21-01
PNNL Characterization Laser Ablation/Mass Spectroscopy
RL36WT41-02
PNNL Pretreatment
RL36WT51-02
PNNL Retrieval \& Closure
RL46WT21-02
WHC Characterization
RL46WT41-01
Cesium Removal Tests Using Hanford DSSF Supernatant
RL46WT51-02
WHC Retrieval \& Closure
SF26WT21-01
LLNL Characterization
SR16WT31-00
WSRC Immobilization 

SR16WT41-03
WSRC Pretreatment
SR16WT51-02
WSRC Retrieval \& Closure
SR16WT99-00
LDUA Remote Viewing Systems and Technology Transfer to SRS

A revised draft PEG was prepared for the TFA based on changes to the funding, milestones, and scope since the beginning of FY96. Associated Fin Plan Changes were also generated and sent to DOE-RL and DOE-HQ for review and signature.

An article on selected TFA FY96 technology demonstrations for the WPI Initiatives in Environmental Technology Investment was prepared by the staff for DOE-RL. This input was requested by WPI-Blacksburg to illustrate the work currently going on within the Tanks Focus Area.

Staff prepared a briefing on Russian Technical Exchange Activities for tank retrieval and closure background and issues and presented it to DOE-RL to provide backup information for their meeting in Phoenix, Arizona in early May on this subject.

Information on the FY95, 96, 97 and 98 budgets for all Focus Areas and Crosscut Areas was prepared by the WPI Team and provided to DOE-RL in response to questions asked by the Hanford Advisory Board's (HAB) Dollar and Sense Committee. This response has developed in line with a matrix provided by DOE-RL and may involve more participation by the WPI Team to fully answer all questions posed by the HAB.

Staff attended meetings with the TFA technical team to develop the work packages that would become the basis for the FY97 PEG and the FY98 IRB and reviewed the final work packages in response to needs, appropriateness, and consistency. The team provided comments to the Administrative Lead and the technical team.

Staff prepared the first draft of the Internal Review Budget Briefing for the TFA and DOE-RL according to the guidelines provided by DOE-HQ.

The staff assisted in developing background information for TFA's Risk Data Sheet package for the FY98 IRB (e.g., primary users, primary drivers, maturity level, expected completion date, and related EM-30/40 tasks) and identified key EM 30/40 RDS's and reviewed them for consistency with the TFA submittal. The staff also inputted the information into the ADS database for cross referencing by other programs.

Staff attended a meeting to outline CMST/TFA supported technology development strategy. The purpose of the meeting was to allocate CMST funding to initiate technology development for the TFA in FY97 and 98. The major focus of the meeting was directed towards the ultrasonic sensors for characterization of waste and Tc speciation studies and discussions about available technologies to meet the needs. The TFA/CMST team proposed a "bake off" study in FY97 for evaluating the ultrasonic sensor work. The Tc speciation studies were not accepted as technology development by 
the CMST participants. A review of the technologies supported by CMST was dispositioned to DOE-RL.

WPI staff assisted the TFA Technical Integration Manager of Retrieval and Closure to organize a weekly telecon with SNL and to schedule meetings to provide DOE-RL and the technical team a method for efficient communication with the retrieval and closure technical team.

The February PTS was reviewed by the WPI team for estimate of potential FY96 uncosted balances for DOE-RL. Various errors were noted causing an inflated estimate of carryover. A realistic estimate of $\$ 3 \mathrm{M}$ was calculated. Rationale for projected carryover and ideas for minimizing uncosted areas were incorporated into the business review package.

The staff reviewed proposed TFA program changes as a result of closeout of the Long Reach Manipulator contract and reported information to DOE-RL.

\section{SUBSURFACE CONTAMINANTS FOCUS AREA (SCFA)}

Staff Members provided inputs to the Subsurface Contamination Focus Area's FY98 Internal Review Budget (IRB). This presentation provides the backbone for the strategy to be employed by Subsurface Contamination during FY98 including a division of the budget into technical work packages.

Staff members reviewed a spreadsheet on IRB Work Packages provided on the FTP server dated 4/15/96, and developed technical input to Subsurface Contaminants Focus Area strategic goals relating to these IRB Work Packages.

Team members provided input to the January 1996 Business Review Meeting for the Plumes Focus Area. A briefing was given to DOE to assure appropriate progress by the PFA towards meeting its performance measures within its appropriated budget.

A table was developed analyzing all Plumes Focus Area FY96 TTPs and their status concerning submission and fulfillment of PFA-Lead Office requirements for the FY98 IRB.

A monthly review of the Cost/Performance Variance Analysis Report for Plumes Focus Area and the Landfill Focus Area was conducted. Staff identified incorrect or misleading statements and/or conclusions and prepared statements to explain cost and schedule variances which exceeded the $3 \%$ schedule $/ 10 \%$ cost reporting threshold and established a reporting link to the Progress Tracking System (PTS). The team assisted in the establishment of routine procedures for monthly cost/schedule variance reporting to the PFA and LSFA Lead Managers. 
Budget analysis spreadsheets for both focus areas which present current budget data by product line and area were provided. These spreadsheets indicate the budget for FY96 PEG, current reporting month PTS budget, and January through the current month Financial (FIN) Plan. The spreadsheets are utilized by DOE-SR LOM to monitor and correct project schedule and cost completion.

The WPI team prepared the monthly Business Review briefing for the Subsurface Contaminants Focus Area and technical responses to Monthly Business Review Action Items and coordinated input from other members of the Focus Area staff to answer action items. Staff prepared Cost/Variance Analyses for the monthly Cost/Performance Variance Analysis reports from DOE-HQ. Reference materials to support DOE-SR responses and address cost/variances and milestone completion were completed.

WPI team members reviewed a letter from Susan Mockler from the National Academy of Sciences to the Subsurface Contaminants Focus Area Lead Office Manager. This letter requested information based on a report, Barriers to Science, developed by the NRC/NAS Committee on Remediation of Buried and Tank Wastes. The team then provided detailed recommendations for a technical response, together with supporting technical backup information. The material provided was edited and incorporated into a response and the response has been issued to NAS by DOE.

\section{DECONTAMINATION AND DECOMMISSIONING (D\&D) FOCUS AREA}

Staff prepared the D\&DFA March Monthly Progress Report. The WPI Team evaluated report input data from multiple sources, technically reviewed the data, and provided appropriate input to develop the report.

Members of the team developed a D\&D/DOE Weapons Complex training package designed to provide employees of the USACOE with vital information necessary to support METC D\&D-related programs including an overview of the DOE Weapons Complex, DOE's D\&D Program, Health Physics, Waste Management, Regulatory Constraints, and common terminology used within the D\&D Program.

A team member attended the DOE D\&D National Committee Meeting in Sante Fe, New Mexico held in conjunction with the TIE Workshop. He provided information to meeting attendees on D\&DFA projects and gained valuable information on site needs and issues. Meeting notes are being prepared.

The WPI team provided technical input to the planning process for the D\&D Focus Area Internal Review Budget for Fiscal Year 1998. This included assessing Activity Data Sheets and Risk Data Sheets relevant to D\&D activities in EM-40 and EM-60.

The WPI team completed the Second Pass input of FY96 D\&D Technical Task Plan data on Principal Investigators and contractor organizations into the Morgantown Energy Technology Center (METC) Project Management System (MPMS). MPMS is used by 
METC for tracking and managing technical tasks, including the D\&D Focus Area Technical Tasks.

Staff members provided continued technical support and overall lead coordination for the development of the D\&D Focus Area FY96 Technology Summary Report.

The team provided technical support in response to a HQ request for project status information for FY96 uncosted D\&D projects.

The WPI team provided technical support for the D\&D response to the NAS/NRC report entitled "Environmental Management Technology Development Program at the Department of Energy 1995 Review"

Staff members assessed the PTS/TTP baseline cost data and provided technical support for the Focus Area Monthly Business Review.

\section{MIXED WASTE FOCUS AREA (MWFA)}

The WPI team developed a draft of the MWFA Response to the Thermal Treatment Technologies Review, held on November 13-15, 1996, in Dallas, TX. This document incorporates an Implementation Plan for thermal treatment technologies.

Members of the team attended MWFA Mid-year Review from 4/30/96 to 5/2/96 and prepared meeting notes for $D O E$.

The staff continued involvement in the Request for Information/ Request for Proposal for the MWFA. Several informal meetings were attended regarding the future procurement schedule and approaches to procurement. Staff then prepared the meeting notes for DOE.

The WPI team attended meetings with DOE-ID and EM-50 personnel related to tribal, regulatory, and stakeholder issues. Regulatory consistency and cooperation is still not at desired levels, but regulators now realize the need to address the mixed waste problem in non-traditional ways. Staff took meeting minutes to record proceedings and identify deliverables.

Staff participated in the Community Leaders Network Socratic Dialogue planning meeting on April 22, 1996.

An Independent Review Process Strategy Paper for reviewing documents that are submitted to DOE-HQ and other involved parties by DOE-ID was prepared.

\section{TASK C-TECHNOLOGY INTEGRATION}

Staff members provided a technical analysis of the Electrokinetics Project (TTP \# - OR16-PL-41) Gate Review and Return on Investment Reports. Technical input was provided 
in a draft memo from Jim Wright to the TPO at Oak Ridge concerning an approved scope of work that can be enacted between the present time and approval of an as yet to be submitted FY96 TTP.

Members of the staff reviewed the systems engineering draft report produced under TTP ID7-6-LF-12. Although the report covers the TTP objectives, substantial technical revision was identified to improve readability. Technical recommendations were prepared to assist DOE-SR in the management of future systems engineering studies.

A draft Cost/Variance Analysis report was provided for technical review by TPOs. Overdue milestones from February PTS report were analyzed and staff requested explanation of overdue status.

Staff completed a review of the METC QA/QC Manual as a secondary activity to the DQO gap analysis, as directed by the METC QA group. Briefed Tom Keech, Director of the Fuels Resource Management Division at METC, and are awaiting his comments.

The WPI team continued development of the U.S. Department of Energy Focus Area (DOE FA) Technology Summary books (Rainbow Books) and submitted rough drafts of the Decontamination and Decommissioning FA (D\&D) and the Landfill Stabilization FA (LS) Rainbow Books to the DOE Headquarters Information for Decisions (IFD) Program Manager for an early preview. Held on-site working sessions with field technical leads in both Focus Areas. The publication team met regularly to coordinate production activities and resolve issues. The complete set of Rainbow Books will reach a wide audience, including industry and the general public. The project also serves as an outreach activity as DOE shares its current information on technology development.

Efforts to complete the white paper on needs assessments conducted within the DOE Focus Areas were placed on hold to work on the Rainbow Books. Progress did include collecting additional information and making contacts for further clarifications. The purpose of the paper is to communicate processes utilized by each of the FAs and share ideas on integration and standardization activities that may add value to the FAs' processes. 
ATTACHMENT A

PRODUCTS DELIVERED: TASKA - TECHNOLOGY ASSESSMENT

TANKS FOCUS AREA (TFA)

- Mid-Year Review Wrap Up Report

- Background Notes on Russian Technical Exchange Activities of the TFA

- Secured and mailed poster to Applied Research Incorporated for DOE-RL

- Characterization Monitoring and Sensor Technology Programmatic Review

- Review of EM Retrieval and Closure Activities to Support the Hanford Tank Initiative

\section{SUBSURFACE CONTAMINANTS FOCUS AREA (SCFA)}

- Matrix updating deployment schedule for Plumes and Landfill Focus Area AMEBA technologies

- Technical Review of TTP RL3-6-PL-21 Milestone 3A1 Report to DOE-SR on Governing Factors for Passive Soil Vapor Extraction

- Technical Review of relevant Efficient Separations and Processing Focus Area (ESP) Technologies

\section{DECONTAMINATION AND DECOMMISSIONING (D\&D) FOCUS AREA}

- Briefing on Focus Area Program to Recycle Radioactively-Contaminated Scrap Metal and Available Commercial Capability

- Meeting record for Fernald Plant 1 Large-Scale Demonstration project meeting on April 11, 1996.

- Revised BEMR Input

MIXED WASTE FOCUS AREA (MWFA)

- Waste Form Initiative Meeting Minutes

- Business Strategy Panel Meeting Minutes 
- Refractory Performance Data

- Minutes of Meetings held with DOE-ID and DOE-HQ Personnel/Overview of MWFA

- Technology Development Requirements Documents

- Independent Review Process Implementation Plan

- Memorandum of Understanding for the Transportable Vitrification System

PRODUCTS DELIVERED: TASK B: PROJECT ASSESSMENT

TANKS FOCUS AREA (TFA)

- Mid-Year Review Break Out Notes

- Report of EM Activities Related to Tanks

- Points-of-Contact List for FY96 TFA Rainbow Book update.

- Review of Recommended Air Force Prioritization Methodology for Prioritization Process Improvement Team

- Reviews of latest revision of all TFA Technical Task Plans (TTPs) and prepared disposition memoranda for DOE-RL

- Article for Initiatives in Environmental Technology Investment

- FY98 TFA Internal Review Budget - First Draft Package

- Comments on IRB Package

- Provided binders with latest TFA TTPs for DOE-RL

- Provided work statements on technical support provided to DOE-RL and TFA

- TFA Business Review Briefing

- Fin Plan Change Request for SR16WT51

- Immobilization TTP Briefing to DOE-RL 
- Budget spreadsheets in support of Hanford Advisory Board's Dollar and Sense Committee

\section{SUBSURFACE CONTAMINANTS FOCUS AREA (SCFA)}

- Monthly Business Review Briefing for the subsurface Contaminants Focus Area

- Monthly review of Cost/Performance Variance Analysis Report for Plumes Focus Area and the Landfill Stabilization Focus Area

- Budget Analysis Spreadsheets for both focus area which present current budget data by product line and area

- Review spreadsheet on IRB Work Packages

- Table of Plumes Focus Area FY96 TTPs and their status concerning submission and fulfillment

- Review of Letter from NAS to SCFA Lead Office Manager

DECONTAMINATION AND DECOMMISSIONING (D\&D) FOCUS AREA

- February D\&DFA Monthly Progress Report

- Issue Paper of the Release of Volumetrically Contaminated Metals

- Project summary and status for FY96 uncosted D\&D projects.

- Draft response input and attachments for D\&D response to the NAS/NRC report

- Baseline cost comparison matrix for D\&D's FY96 projects

- Risk Data Sheets and Task Prioritization Matrix for the FY98 IRB

MIXED WASTE FOCUS AREA (MWFA)

- March Monthly Report

\section{PRODUCTS DELIVERED: TASK C: TECHNOLOGYINTEGRATION}

- Defense Nuclear Facilities Safety Board on the Hanford Tank Initiative

- Press release on the Hanford Tank Initiative 
- Follow-up mailing to the National Academy of Science, Subcommittee on Environmental Management Technologies and final briefing notes

- Technical analysis on the Electrokinetics Project Gate Review and Return on Investments Reports

- Review of Systems Engineering Draft Report produced under TTP \# ID7-6-LF-12

- Draft Cost/Variance Analysis Report for Technical Review by TPOs 


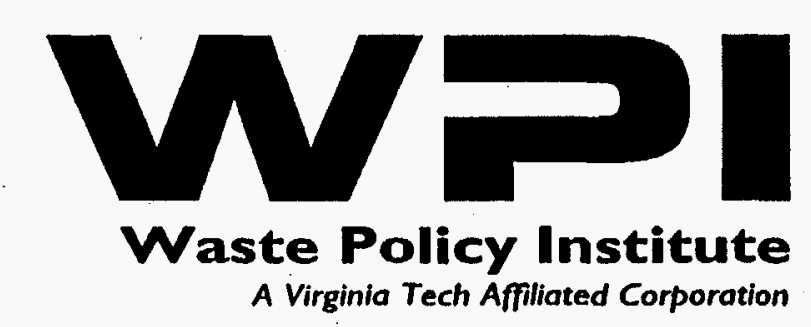

\section{MONTHLY \\ COST AND LABOR REPORT}

\section{UNIVERSITY OF NORTH DAKOTA \\ ENERGY AND ENVIRONMENTAL RESEARCH CENTER}

Subcontract No. 359636

April, 1996 


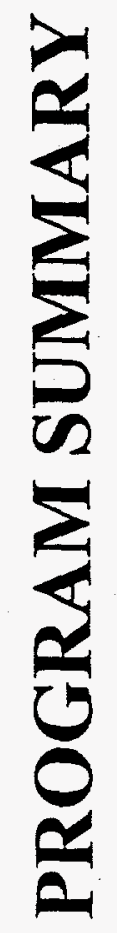


WPI Subcontract--EERC Coop. Agreement

$(\$ \times 1000)$

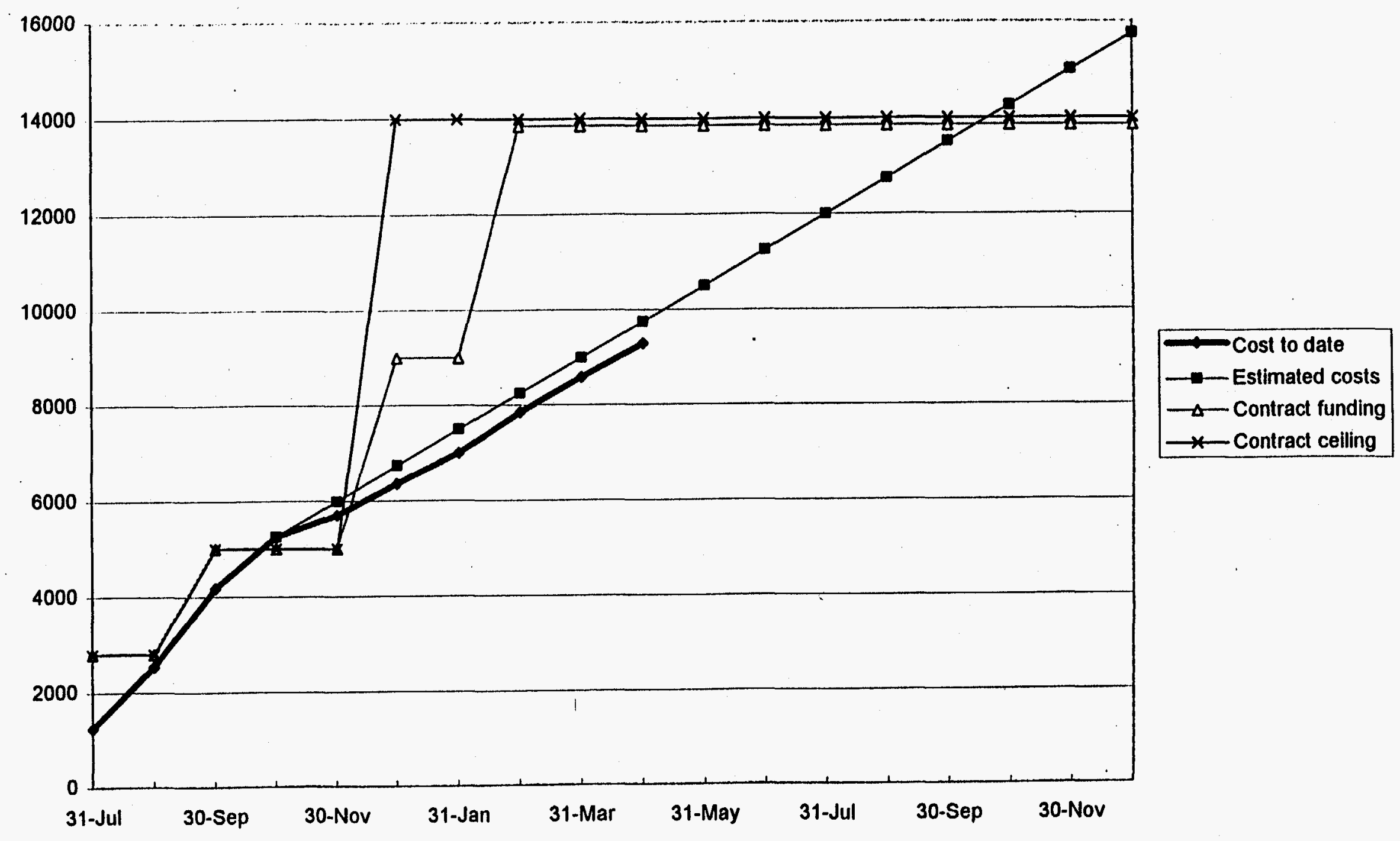

Page 1 
Subcontract No. 359636

Actuals through Apr 96

WBS: 1043 EERC

Manager: Dr. John S. Wilson

Start Date: $6 / 27 / 95$

End Date: $12 / 1 / 96$

Task Description: Provide assistance to EERC's conduct of technology development inlegration activities.

Cost Performance Summary:

\begin{tabular}{|c|c|c|c|}
\hline & \multicolumn{3}{|c|}{ Current Period } \\
\hline & Budget & Actuals & Varlance \\
\hline ours: & 10,506 & 8,653 & 1,853 \\
\hline Price: & 818,078 & 707.388 & 110,689 \\
\hline
\end{tabular}

\begin{tabular}{|c|c|c|}
\hline \multicolumn{3}{|c|}{ Inceptlon to Date } \\
\hline Budget & Actuals & Varlance \\
\hline 126,286 & 108,623 & 17,663 \\
\hline $9,904,494$ & $9,297,843$ & 606,652 \\
\hline
\end{tabular}

\begin{tabular}{|c|c|c|}
\hline \multicolumn{3}{|c|}{ At Complete } \\
\hline Budget. & Estimate & Varlance \\
\hline 178,816 & 161,153 & 17,663 \\
\hline $13,994,863$ & $13,388,232$ & 606,652 \\
\hline
\end{tabular}

Monthly Financial Recap:

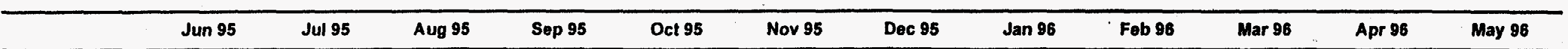

Actuals:

Monthly Hours:

Cumu Hours:

Monthly Price:

\begin{tabular}{|c|c|c|c|}
\hline 149 & 15,710 & 17,723 & 19,161 \\
\hline 149 & 15,859 & 33,582 & 52,743 \\
\hline 8,492 & $1,240,210$ & $1,300,381$ & $1,628,866$ \\
\hline 8,492 & $1,248,702$ & $2,549,083$ & $4,177,949$ \\
\hline
\end{tabular}

\begin{tabular}{|r|r|r|r|r|}
\hline 10,639 & 6,367 & 6,669 & 6,932 & 8,057 \\
\hline 63,382 & 69,749 & 76,418 & 83,350 & 91,408 \\
\hline $1,072,629$ & 508,957 & 674,480 & 577,622 & 844,119 \\
\hline $5,250,578$ & $5,759,535$ & $6,434,015$ & $7,011,637$ & $7,855,755$ \\
\hline
\end{tabular}

\begin{tabular}{|c|c|c|}
\hline 8,562 & 8.653 & 0 \\
\hline 99,970 & 108,623 & 108,623 \\
\hline 734,699 & 707,388 & 0 \\
\hline $8,590,455$ & $9,297,843$ & $9,297,843$ \\
\hline
\end{tabular}

Budget:

Monthly Hours:

Cumu Hours:

Monthly Price:

\begin{tabular}{|r|r|r|r|}
\hline 1,437 & 18,428 & 22,308 & 10,570 \\
\hline 1,437 & 19,865 & 42,173 & 52,743 \\
\hline 89,294 & $1,251,829$ & $1,454,843$ & $1,381,982$ \\
\hline 89,294 & $1,341,124$ & $2,795,967$ & $4,177,949$ \\
\hline
\end{tabular}

\begin{tabular}{|r|r|}
\hline 10,506 & 10,506 \\
\hline 63,249 & 73,755 \\
\hline 818,078 & 818,078 \\
\hline $4,996,027$ & $5,814,106$ \\
\hline
\end{tabular}

\begin{tabular}{|r|r|}
\hline 10,506 & 10,506 \\
\hline 84,261 & 94,767 \\
\hline 818,078 & 818,078 \\
\hline $6,632,183$ & $7,450,261$ \\
\hline
\end{tabular}

\begin{tabular}{|r|r|r|r|}
\hline 10,506 & 10,506 & 10,506 & 10,506 \\
\hline 105,273 & 115,779 & 126,286 & 136,792 \\
\hline 818,078 & 818,078 & 818,078 & 818,078 \\
\hline $8,268,339$ & $9,086,417$ & $9,904,494$ & $10,722,572$ \\
\hline
\end{tabular}


Subcontract No. 359636

Actuals through Apr 96

WBS: 1043 EERC

Manager: Dr. John S. Wilson

Start Date: 6/27/95

End Date: 12/1/96

Task Description: Provide assistance to EERC's conduct of technology development integration activities.

Cost Performance Summary:

\begin{tabular}{|c|c|c|c|}
\hline & \multicolumn{3}{|c|}{ Current Period } \\
\hline & Budget & Actuals & Varlance \\
\hline Hours: & 10,506 & 8,653 & 1,853 \\
\hline Price: & 818,078 & 707,388 & 110,689 \\
\hline
\end{tabular}

Inception to Date

\begin{tabular}{|c|c|c|}
\hline Budget & Actuals & Variance \\
\hline 126,286 & 108,623 & 17,663 \\
\hline $9,904,494$ & $9,297,843$ & 606,652 \\
\hline
\end{tabular}

\begin{tabular}{|c|c|c|}
\hline \multicolumn{3}{|c|}{ At Complete } \\
\hline Budget & Estimate & Varlance \\
\hline 178,816 & 161,153 & 17,663 \\
\hline $13,994,883$ & $13,388,232$ & 606,652 \\
\hline
\end{tabular}

Monthly Financlal Recap:

\begin{tabular}{|c|c|c|c|c|c|c|c|c|c|c|c|c|}
\hline & Jun 96 & Jul 96 & Aug 96 & Sep 96 & Oct 96 & Nov 96 & Dec 96 & Jan 97 & Feb 87 & Mar 97 & Apr 97 & May 97 \\
\hline \multicolumn{13}{|l|}{ Actuals: } \\
\hline Monthly Hours: & 0 & 0 & 0 & 0 & 0 & 0 & & & & & & \\
\hline Cumu Hours: & 108,623 & $108, \overline{623}$ & 108,623 & 108,623 & 108,623 & 108,623 & & & & & & \\
\hline Monthly Price: & 0 & 0 & 0 & 0 & 0 & 0 & & & & & & \\
\hline Cumu Price: & $9,297,843$ & $9,297,843$ & $9,297,843$ & $9,297,843$ & $9,297,843$ & $9,297,843$ & & & & & & \\
\hline
\end{tabular}

Budget:

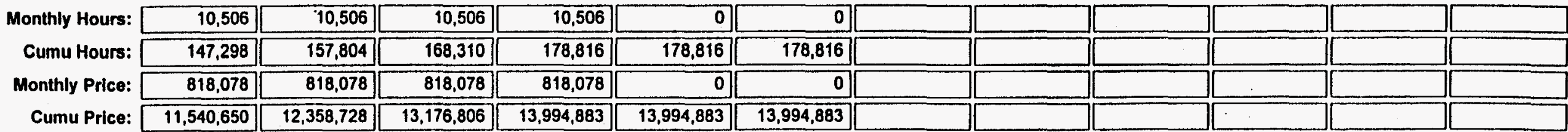


通 
Subcontract No. 359636

Actuals through Apr 96

WBS: 1043.01.01 Technology Management

Manager: Dr. John S. Wilson

Start Date: 6/27/95

End Date: 12/1/96

Task Description: Perform technical reviews of requirements, needs and assessments related to wasle characterization, containment, in-situ and ex-situ treatment, waste storage, disposal, robotics handling, monitoring, laboratory analysis, sile characterization and remediation.

Cost Performance Summary:

\begin{tabular}{|c|c|c|c|}
\hline & \multicolumn{3}{|c|}{ Current Perlod } \\
\hline & Budget & Actuals & Variance \\
\hline Hours: & 5,474 & 2,963 & 2.511 \\
\hline Price: & 297,160 & 246,524 & 50,635 \\
\hline
\end{tabular}

Inception to Date
\begin{tabular}{r|r|r|}
\hline \multicolumn{1}{c}{ Budget } & Actuals & Variance \\
\hline 60,087 & 48,032 & 12,055 \\
\hline $3,937,787$ & $4,415,577$ & $-477,790$ \\
\hline
\end{tabular}

\begin{tabular}{|c|c|c|}
\hline \multicolumn{3}{|c|}{ At Complete } \\
\hline Budget & Estlmate & Varlance \\
\hline 87,456 & 75,401 & 12,055 \\
\hline $5,423,585$ & $5,901,375$ & $-477,790$ \\
\hline
\end{tabular}

Monthly Financial Recap:

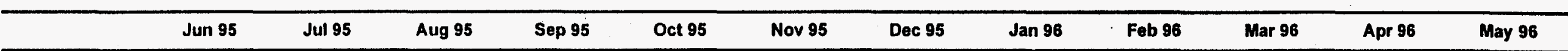

Actuals:

Monthly Hours:

Cumu Hours:

Monthly Price:

Cumu Price:

\begin{tabular}{|c|c|c|c|c|c|c|c|c|c|c|c|}
\hline 50 & 6.255 & 7,504 & 7,961 & 6,453 & 4,330 & 3,138 & 2,600 & 3,300 & 3,479 & 2,963 & 0 \\
\hline 50 & 6,305 & 13,809 & 21,770 & 28,224 & 32,553 & 35,691 & 38,291 & 41,591 & 45,069 & 48,032 & 48,032 \\
\hline 2,574 & 533,931 & 582,189 & 738,970 & 657,545 & 359,376 & 316,660 & 247,333 & 406,806 & 323,669 & 246,524 & 0 \\
\hline 2,574 & 536,505 & $1,118,694$ & $1,857,664$ & $2,515,209$ & $2,874,585$ & $3,191,245$ & $3,438,578$ & $3,845,383$ & $4,169,052$ & $4,415,577$ & $4,415,577$ \\
\hline
\end{tabular}

Budget:

Monthly Hours:

\begin{tabular}{|c|c|c|c|c|c|c|c|c|c|c|c|}
\hline 328 & 7,196 & 8,711 & 5.534 & 5,474 & 5,474 & 5,474 & 5,474 & 5,474 & 5,474 & 5,474 & 5,474 \\
\hline 328 & 7,525 & 16,236 & 21,770 & 27,244 & 32,718 & 38,191 & 43,665 & 49,139 & 54,613 & 60,087 & 65,561 \\
\hline 14,090 & 498,386 & 570,555 & 774,636 & 297,160 & 297,160 & 297,160 & 297,160 & 297,160 & 297,160 & 297,160 & 297,160 \\
\hline 14,090 & 512,477 & $1,083,032$ & $1,857,668$ & $2,154,828$ & $2,451,988$ & $2,749,148$ & $3,046,308$ & $3,343,467$ & $3,640,627$ & $3,937,787$ & $4,234,946$ \\
\hline
\end{tabular}

Cumu Hours:

Monthly Price:

Cumu Price:

\begin{tabular}{lll}
14,090 & 512,477 & $1,083,032$ \\
\hline
\end{tabular} 1,857,668

154,828

$2,451,988$ 
1043.01.01

Waste Policy Institute

Subcontract No. 359636

Actuals through Apr 96

WBS: 1043.01.01 Technology Management

Manager: Dr. John S. Wilson

Start Date: 6/27/95

End Date: 12/1/96

Task Description: Perform technical reviews of requirements, needs and assessments related to waste characterization, containment, in-situ and ex-situ treatment, waste storage, disposal, robotics handling, monitoring, laboratory analysis, site characlerization and remediation.

Cost Performance Summary:

\begin{tabular}{|c|c|c|c|}
\hline & \multicolumn{3}{|c|}{ Current Period } \\
\hline & Budget & Actuals & Variance \\
\hline Hours: & 5,474 & 2,963 & 2,511 \\
\hline Price: & 297,160 & 246,524 & 50,635 \\
\hline
\end{tabular}

\begin{tabular}{l|l|l|}
\multicolumn{3}{c}{ Inception to Date } \\
\hline Budget & Actuals & Variance \\
\hline 60,087 & 48,032 & 12,055 \\
\hline $3,937,787$ & $4,415,577$ & $-477,790$ \\
\hline
\end{tabular}

\begin{tabular}{|c|c|c|}
\hline \multicolumn{3}{|c|}{ At Complete } \\
\hline Budget & Estimate & Varlance \\
\hline 87,456 & 75,401 & 12,055 \\
\hline $5,423,585$ & $5,901,375$ & $-477,790$ \\
\hline
\end{tabular}

Monthly Financlal Recap:

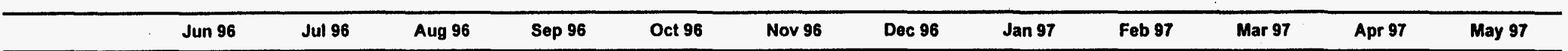

Actuals:

Monthly Hours:

Cumu Hours:

Monthly Price:

Cumu Price:

\begin{tabular}{|r|r|r|r|r|}
\hline 0 & 0 & 0 & 0 \\
\hline 48,032 & 48,032 & 48,032 & 48,032 \\
\hline 0 & 0 & 0 & 0 \\
\hline $4,415,577$ & $4,415,577$ & $4,415,577$ & $4,415,577$ \\
\hline
\end{tabular}

\begin{tabular}{|r|r|r|r|}
\hline 0 & 0 \\
\hline 48,032 & 48,032 \\
\hline & 0 & \\
\hline $4,415,577$ & $4,415,577$ \\
\hline
\end{tabular}

(1)

Budget:

Monthly Hours:

Cumu Hours:

Monthly Price:

\begin{tabular}{|r|r|}
\hline 5,474 & 5,474 \\
\hline 71,034 & 76,508 \\
\hline 297,160 & 297,160 \\
\hline $4,532,106$ & $4,829,266$ \\
\hline
\end{tabular}

\begin{tabular}{r|}
5,474 \\
\hline 81,982 \\
\hline 297,160 \\
\hline $5,126,426$
\end{tabular}

\begin{tabular}{|r|}
\hline 5,474 \\
\hline 87,456 \\
\hline 297,160 \\
\hline $5,423,585$ \\
\hline
\end{tabular}

\begin{tabular}{|c|c|}
\hline 474 & 0 \\
\hline 156 & 87,456 \\
\hline 160 & 0 \\
\hline 585 & $5,423,585$ \\
\hline
\end{tabular}

$\begin{array}{r}0 \\ \hline 87,456 \\ \hline 5,423,585\end{array}$

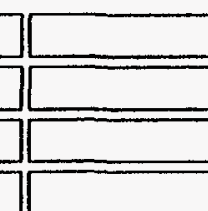

(1)

(1)


象 
Subcontract No. 359636

Actuals through Apr 96

WBS: 1043.01 .02 Project Management

Manager: Dr. John S. Wilson

Start Date: 6/27/95

End Date: 12/1/96

Task Description: Conduct reviews, analyze and develop strategies for program management systems for integration and control of programs, projects, tasks and documentation.

Cost Performance Summary:

\begin{tabular}{l|r|r|} 
& \multicolumn{1}{c}{ Current Period } \\
\hline Budget & \multicolumn{1}{c}{ Actuals } & \multicolumn{1}{c}{ Variance } \\
Hours: & 2,704 & 3,321 \\
Price: & -617 \\
\hline 273,798 & 269,945 & 3,854 \\
\hline
\end{tabular}

\begin{tabular}{|c|c|c|}
\hline \multicolumn{3}{|c|}{ Inception to Date } \\
\hline Budget & Actuals & Variance \\
\hline 44,473 & 47,388 & $-2,915$ \\
\hline $3,808,650$ & $3,768,486$ & 40,163 \\
\hline
\end{tabular}

\begin{tabular}{|c|c|c|}
\hline \multicolumn{3}{|c|}{ At Complete } \\
\hline Budget & Estimate & Variance \\
\hline 57,993 & 60,908 & $-2,915$ \\
\hline $5,177,640$ & $5,137,477$ & 40,163 \\
\hline
\end{tabular}

Monthly Financial Recap:

\begin{tabular}{|c|c|c|c|c|c|c|c|c|c|c|c|c|}
\hline & Jun 95 & Jul 95 & Aug 95 & Sep 95 & Oct 95 & Nov 95 & Dec 95 & Jan 96 & Feb 96 & Mar 96 & Apr 96 & May 96 \\
\hline \multicolumn{13}{|l|}{ Actuals: } \\
\hline Monthly Hours: & 98 & 8,116 & 8.247 & 9,084 & 3,578 & 1.588 & 2,868 & 3,297 & 3.561 & 3,631 & 3,321 & 0 \\
\hline Cumu Hours: & 98 & 8,214 & 16,462 & 25,545 & 29,123 & 30,711 & 33,578 & 36,875 & 40,436 & 44,067 & 47,388 & 47,388 \\
\hline Monthly Price: & 5,779 & 599,758 & 566,591 & 719,936 & 341,971 & 108,114 & 275,047 & 255,073 & 319,577 & 306,696 & 269,945 & 0 \\
\hline Cumu Price: & 5.779 & 605,537 & $1,172,128$ & $1,892,064$ & $2,234,035$ & $2,342,149$ & $2,617,196$ & $2,872,269$ & $3,191,846$ & $3,498,542$ & $3,768,486$ & $3,768,486$ \\
\hline \multicolumn{13}{|l|}{ Budget: } \\
\hline Monthly Hours: & 309 & 6,643 & 8,042 & 10,551 & 2.704 & 2,704 & 2,704 & 2,704 & 2,704 & 2,704 & 2,704 & 2,704 \\
\hline Cumu Hours: & 309 & 6,952 & 14,994 & 25,545 & 28,249 & 30,953 & 33,657 & 36,361 & 39,065 & 41,769 & 44,473 & 47.177 \\
\hline Monthly Price: & 21,034 & 453,804 & 527,559 & 889,666 & 273,798 & 273,798 & 273,798 & 273,798 & 273,798 & 273,798 & 273.798 & 273,798 \\
\hline Cumu Price: & 21,034 & 474,838 & $1,002,397$ & $1,892,063$ & $2,165,861$ & $2,439,659$ & $2,713,457$ & $2,987,255$ & $3,261,053$ & $3,534,652$ & $3,808,650$ & $4,0 8 \longdiv { 2 , 4 4 8 }$ \\
\hline
\end{tabular}


Actuals through Apr 96

WBS: 1043.01.02 Project Management

Manager: Dr. John S. Wilson

Start Date: 6/27/95

End Date: 12/1/96

Task Description: Conduct reviews, analyze and develop strategies for program management systems for integration and control of programs, projects, tasks and documentation.

\section{Cost Performance Summary}

\begin{tabular}{|c|c|c|c|}
\hline & \multicolumn{3}{|c|}{ Current Period } \\
\hline & Budget & Actuals & Varlance \\
\hline Hours: & 2,704 & 3,321 & -617 \\
\hline Price: & 273,798 & 269,945 & 3,854 \\
\hline
\end{tabular}

\begin{tabular}{|c|c|c|}
\hline \multicolumn{3}{|c|}{ Inception to Date } \\
\hline Budget & Actuals & Varlance \\
\hline 44,473 & 47,388 & $-2,915$ \\
\hline $3,808,650$ & $3,768,486$ & 40,163 \\
\hline
\end{tabular}

\begin{tabular}{|c|c|c|}
\hline \multicolumn{3}{|c|}{ At Complete } \\
\hline Budget & Estimate & Varlance \\
\hline 57,993 & 60,908 & $-2,915$ \\
\hline $5,177,640$ & $5,137,477$ & 40,163 \\
\hline
\end{tabular}

Monthly Financial Recap:

\begin{tabular}{|c|c|c|c|c|c|c|c|c|c|c|c|c|}
\hline & Jun 96 & Jul 96 & Aug 96 & Sep 96 & Oct 96 & Nov 96 & Dec 96 & Jan 97 & Feb 97 & Mar 97 & Apr 97 & May 97 \\
\hline \multicolumn{13}{|l|}{ Actuals: } \\
\hline Monthly Hours: & 0 & 0 & 0 & 0 & 0 & 0 & & & & & & \\
\hline Cumu Hours: & 47,388 & 47,388 & 47,388 & 47,388 & 47,388 & 47,388 & & & & & & \\
\hline Monthly Price: & 0 & 0 & 0 & 0 & 0 & 0 & & & & & & \\
\hline Cumu Price: & $3,768,486$ & $3,768,486$ & $3,768,486$ & $3,768,486$ & $3,768,486$ & $3,768,486$ & & & & & & \\
\hline \multicolumn{13}{|l|}{ Budget: } \\
\hline Monthly Hours: & 2,704 & 2,704 & 2,704 & 2,704 & 0 & 0 & & & & & & \\
\hline Cumu Hours: & 49,881 & 52,585 & 55,289 & 57,993 & 57,993 & 57,993 & & & & & & \\
\hline Monthly Price: & 273,798 & 273,798 & 273,798 & 273,798 & 0 & 0 & & & & & & \\
\hline Cumu Price: & $4,356,246$ & $4,630,044$ & $4,903,842$ & $5,177,640$ & $5,177,640$ & $5,177,640$ & & & & & & \\
\hline
\end{tabular}


$\frac{U}{4}$ 
Subcontract No. 359636

Actuals through Apr 96

WBS: 1043.01.03 Technology Integration

Manager: Dr. John S. Wilson

Start Date: 6/27/95

End Date: $12 / 1 / 96$

Task Description: Provide support in establishing criteria for identifying risks to the public health and safety posed by conditions at the weapons complex facilities, evaluate the exlent of these risks, determine the urgency and priorities for eliminating or minimizing the risks, and access the cost of activities required to meet applicable compliance agreements.

Cost Performance Summary:

\begin{tabular}{|c|c|c|c|}
\hline & \multicolumn{3}{|c|}{ Current Period } \\
\hline & Budget & Actuals & Variance \\
\hline Hours: & 2,328 & 2,370 & -41 \\
\hline Price: & 247.120 & 190,919 & 56.201 \\
\hline
\end{tabular}

\begin{tabular}{|c|c|c|}
\hline \multicolumn{3}{|c|}{ Inception to Date } \\
\hline Budget & Actuals & Variance \\
\hline 21.726 & 13,203 & 8,523 \\
\hline $2,158,058$ & $1,113,780$ & $1,044,278$ \\
\hline
\end{tabular}

\begin{tabular}{|c|c|c|}
\hline Budget & Estimate & Varlance \\
\hline 33,367 & 24,845 & 8,523 \\
\hline $3,393,658$ & $2,349,380$ & $1,044,278$ \\
\hline
\end{tabular}

Monthly Financial Recap:

\begin{tabular}{|c|c|c|c|c|c|c|c|c|c|c|c|c|}
\hline & Jun 95 & Jul 95 & Aug 95 & Sep 95 & Oct 95 & Nov 95 & Dec 95 & $\operatorname{Jan} 96$ & Feb 96 & Mar 96 & Apr 96 & May 96 \\
\hline \multicolumn{13}{|l|}{ Actuals: } \\
\hline Monthly Hours: & 1 & 1.339 & 1,972 & 2,117 & 608 & 450 & 664 & 1,036 & 1,196 & 1.453 & 2,370 & 0 \\
\hline Cumu Hours: & 1 & 1,340 & 3,312 & 5,428 & 6.036 & 6,486 & 7,150 & 8,185 & 9,381 & 10,834 & 13,203 & 13,203 \\
\hline Monthly Price: & 139 & 106,521 & 151,601 & 169,960 & 73,113 & 41,466 & 82,773 & 75,216 & 117.736 & 104,335 & 190,919 & $\underline{0}$ \\
\hline Cumu Price: & 139 & 106,660 & 258,261 & 428,221 & 501,334 & 542,800 & 625,574 & 700,790 & 818,526 & 922,860 & $1,113,780$ & $1,113,780$ \\
\hline
\end{tabular}

Budget:

Monthly Hours:

Cumu Hours:

Monthly Price:

\begin{tabular}{|r|r|}
\hline 800 & 4,589 \\
\hline 800 & 5,555 \\
\hline 54,170 & 5,388 \\
\hline 54,170 & 10,943 \\
\hline 359,639 & 356,729 \\
\hline & 710,538 \\
\hline
\end{tabular}

\begin{tabular}{|r|r|r|}
\hline$-5,515$ & 2,328 & 2,328 \\
\hline 5,428 & 7,756 & 10,085 \\
\hline$-282,320$ & 247,120 & 247,120 \\
\hline 428,218 & 675,338 \\
\hline
\end{tabular}

\begin{tabular}{|c|c|c|c|c|c|}
\hline 2,328 & 2,328 & 2,328 & 2,328 & 2,328 & 2,328 \\
\hline 12,413 & 14,741 & 17,069 & 19,398 & 21,726 & $\overline{24.054}$ \\
\hline 247,120 & 247,120 & 247,120 & 247,120 & 247,120 & 247,120 \\
\hline $1,169,578$ & $1,416,698$ & $1,663,818$ & $1,910,938$ & $2,158,058$ & $2,405,178$ \\
\hline
\end{tabular}


Subcontract No. 359636

Actuals through Apr 96

WBS: 1043.01.03 Technology Integration

Start Date: 6/27/95

End Date: $12 / 1 / 96$

Task Description: Provide support in establishing criteria for identifying risks to the public health and safety posed by conditions at the weapons complex facilities, evaluate the extent of these risks, determine the urgency and priorities for eliminating or minimizing the risks, and access the cost of activities required to meet applicable compliance agreements.

Cost Performance Summary:

\begin{tabular}{|c|c|c|c|}
\hline & \multicolumn{3}{|c|}{ Current Perlod } \\
\hline & Budget & Actuals & Variance \\
\hline Hours: & 2,328 & 2,370 & -41 \\
\hline Price: & 247,120 & 190,919 & 56,201 \\
\hline
\end{tabular}

\begin{tabular}{|c|c|c|}
\hline \multicolumn{3}{|c|}{ Inception to Date } \\
\hline Budget & Actuals & Variance \\
\hline 21,726 & 13,203 & 8.523 \\
\hline $2,158,058$ & $1,113,780$ & $1,044,278$ \\
\hline
\end{tabular}

\begin{tabular}{|c|c|c|}
\hline Budget & Estimate & Variance \\
\hline 33,367 & 24,845 & 8,523 \\
\hline $3,393,658$ & $2,349,380$ & $1,044,278$ \\
\hline
\end{tabular}

Monthly Financial Recap:

\begin{tabular}{|c|c|c|c|c|c|c|c|c|c|c|c|c|}
\hline & Jun 96 & Jul 96 & Aug 96 & Sep 96 & Oct 96 & Nov 96 & Dec 96 & $\operatorname{Jan} 97$ & Feb 97 & Mar 97 & Apr 97 & May 97 \\
\hline \multicolumn{13}{|l|}{ Actuals: } \\
\hline Monthly Hours: & 0 & 0 & 0 & 0 & 0 & 0 & & & & & & \\
\hline Cumu Hours: & 13,203 & 13,203 & 13,203 & 13,203 & 13,203 & 13,203 & & & & & & \\
\hline Monthly Price: & 0 & 0 & 0 & 0 & 0 & 0 & & & & & & \\
\hline Cumu Price: & $1,113,780$ & $1,113,780$ & $1,113,780$ & $1,113,780$ & $1,113,780$ & $1,113,780$ & & & & & & \\
\hline
\end{tabular}

Budget:

Monthly Hours:

Cumu Hours:

Monthly Price:

\begin{tabular}{|r|r|r|r|}
\hline 2,328 & 2,328 \\
\hline 26,382 & 2,328 & 2,328 & 0 \\
\hline 247,120 & 24,711 & 31,039 & 33,367 \\
\hline $2,652,298$ & $2,899,418$ & 33,367 \\
\hline $3,146,538$ & $3,393,658$ & $3,393,658$ \\
\hline
\end{tabular}

\begin{tabular}{|r|r|}
\hline 33,367 \\
\hline $3,393,658$
\end{tabular}

(1)



WASTE POLICY INSTITUTE MONTHLY REPORT
TO THE EERC, MAY 1996

APPENDIX B 



\section{UNIVERSITY OF NORTH DAKOTA ENERGY AND ENVIRONMENTAL RESEARCH CENTER}

\section{Monthly Report}

May, 1996

\section{TECHNOLOGY DEVELOPMENT INTEGRATION WPI SUBCONTRACT NUMBER 359636}

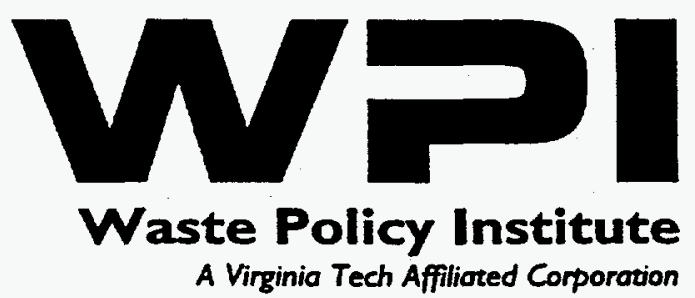



June 15,1996

Mr. John G. Hendrikson

Assistant to the Director

Energy and Environmental Research Center

University of North Dakota

15 North 23rd Street

Grand Forks, ND 58203

Subject: UNDEERC Fund No. 4624-0936, Technology Development Integration

WPI Subcontract No. 359636

Dear Mr. Hendrikson:

The Waste Policy Institute (WPI) is pleased to submit the enclosed report of activities conducted during the period of May 1, 1996 through May 31,1996, in compliance with Article VI and Appendix A of Subcontract Number 359636. A list of products developed during this period is provided as Attachment A to the activities report.

Through May 31 , WPI has expended $\$ 10,280,023$. Our monthly cost and labor report provides the details of our costs to date. Although the current contract period extends through December 1, 1996, it should be noted that we anticipate the subcontract ceiling will be reached on or about September 30, 1996. This expenditure rate is consistent with our proposal for the new budget period.

Please do not hesitate to call me if you have any questions or require additional information.

Sincerely,

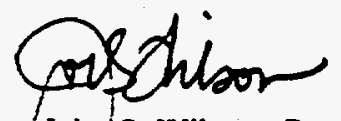

John S. Wilson, Program Manager

Waste Policy Institute

H

cc: L. D. Eyman

C. Roberson 
SUBCONTRACT NUMBER: 359636

Report Period: 5/1/96-5/31/96

CONTRACTOR NAME: Waste Policy Institute

555 Quince Orchard Road

Suite 600

Gaithersburg, MD 20878-1437

CONTRACT PERIOD: $\quad 6 / 28 / 95-12 / 01 / 96$

\section{SUBCONTRACT DELIVERABLES:}

This report is submitted in fulfillment of requirements specified for the University of North Dakota Energy and Environmental Research Center (UNDEERC)

Subcontract Number 359636. A list of products developed under this subcontract is provided as Attachment $A$.

\section{SUMMARY OF ACTIVITIES:}

Significant efforts were made in each office during the month to finalize the FY98 IRB budgets and support the briefings to headquarters.

A new task (Task D) on Systems Engineering Analysis was initiated during May. It is a collaborative effort between METC, EERC and the WPI team. The first assignment, analysis of thermal and non-thermal treatment of mixed low level waste, has been initiated.

\section{TASKA-TECHNOLOGY ASSESSMENT}

\section{TANKS FOCUS AREA (TFA)}

WPI staff completed a case study that documents the factors leading to replacing LLW grout with LLW glass in the Hanford baseline. The Hanford Waste Task Force was identified as the leading stakeholder group that set the values that precipitated this change. Several documents, including the report of the Hanford Tank Waste Task Force, were obtained and sent to WPI-Idaho as supporting material.

WPI staff participated in the technical scope definition meeting for the Hanford Tank Initiative, HTI. Other participants included the PNNL Technical Team, the TFA Technical Integration Managers, and representatives from Westinghouse Hanford Company's Tank Waste Remediation System (TWRS). The purpose of the meeting was to identify technologies for operational deployment be it an initial use or full-scale demonstration. For the most part, the results validated the FY98 IRB package. 
WPI staff participated in a review and provided recommendations on Characterization, Monitoring and Sensor Technology (CMST) crosscutting projects that are related to the TFA. Project status and deliverable updates as well as recommendations for project termination or continuation were provided to DOE-RL. This information will be used to assess the FY97 program and the FY98 IRB.

The staff provided information to the Efficient Separations and Processing Crosscut Program on TFA's technology development activities for FY98. The information will be used to compare tasks to avoid any possible overlap.

Staff reviewed two SBIR proposals, generated comments regarding the technical quality of the proposals and potential impacts for DOE-EM's remediation technology challenges, and transmitted the results to DOE-HQ.

Staff reviewed the following milestone deliverables: TTP RL36WT51/1.1-2, "Design Review of the Confined Sluicing End Effector," TTP RL46WT21/2-C2, "Feasibility of CPT Deployed Vertical Electrode Array in Single-Shell Tank Farms,", and TTP RL36WT11/A1, "Recommended FY96 Program Adjustments."

\section{SUBSURFACE CONTAMINANTS FOCUS AREA (SCFA)}

Team members developed a one page fact sheet and cover letters for 68 inquiries from a Chemical Engineering article regarding Viscous Liquids Barrier technology

The WPI team prepared, planned, and coordinated the technical review of LSFA Treatment Systems Technologies proposed to the MWFA prior to FY97. Activities include technical input to a memo contracting meeting facilities, defining elements for presentation format and preparing draft and final agendas.

Lists of PFA and LSFA accomplishments spanning the period FY 1994-1998 were prepared and drafts were sent by FAX to DOE-HQ on May 21 and 22. Improvements were made based on HQ responses and on telephone conversations between Jim Brown DOE-SR and DOE-HQ.

\section{DECONTAMINATION AND DECOMMISSIONING (D\&D) FOCUS AREA}

The WPI team completed a draft report on Recycling Radioactive Scrap Metal and forwarded to DOE-METC for comment. The report was prepared to address issues raised by Big 5 .

The WPI team completed a draft meeting record for Richland 105C-Reactor Cocooning Large-scale Demonstration project meeting of April 25 and 26, 1996 and forwarded to DOE-METC for comment. 
The WPI team performed technical review of the Preferred Alternatives Technology Guide prepared by EM- 40 and evaluated the feasibility of including innovative technology evaluations within the same framework. Comments forwarded to DOEMETC for review and presentation to EM-40.

The team prepared a technical slide presentation for Steve Bossart on the Large-scale Demonstration program and selected technologies for the National Association of Environmental Professionals meeting to be held in June, 1996.

A staff member attended the Technology Assessment Screening Team meeting for the CReactor Large-Scale Demonstration project. Support was provided to the site LSD team in formulating an Integrating Contractor Team and establishing a path forward for a technology selection process. At this meeting, WPI also provided a presentation describing D\&D Focus Area needs and responsibilities associated with this LSD. WPI formulated a meeting record from the meeting to ensure all associated parties understood and supported current LSD activities.

Staff attended a health physics instrumentation technology vendor (Shalco Inc.) presentation at METC and provided feedback to DOE on potential applications of the technology within the complex-wide D\&D program.

The WPI team provided radiological training to USACE personnel supporting ongoing LSD projects. This training was designed to assist USACE personnel in understanding terms and processes, and radiological issues associated with the DOE Nuclear Weapons Complex D\&D program.

Meeting notes associated with the April meeting of the DOE National D\&D Committee held in conjunction with the TIE Meeting were completed and delivered. The meeting notes prepared by WPI emphasized issues that impact technology usage and technology development associated with each site's D\&D program.

Staff provided technical support and review of the Brookhaven Asbestos Project (TTP\# CH3-4-DD-52 "Conversion of Asbestos Containing Material into Non-Regulated Material) in response to a request from the Principal Investigator for continued funding in FY97.

\section{MIXED WASTE FOCUS AREA (MWFA)}

Members of the team continued incorporating comments into the Site Regulatory Summaries and adding new information that was gathered. Staff also discussed the current approach with MWFA Regulatory and Stakeholder Lead.

Team members prepared and revised Mixed Waste Focus Area Technology Development Requirements Documents for: salt stabilization, ash stabilization, radionuclide 
partitioning, alpha monitoring, volatile organic compound monitoring, mercury monitoring and heavy metal monitoring.

The Mixed Waste Characterization Baseline Document was reviewed.

The WPI team provided continued assistance to DOE-ID on Waste Forms Initiative. Tasks included: continued the literature review of waste acceptance criteria and performance assessment, updated the Waste Forms bibliography, attended the Waste Forms Initiative weekly meetings, prepared summary tables, reviewed comments on the draft Waste Form Initiative paper, developed a matrix to review and collect information pertinent to identifying and selecting final mixed waste forms, continued to collect and review Final Waste Form information, compiled information into matrix format, evaluated and integrated information with site selection and waste acceptance criteria to choose an optimal low level mixed waste form.

The following documents were reviewed to support participation in DOE-ID meetings: (a) Combustion Rule and (b) MWFA Technology Development and Transition Guide (draft).

Team members evaluated the performance of refractories at MWFA-funded plasma and vitrification projects. Refractory life was estimated as a function of melt temperature, $\mathrm{pH}$, number of thermal cycles, and operating procedures.

Staff members researched proposed Hazardous Waste Combustion Regulations to address continuous emissions monitor system issues and comments.

\section{TASK B-PROJECT ASSESSMENT}

\section{TANKS FOCUS AREA (TFA)}

A draft letter was prepared by the WPI staff for DOE-RL responding to comments from Dr. Rico Cruz of the Nez Perce Tribe to the Tank Focus Area regarding the FY98 IRB. Dr. Cruz had concerns regarding stakeholder involvement and technology acceptability to stakeholders. The method of responding to his comments was to iterate the TFA strategy and philosophy.

The WPI Team coordinated a tour of 200 area Tank Farms for RL clients and visiting site representatives from Savannah River. The tour covered visiting the 101-SY mixer pump control trailer, 242A Evaporator (72M gal. boiled-off since startup in 1977), sludge voidmeter (gaseous fraction) testing at 103-AN, and the surface moisture measurement deployment system developed by EM-30.

The staff assisted with preparation of the FY98 Internal Review Budget. This preparation included participation in multiple teleconferences and HQ review meetings. Materials developed in support of this effort included prioritized task lists and related needs 
documentation; risk data sheets; and briefings to the DOE-RL Site Manager, EM-50, and EM-1. The culmination of these activities was a needs driven program for FY98 that has been bought off by each of the four TFA involved sites.

Staff coordinated a last-round comment review of the TFA Rainbow Book requested by EM-54 to make sure that all the DOE-Headquarters Program Managers and the Operations Office focus area leads had the opportunity to review and comment on the books. The Crosscutting Programs section of the TFA Rainbow Book was rewritten to incorporate comments from RL. The final draft of the Rainbow Book is in "comfort review."

The WPI staff made presentations to WPI, DOE-RL, and PNNL providing an overview of the discussions at the MWFA Mid-Year Review (April 30, 1996 to May 2, 1996) in Idaho Falls, Idaho. The presentations focused on critical follow-on activities to increase collaboration between TFA and the MWFA. Information from the meeting will assist the TFA in identifying potential areas of cooperation and mutual interest for the MWFA Laboratory Call for Proposals in June, 1996, and in facilitating TFA involvement with the MWFA Waste Forms Initiative.

The WPI staff prepared Table 2-2 for the TFA MYPP. Table 2-2 identifies the FY96-99 budgets for TFA and the corresponding budgets for the EM-50 crosscuts, EM-30, and EM-40.

Staff contacted Argonne National Laboratory (ANL) and Westinghouse Savannah River Company (WSRC) to determine the extent of industrial partnership in their immobilization TTPs in response to a request by DOE-RL.

Staff obtained a number of performance assessment documents to forward to WPI-Idaho to support the MWFA Waste Forms Initiative.

The joint call for proposals between the CMST crosscutting program and the TFA was reviewed, and inputs and recommendations to CMST program managers as well as the TFA characterization TIM on the project scope and allocated funding was provided by the WPI staff. The recommendations were transmitted to DOE-RL for approval. The call for proposals will be made to industry and/or national laboratories. The RFP will be initiated in the June/July time frame for initiation of startup at the beginning of FY97.

The WPI Team briefed newly joined members of DOE-RL's TFA program on Retrieval and Closure technology development activities. The presentations included specific problems, needs, technologies, and scope of work.

Staff prepared a draft response to the Hanford Tank Waste Remediation System (TWRS) request for consideration of additional technology development funding in FY98 to support Risk Reduction for Privatization. A table showing a match-up of TFA tasks to 
TWRS needs was developed. It is apparent that TWRS funding priorities had changed since their initial TD needs were submitted to the TFA in November 1995.

The WPI Team responded to a request from DOE/RL for a rough estimate of additional tasks that could be completed in FY96 and funding that would be required for those tasks. The estimate was provided to DOE/RL.

A deliverable for the Cone Penetrometer/Electrical Resistance Tomography CPT/ERT task was reviewed by the WPI staff and the recommendation was made to transmit the deliverable as submitted. Staff also recommended reviewing the progress of the task by the end of FY96 to determine direction of the task for FY97.

Staff prepared a Draft of FY96 Dollars to Industry for the TFA. First cut indicates about $\$ 4.5 \mathrm{M}$ to industry/universities from the core program TTPs. There are additional funds going to AEA Technologies (about $\$ 1.3 \mathrm{M}$ ) and the Russians for work directly supporting the TFA

\section{SUBSURFACE CONTAMINANTS FOCUS AREA (SCFA)}

Members of the team identified proposed SCFA projects that could be candidates for FY97 funding by METC Industrial Partnership Program. This information was incorporated into a primary list and a secondary list of projects. The primary list includes projects which could use more participation by private industry and provide the most opportunity for cost savings to the SCFA. The secondary list provides some additional projects which may be able to utilize IPP funding. Rationale for how private industry could be involved with these projects is discussed in more detail in the attached lists.

A predecisional draft memo addressing the participants of the Atlanta Prioritization Criteria Evaluation Meeting were prepared. The draft contained a summary of accomplishments during the meeting and planned actions resulting from the meeting.

WPI team members developed background material for the FY98 IRB presentation given in Gaithersburg, MD. The background material included definitions of FY95-98 mortgages and new starts, estimates of treated landfills and plumes, as well as estimates of dollars spent on developed technologies, and a detailed breakout of the technologies listed in a performance measure table.

Staff provided supporting materials for the SCFA FY97 Program Execution Guidance Meeting in Atlanta, GA. These materials included briefing slides, background information and meeting/workgroup session minutes. This package will provide a valuable reference for preparation of the FY97 PEG.

Slides of the IRB presentation were prepared summarizing the technical status of new projects status, mortgages from previous years, and deployment. The slides also summarized assumptions used to develop the material. 
The WPI team submitted initial guidance for improvement of content of short form TTPs in support of FY97 PEG. Reviews of FY96 TTPs have indicated a need to standardize specific types of information to be included in the FY97 TTPs which will make collection of budget data, identification of milestones and performance measures, and work scope definition more accurate. If these key items of information are accurately entered into the FY97 TTPs, then the transfer of this same budget and milestone data into PTS should also be more accurate.

\section{DECONTAMINATION AND DECOMMISSIONING (D\&D) FOCUS AREA}

A WPI team member attended a meeting of the Fernald Plant 1 Large-scale Demonstration Integrating Contractor Team on May 7 and prepared a detailed meeting record for approval by the METC project manager.

The WPI team supported METC in the planning of the D\&DFA's mid-year review (May $21-22,1996)$. The team helped identify peer-reviewers and procure their services, prepared review questionnaires, and supported METC during the two-day review. Currently, the WPI team is coordinating compilation of peer-review comments.

Staff provided final technical review and comments for the development of the D\&D Focus Area FY96 Technology Summary Report.

Team members provided technical support in response to a HQ request for information on D\&D mortgages and percentage of funding to industry for FY95 through FY98.

Technical support and input to the METC Process Improvement Team for the METC Project Management System (MPMS) was provided by staff members.

The WPI team provided technical support for the collection and assessment of D\&D technology needs submitted from DOE sites (STCGs) throughout the complex.

The team delivered the April Monthly and the D\&DFA Annual Report and developed the D\&D Focus Area Monthly Report for May, 1996.

The WPI team continued to provide technical input and guidance to the preparation of the D\&D Focus Area Internal Review Budget (IRB) for Fiscal Year 1998. This included input to the preparation of overheads for the Field D\&D Focus Area Lead to present the 1988 IRB for D\&D to the Deputy Assistant Secretary for Science and Technology.

The WPI team provided supplementary information to the FY96 D\&D Technical Task Plan data, on Principal Investigators, contractor organizations, and contractor congressional districts, for METC MPMS. MPMS is used by METC for tracking and managing technical tasks, including the D\&D Focus Area Technical Tasks. 


\section{MIXED WASTE FOCUS AREA (MWFA)}

Staff assisted the Technical Editor for the Mixed Waste Characterization, Treatment, and Disposal Focus Area Technology Summary Book by obtaining and incorporating DOE$\mathrm{HQ}$ and DOE-ID comments.

The team researched information and issues pertaining to current status of development of tribal environmental regulations.

Members of the WPI team attended the MWFA Mid-Year review, prepared notes, compiled action items, and distributed them to attendees.

The following documents to support participation in DOE-ID meetings were reviewed: (a) Financial Authorization, Baseline and Actual Documents and (b) Program Execution Guidance (May change) packages.

Staff members coordinated with the WPI contract personnel in developing subcontract language to obtain the services for two technical resource team members.

The Draft Independent Review Process Implementation Plan was submitted to DOE-ID for review and comment.

An electronic system for the review of the Integrated Master Schedule was tested and comments incorporated.

\section{TASK C-TECHNOLOGY INTEGRATION}

Staff assisted the Community Leaders Network Socratic Dialogue planning committee in collecting names and addresses of industries that have a vested interest in mixed waste treatment technologies.

A memo for TPOs including technical information for guidance to improve the quality of PTS data was drafted The guidance contains actions to be performed and time frames to ensure that the data is available for the Monthly Business Review.

WPI team submitted a variance analysis report created for the Landfill Stabilization and Plumes Focus Areas for the month of March monthly business review. The procedure to collect this data and identify the significant variances is now well established. An initial analysis of the variances for April has been completed for input provided from the April PTS input.

A meeting record which documents the discussions and assigned action items from the Joint Treatment Systems Program Review conducted by the Mixed Waste Focus Area and the Subsurface Contaminants Focus Area in Santa Fe, New Mexico on April 18, 
1996 was submitted. Items specifically designated at the meeting for management review and attention were highlighted.

The team forwarded to the Richland Office information about EPA's proposed "Hazardous Waste Identification Rule--Process Wastes" consisting of copies of: (a) a WPI summary of the proposal; (b) the full preamble and text of the proposed rule; (c) DOE's official comments on the proposed rule; (d) the Washington Department of Ecology comments on the proposal; and (e) the DoD comments on the proposed rule.

The team forwarded to the Idaho Falls Office information about the same Rule consisting of (a) DOE's comments on the proposed rule; (b) the Idaho Division of Environmental Quality's comments on the proposed rule; and (c) DoD's comments on the proposal.

Members of the team researched, analyzed, prepared and forwarded a summary of the State Clean Air Act permitting regulations for Colorado, Idaho, Nevada, Ohio, South Carolina, and Tennessee, including copies of the current regulations for the Idaho Falls Office.

The WPI team researched, analyzed, and forwarded copies of 10 articles/materials concerning the authority and practices of American Indian Tribes to the Idaho Falls Office.

Team members provided a summary of EPA's Proposed Guidelines for Carcinogen Risk Assessment for informational purposes to the field offices.

The WPI team provided meeting planning support for the SubCon Focus Area Meeting, May 22-23, 1996 at the Hilton, Atlanta, Georgia.

Planning support has commenced for the following upcoming meetings: Tanks, June 2526, 1996 at the Stouffer Concourse Hotel in Denver, Colorado and In Situ Stabilization Workshop, June 26-27, 1996 in the Landmark Inn, Park City, Utah.

Members of the team provided technical support for the development of a Decision Support System to aid the Focus Areas in the prioritization of their technology development portfolios.

A member of the team researched, wrote, and distributed the April-May "State Environmental Watch."

\section{TASK D - SYSTEMS ENGINEERING}

A new task was initiated during the month in Systems Engineering Analysis. This task involves a subcontract to Dr. Wolter Fabrycky of Virginia Tech's Department of Industrial and Systems Engineering and WPI team staff at Morgantown. The first work assignment was defined in a meeting at METC on May 16 to analyze and develop a 
report outlining the key assumptions and sensitivities of those assumptions on the results of Thermal and Non-Thermal Low Level Mixed Waste Processing systems studies conducted by INEL. This report will be an input to a peer review of the Non-Thermal study planned for August. The task has been started and a general approach outlined with EERC leading the effort. The report is due to METC on July 22. WPI will be providing the analysis of the regulatory drivers on the studies and the general approach to systems engineering that has been taken.

The WPI team reviewed the Integrated Thermal Treatment Systems Study (Parts I \& II) and the Integrated Nonthermal Treatment System Study prepared by Idaho National Engineering Laboratory (INEL). The area of review was regulations (DOE, NRC, EPA), permitting, stakeholders' input, input waste characteristics, and waste characterization. The findings from this review will be used as a basis for improvements in future systems engineering studies of treatment technologies and treatment systems. 


\section{ATTACHMENT A}

\section{PRODUCTS DELIVERED: TASK A - TECHNOLOGY ASSESSMENT}

\section{TANKS FOCUS AREA (TFA)}

- Trip report on MWFA Midyear Review

- Memorandum on Questions on Hanford's Abandonment of Grout as a Waste Form

- Packet of information on EM-related closure activities to support CCEM

- Position Paper on Grout vs Glass Decision for Hanford to support MWFA Waste Form Initiative

- Comments on Tank Closure Workshop

- Crosscutting Program Section for TFA Rainbow Book

- TFA Needs Table in Relation to the Efficient Separation Process

SUBSURFACE CONTAMINANTS FOCUS AREA (SCFA)

- Coordination of technical review of LSFA Treatment Systems Technologies

DECONTAMINATION AND DECOMMISSIONING (D\&D) FOCUS AREA

- Draft report entitled, "Recycling Radioactive Scrap Metal"

- Draft meeting record, 105C-Reactor Cocooning Large-scale Demonstration project meeting of April 25 and 26, 1996

- Comments on Preferred Alternatives Technology Guide prepared by EM-40

- Meeting Record, Fernald Plant 1 Large-scale Demonstration Project, May 7, 1996. Distributed on May 15, 1996

- Technical Presentation on Large-scale Demonstration program and selected technologies for the National Association of Environmental Professionals meeting in June, 1996

- Issue Paper for DOE/METC highlighting the status and outstanding concerns of the Brookhaven Asbestos Project (TTP\# CH3-4-DD-52 "Conversion of Asbestos Containing Material into Non-Regulated Material) 
- Draft memo from DOE/METC program manager to the Brookhaven Asbestos Project (TTP\# CH3-4-DD-52 "Conversion of Asbestos Containing Material into NonRegulated Material) principal investigator (Leon Petrakis) which discusses the D\&D Focus Areas approach to review proposed projects for FY97 funding

- Mailing list to distribute Fernald LSD Meeting Minutes

- Notes from EM-40 D\&D Focus Group Workshop held in conjunction with TIE Meeting

\section{MIXED WASTE FOCUS AREA (MWFA)}

- Draft Technology Development Requirements Documents (TDRDs)

- Draft Mixed Waste Characterization, Treatment and Disposal Focus Area "Rainbow Book"

- Comments to the Draft Mixed Waste Focus Area Integrated Master Schedule

- Responses to Comments from Alison Johnson on the Draft Mixed Waste Characterization, Treatment, and Disposal Focus Area "Rainbow Book"

\section{PRODUCTS DELIVERED: TASK B - PROJECT ASSESSMENT}

\section{TANKS FOCUS AREA (TFA)}

- Review of RL36WT51 Milestone 1.1-2: Design Review of the Confined Sluicing End Effector

- Linking of IRB to Hanford Needs

- Review of RL46WT21 Subtask 2-CPT/ERT Deployment Milestone 2-C2

- Table of potential TFA FY96 additional tasks

- Document Review: Needs Assessment Process Summary

- Draft memo to SR, OR, RL and ID transmitting summary RDS reports for use while searching for EM-30/40 funding for tanks

- TFA IRB Briefing for Al Alm

- New PEG TTP SR16C231, DWPF Analytical Sampling 
- CMST March Progress Report

- Crosswalk information (Table 2.2) for MYPP

- TFA Business Review Briefing for DOE-RL

- Draft memorandum from TFA Lead to Stakeholder (Rico Cruz, Nez Perce Tribe) on FY98 IRB comments

- Memorandum to DOE-RL on Review of TTP RL36WT11 Milestone Deliverable A1 with Review Report Attachment

- Table of TFA development activities for FY98 in response to EM-30 TWRS Alternate Path/Risk Reduction Technology Development Needs Review

- Draft Transmittal of Pretreatment Technical Task Packages

SUBSURFACE CONTAMINANTS FOCUS AREA (SCFA)

- Initial guidance on improvements to content of short form TTPs in support to of FY97 PEG

- SCFA Weekly Reports

- Background material for FY98 IRB Presentation

- Predecisional draft memo addressed to the participants of the Atlanta Prioritization Criteria Evaluation Meeting

- ( idance to the TPOs drafted to improve the quality of PTS data

- Lists of SCFA projects identified as possible candidates for FY97 funding by METC's Industrial Partnership Program

- Spreadsheets to backup August 95 charts in briefing on PEG for Landfills and Plumes

- Lists of PFA and LSFA accomplishments for FY94-98

- Supporting documentation for the FY97 SCFA Program Execution Guidance Meeting 


\section{DECONTAMINATION AND DECOMMISSIONING (D\&D) FOCUS AREA}

- Final draft of the D\&D Technology Summary was submitted to HQ for layout. (Draft document from WPI graphics in deliverables file)

- Draft input to the MPMS Process Improvement Team document outlining current and potential uses and improvements to the MPMS.

- Draft memo from DOE/METC to the STCGs requesting site D\&D technology needs.

- A funding matrix for D\&D mortgages and percentage of funding to industry for FY95 through FY98.

- D\&D FA Mid-Year Review Peer Reviewer Notebooks

- D\&DFA FY95 Annual Report

- D\&DFA FY98 IRB briefing

MIXED WASTE FOCUS AREA (MWFA)

- April Monthly Report

\section{PRODUCTS DELIVERED: TASK C - TECHNOLOGX INTEGRATION}

- Review and comments on SBIR Proposals for DOE-HQ

- Variance analysis report for LSFA \& PFA for March monthly business review

- Joint Treatment Systems Program Review conducted by MWFA \& SCFA, meeting record

- Technical input for guidance document to TPOs

- - PTS Reports on Cost Schedule Variances requiring action by PTOs

- Overdue milestone report

- One page fact sheet and cover letters for 68 inquiries from a Chemical Engineering article regarding viscous liquids barrier technology

- EM Activity/Life Cycle Cost Chart 


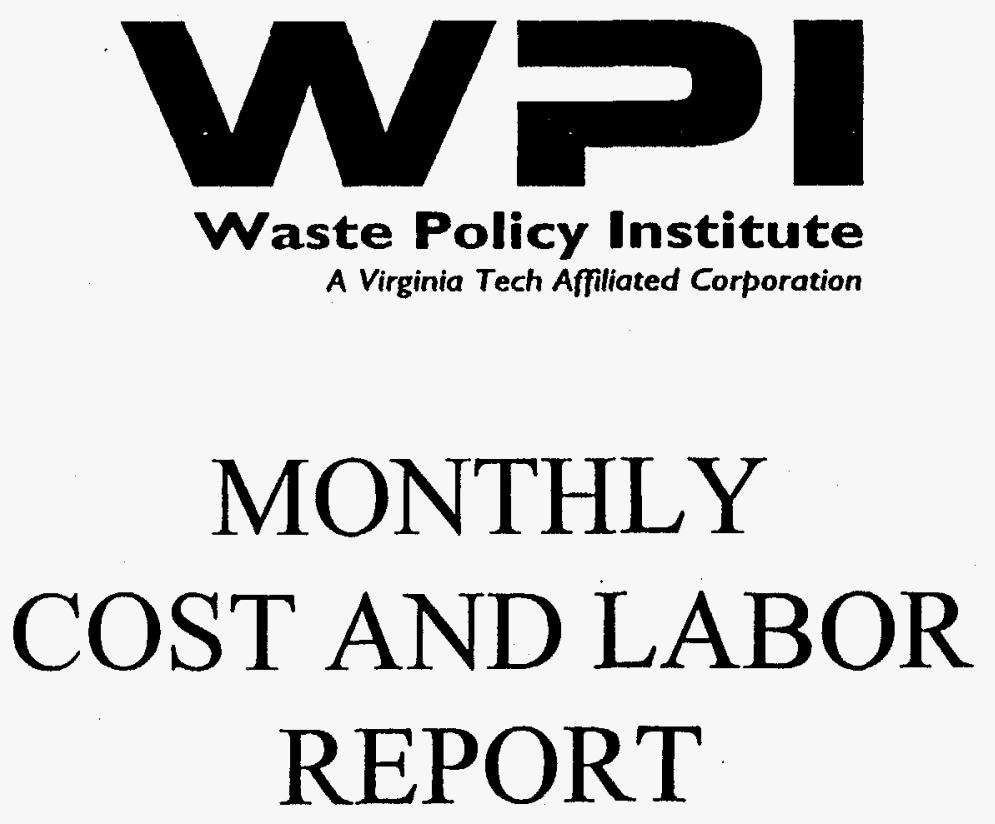

UNIVERSITY OF NORTH DAKOTA ENERGY AND ENVIRONMENTAL RESEARCH CENTER

Subcontract No. 359636

May, 1996 


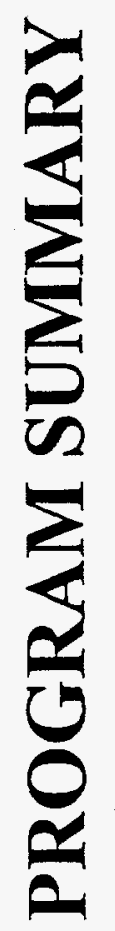


WPI Subcontract--EERC Coop. Agreement

$(\$ \times 1000)$

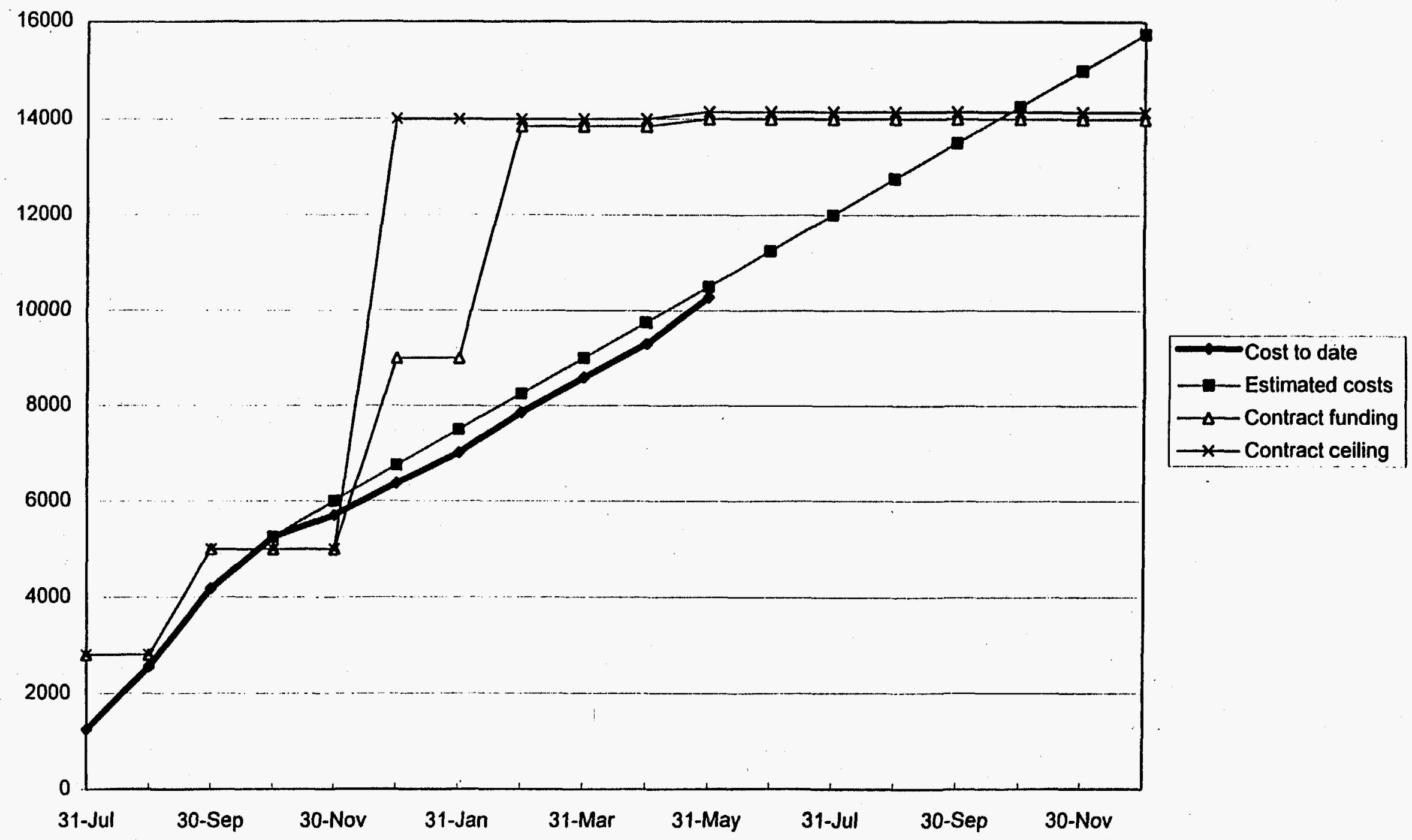

Page 1 
Subcontract No. 359636

Actuals through May 96

WBS: 1043 EERC

Manager: Dr. John S. Wilson

\section{Start Date: 6/27/95}

End Date: 12/1/96

Task Description: Provide assistance to EERC's conduct of technology development integration activities.

\section{Cost Performance Summary:}

\begin{tabular}{|c|c|c|c|}
\hline & \multicolumn{3}{|c|}{ Current Period } \\
\hline & Budget & Actuals & Variance \\
\hline Hours: & 10,669 & 11,408 & -739 \\
\hline Price: & 839,498 & 982,181 & $-142,683$ \\
\hline
\end{tabular}

\begin{tabular}{|c|c|c|}
\hline \multicolumn{3}{|c|}{ Inception to Date } \\
\hline Budget & Actuals & Variance \\
\hline 136,954 & 120,031 & 16,923 \\
\hline $10,743,992$ & $10,280,023$ & 463,969 \\
\hline
\end{tabular}

\begin{tabular}{r|r|r|}
\multicolumn{3}{c}{ At Complete } \\
\hline \multicolumn{1}{c|}{ Budget } & \multicolumn{1}{c}{ Estimate } & Variance \\
\hline 179,950 & 163,027 & 16,923 \\
\hline $14,144,823$ & $13,680,855$ & 463,969 \\
\hline
\end{tabular}

Monthly Financial Recap:

\begin{tabular}{|c|c|c|c|c|c|c|c|c|c|c|c|c|}
\hline & Jun 95 & Jul 95 & Aug 95 & Sep 95 & Oct 95 & Nov 95 & Dec 95 & Jan 96 & Feb 96 & $\operatorname{Mar} 96$ & Apr 96 & May 96 \\
\hline \multicolumn{13}{|l|}{ Actuals: } \\
\hline Monthly Hours: & 149 & 15,710 & 17.723 & 19,161 & 10,639 & $6, \overline{367}$ & 6,669 & 6,932 & 8,057 & 8,562 & 8,653 & 11,408 \\
\hline Cumu Hours: & 149 & 15,859 & 33,582 & 52,743 & 63,382 & 69,749 & 76,418 & 83,350 & 91,408 & 99,970 & 108,623 & 120,031 \\
\hline Monthly Price: & 8,492 & $1,240,210$ & $1,300,381$ & $1,628,866$ & $1,072,629$ & 508,957 & 674,480 & 577,622 & 844,119 & 734,699 & 707,388 & $\overline{982,181}$ \\
\hline Cumu Price: & 8,492 & $1,248,702$ & $2,549,083$ & $4,177,949$ & $5,250,578$ & $5,759,535$ & $6,434,015$ & $7,011,637$ & $7,855,755$ & $8,590,455$ & $9,297,843$ & $10,260,023$ \\
\hline
\end{tabular}

Budget:

\begin{tabular}{|c|c|c|c|c|c|c|c|c|c|c|c|c|}
\hline Monthly Hours: & 1,437 & 18,428 & 22,308 & 10,570 & 10,506 & 10,506 & 10,506 & 10.506 & 10,506 & 10.506 & 10,506 & 10,669 \\
\hline Cumu Hours: & 1,437 & 19,865 & 42,173 & 52,743 & 63,249 & 73,755 & 84,261 & 94,767 & 105,273 & 115,779 & 126,286 & 136,954 \\
\hline Monthly Price: & 89,294 & $1,251,829$ & $1,454,843$ & $1,381,982$ & 818,078 & 818,078 & 818,078 & 818,078 & 818,078 & 818,078 & 818,078 & 839,498 \\
\hline Cumu Price: & 89,294 & $1,341,124$ & $2,795,967$ & $4.177,949$ & $4,996,027$ & $5,814,106$ & $6,632,183$ & $7,450,261$ & $8,268,339$ & $9,086,417$ & $9,904,494$ & $10,743,992$ \\
\hline
\end{tabular}




\section{Subcontract No. 359636}

Actuals through May 96

WBS: 1043 EERC

Manager: Dr. John S. Wilson

Start Date: 6/27/95

End Date: 12/1/96

Task Description: Provide assistance to EERC's conduct of technology development integration activities.

Cost Performance Summary:

\begin{tabular}{|c|c|c|c|}
\hline & \multicolumn{3}{|c|}{ Current Perlod } \\
\hline & Budget & Actuals & Variance \\
\hline Hours: & 10,669 & 11,408 & .739 \\
\hline Price: & $\overline{839,498}$ & 982,181 & $-142,683$ \\
\hline
\end{tabular}

\begin{tabular}{|c|c|c|}
\hline \multicolumn{3}{|c|}{ Inception to Date } \\
\hline Budget & Actuals & Variance \\
\hline 136,954 & 120,031 & 16,923 \\
\hline $10,743,992$ & $10,280,023$ & 463,969 \\
\hline
\end{tabular}

\begin{tabular}{r|rr}
\multicolumn{3}{c}{ At Complete } \\
\hline Budget & \multicolumn{1}{c}{ Estimate } & \multicolumn{1}{c}{ Variance } \\
\hline 179,950 & 163,027 & 16,923 \\
\hline $14,144,823$ & $13,680,855$ & 463,969 \\
\hline
\end{tabular}

Monthly Financial Recap:

\begin{tabular}{|c|c|c|c|c|c|c|c|c|c|c|c|c|}
\hline & Jun 96 & Jul 96 & Aug 96 & Sep 96 & Oct 96 & Nov 96 & Dec 96 & Jan 97 & Feb 97 & Mar 97 & Apr 97 & May 97 \\
\hline \multicolumn{13}{|l|}{ Actuals: } \\
\hline Monthly Hours: & 0 & 0 & 0 & 0 & 0 & 0 & & & & & & \\
\hline Cumu Hours: & 120,031 & 120,031 & 120,031 & 120,031 & 120,031 & 120,031 & & & & & & \\
\hline Monthly Price: & 0 & 0 & 0 & 0 & 0 & 0 & & & & & & \\
\hline Cumu Price: & $10,280,023$ & $10,280,023$ & $10,280,023$ & $10,280,023$ & $10,280,023$ & $10,280,023$ & & & & & & \\
\hline
\end{tabular}

Budget:

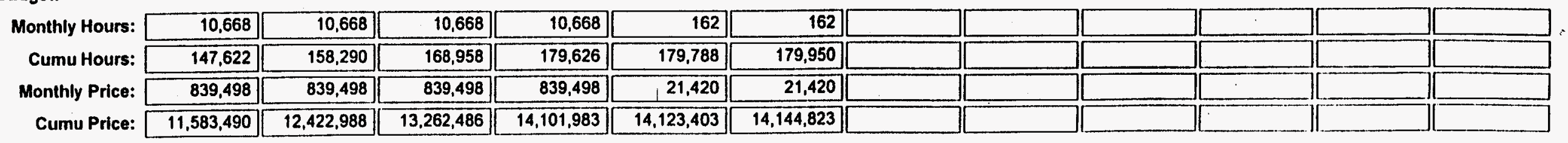




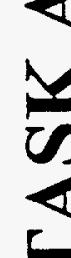


Subcontract No. 359636

Actuals through May 96

WBS: 1043.01 .01 Technology Management

Manager: Dr. John S. Wilson

Start Date: 6/27/95

End Date: $12 / 1 / 96$

Task Description: Perform lechnical reviews of requirements, needs and assessments related to waste characterization, containment, in-situ and ex-situ treatment, waste storage, disposal, robotics handling, monitoring, laboratory analysis, sile characterization and remediation.

Cost Performance Summary:

\begin{tabular}{|c|c|c|c|}
\hline & \multicolumn{3}{|c|}{ Current Period } \\
\hline & Budget & Actuals & Variance \\
\hline Hours: & 5.474 & 4.168 & 1.306 \\
\hline Price: & 297,160 & 383,670 & $-86, \overline{510}$ \\
\hline
\end{tabular}

\begin{tabular}{l|l|l|}
\multicolumn{3}{c}{ Inceptlon to Date } \\
\hline Budget & \multicolumn{1}{c}{ Actuals } & Varlance \\
\hline 65,561 & 52,200 & 13,361 \\
\hline $4,234,946$ & $4,799,247$ & $-564,300$ \\
\hline
\end{tabular}

\begin{tabular}{r|r|r|}
\multicolumn{3}{c}{ At Complete } \\
\hline Budget & \multicolumn{1}{c|}{ Estimate } & Varlance \\
\hline 87,456 & 74,095 & 13,361 \\
\hline $5,423,585$ & $5,987,885$ & $-564,300$ \\
\hline
\end{tabular}

Monthly Financial Recap:

\begin{tabular}{|c|c|c|c|c|c|c|c|c|c|c|c|c|}
\hline & Jun 95 & Jul 95 & Aug 95 & Sep 95 & Oct 95 & Nov 95 & Dec 95 & Jan 96 & Feb 96 & Mar 96 & Apr 96 & May 96 \\
\hline \multicolumn{13}{|l|}{ Actuals: } \\
\hline Monthly Hours: & 50 & 6.255 & 7,504 & 7.961 & 6.453 & 4,330 & 3,138 & 2,600 & 3,300 & 3,479 & 2,963 & 4,168 \\
\hline Cumu Hours: & 50 & 6,305 & 13,809 & 21.770 & 28,224 & 32,553 & 35,691 & 38,291 & 41,591 & 45,069 & 48,032 & 52,200 \\
\hline Monthly Price: & 2,574 & 533.931 & 582,189 & 738,970 & 657,545 & 359,376 & 316,660 & 247,333 & 406,806 & 323,669 & 246,524 & 383,670 \\
\hline Cumu Price: & 2,574 & 536,505 & $1,118,694$ & $1,857,664$ & $2,515,209$ & $2,874,585$ & $3,191,245$ & $3,438,578$ & $3,845,383$ & $4,169,052$ & $4,415,577$ & $4,799,247$ \\
\hline
\end{tabular}

Budget:

\begin{tabular}{|c|c|c|c|c|c|c|c|c|c|c|c|c|}
\hline Monthly Hours: & 328 & 7.196 & 8.711 & 5,534 & 5.474 & 5,474 & 5,474 & 5,474 & 5,474 & 5,474 & 5,474 & 5,474 \\
\hline Cumu Hours: & 328 & 7.525 & 16,236 & 21,770 & 27,244 & 32,718 & 38,191 & 43,665 & 49,139 & 54,613 & 60,087 & 65,561 \\
\hline Monthly Price: & 14,090 & 498,386 & 570.555 & 774,636 & 297,160 & 297,160 & 297,160 & 297,160 & 297,160 & 297,160 & 297,160 & 297,160 \\
\hline Cumu Price: & 14,090 & 512,477 & $1,083,032$ & $1,857,668$ & $2,154,828$ & $2,451,988$ & $2,749,148$ & $3,046,308$ & $3,343,467$ & $3,640,627$ & $3,937,787$ & $4.234,946$ \\
\hline
\end{tabular}




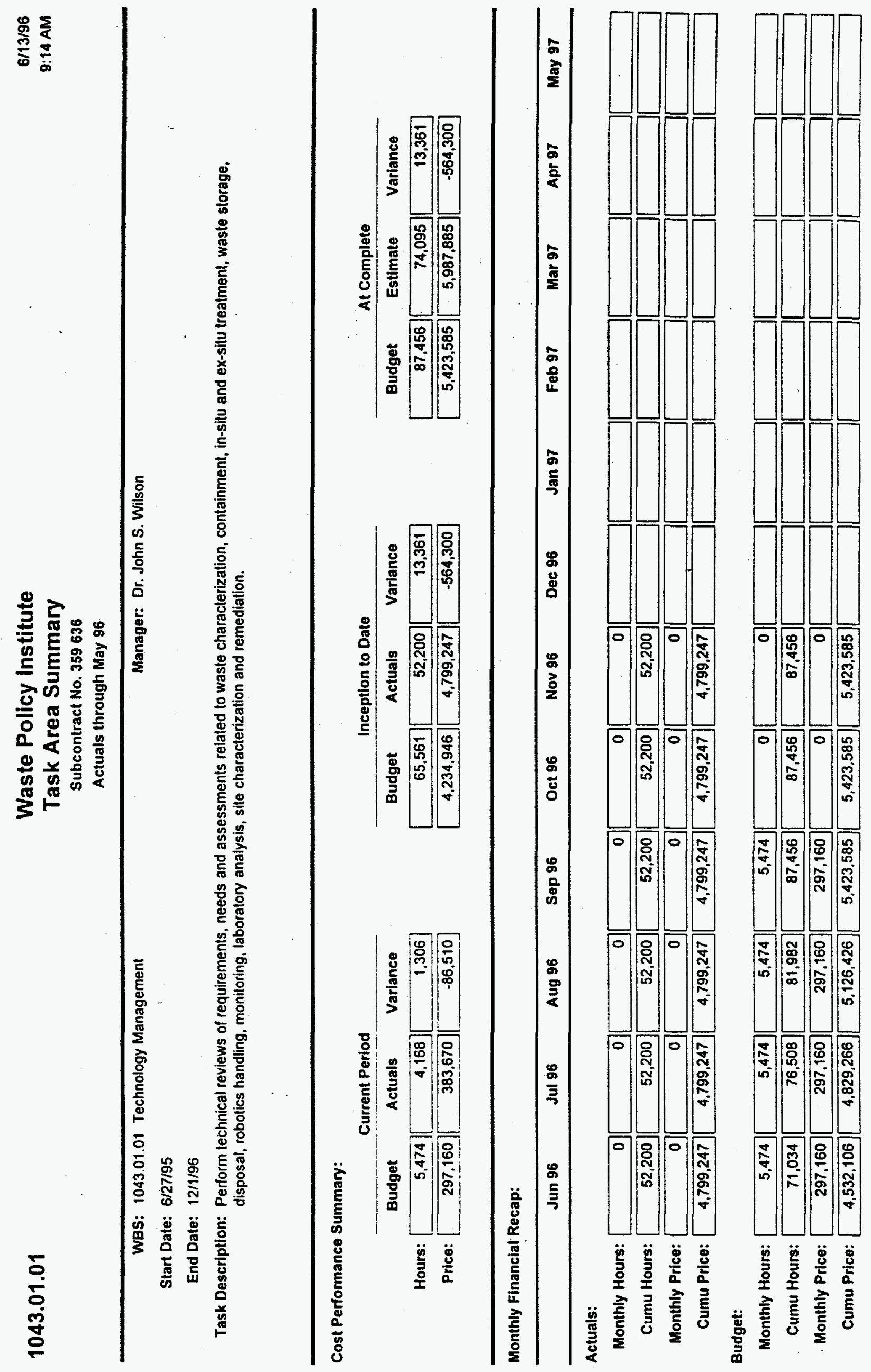


$\frac{a}{4}$ 
Actuals through May 96

WBS: 1043.01.02 Project Management

Manager: Dr. John S. Wilson

Start Date: 6/27/95

End Date: 12/1/96

Task Description: Conduct reviews, analyze and develop strategies for program management systems for integration and control of programs, projects, tasks and documenlation.

Cost Performance Summary:

\begin{tabular}{|c|c|c|c|}
\hline & \multicolumn{3}{|c|}{ Current Period } \\
\hline & Budget & Actuals & Varlance \\
\hline Hours: & 2.704 & $4 . \overline{024}$ & $-1,320$ \\
\hline Price: & 273,798 & 315.382 & $-41,584$ \\
\hline
\end{tabular}

\begin{tabular}{|c|c|c|}
\hline \multicolumn{3}{|c|}{ Inception to Date } \\
\hline Budget & Actuals & Variance \\
\hline 47,177 & 51,412 & $-4,235$ \\
\hline $4,082,448$ & $4,083,869$ & $-1,421$ \\
\hline
\end{tabular}

\begin{tabular}{|c|c|c|}
\hline \multicolumn{3}{|c|}{ At Complete } \\
\hline Budget & Estimate & Variance \\
\hline 57.993 & 62,228 & $-4,235$ \\
\hline $5,177,640$ & $5,179,061$ & -1.421 \\
\hline
\end{tabular}

Monthly Financial Recap:

\begin{tabular}{|c|c|c|c|c|c|c|c|c|c|c|c|c|}
\hline & Jun 95 & Jul 95 & Aug 95 & Sep 95 & Oct 95 & Nov 95 & Dec 95 & $\operatorname{Jan} 96$ & Feb 96 & Mar 96 & Apr 96 & May 96 \\
\hline \multicolumn{13}{|l|}{ Actuals: } \\
\hline Monthly Hours: & 98 & 8,116 & 8,247 & 9,084 & 3,578 & $1,58 B$ & 2,868 & 3,297 & 3,561 & 3,631 & 3,321 & 4,024 \\
\hline Cumu Hours: & 98 & 8,214 & 16,462 & 25,545 & 29,123 & 30,711 & 33,578 & 36,875 & 40,436 & 44,067 & 47,388 & 51.412 \\
\hline Monthly Price: & 5.779 & 599,758 & 566,591 & 719,936 & 341,971 & 108,114 & 275,047 & 255,073 & 319.577 & 306,696 & 269,945 & 315,382 \\
\hline Cumu Price: & 5,779 & 605,537 & $1,172,128$ & $1,892,064$ & $2,234,035$ & $2,342,149$ & $2,617,196$ & $2,872,269$ & $3,191,846$ & $3,498,542$ & $3,768,486$ & $4,083,869$ \\
\hline
\end{tabular}

Budget:

Monthly Hours:

Cumu Hours:

Monthly Price:

\begin{tabular}{|r|r|}
\hline 309 & 6,643 \\
\hline 309 & 6,952 \\
\hline 21,034 & 453,804 \\
\hline 21,034 & 474,838 \\
\hline
\end{tabular}

\begin{tabular}{|r|r|r|}
\hline 8,042 & 10,551 & 2,704 \\
\hline 14,994 & 25,545 & 28,249 \\
\hline 527,559 & 889,666 & 273,798 \\
\hline $1,002,397$ & $1,892,063$ & $2,165,861$ \\
\hline
\end{tabular}

\begin{tabular}{|c|c|c|c|}
\hline 2,704 & 2,704 & 2,704 & 2,704 \\
\hline 30,953 & 33,657 & 36,361 & 39,065 \\
\hline 273,798 & 273,798 & 273,798 & 273,798 \\
\hline $2,439,659$ & $2,713,457$ & $2,987,255$ & $3,261,053$ \\
\hline
\end{tabular}

\begin{tabular}{|r|r|r|}
\hline 2,704 & 2,704 & 2,704 \\
\hline 41,769 & 44,473 & 47,177 \\
\hline 273,798 & 273,798 & 273,798 \\
\hline $3,534,852$ & $3,808,650$ \\
\hline
\end{tabular} \mid $\begin{array}{r}4,082,448 \\
\hline\end{array}$


Actuals through May 96

WBS: 1043.01 .02 Project Management

Manager: Dr. John S. Wilson

Start Date: $6 / 27 / 95$

End Date: 12/1/96

Task Description: Conduct reviews, analyze and develop strategies for program management systems for integration and control of programs, projects, tasks and documentation.

Cost Performance Summary:

\begin{tabular}{|c|c|c|c|}
\hline & \multicolumn{3}{|c|}{ Current Period } \\
\hline & Budget & Actuals & Variance \\
\hline urs: & 2,704 & 4,024 & -1.320 \\
\hline Price: & 273,798 & 315,382 & $.41,584$ \\
\hline
\end{tabular}

\begin{tabular}{|c|c|c|}
\hline \multicolumn{3}{|c|}{ Inception to Date } \\
\hline Budget & Actuals & Variance \\
\hline 47.177 & 51.412 & $-4,235$ \\
\hline $4,082,448$ & $4,083,869$ & $-1,421$ \\
\hline
\end{tabular}

\begin{tabular}{|c|c|c|}
\hline \multicolumn{3}{|c|}{ At Complete } \\
\hline Budget & Estimate & Varlance \\
\hline 57,993 & 62,228 & $-4,235$ \\
\hline $5,177,640$ & $5,179,061$ & $-1,421$ \\
\hline
\end{tabular}

Monthly Financial Recap:

\begin{tabular}{|c|c|c|c|c|c|c|c|c|c|c|c|}
\hline Jun 96 & Jul 96 & Aug 96 & Sep 96 & Oct 96 & Nov 96 & Dec 96 & $\operatorname{Jan} 97$ & Feb 97 & Mar 97 & Apr 97 & May 97 \\
\hline
\end{tabular}

Actuals:

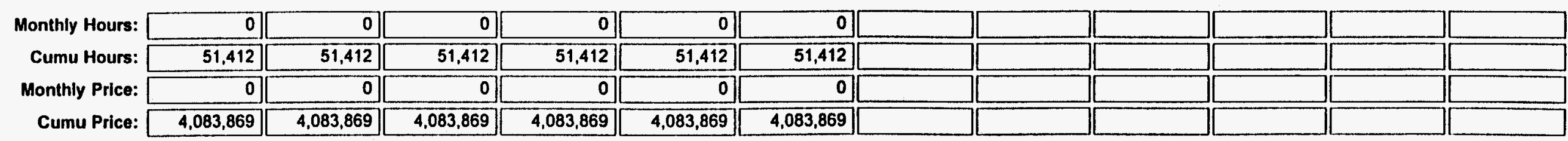
Budget:

Monthly Hours:

Cumu Hours:

Monthly Price:

\begin{tabular}{|r|r|r|r|r|r|}
\hline 2,704 & 2,704 & 2,704 & 2,704 & 0 & 0 \\
\hline 49,881 & 52,585 & 55,289 & 57,993 & 57,993 & 57,993 \\
\hline 273,798 & 273,798 & 273,798 & 273,798 & 0 & 0 \\
\hline $4,356,246$ & $4,630,044$ & $4,903,842$ & $5,177,640$ & $5,177,640$ & $5,177,640$ \\
\hline
\end{tabular}

(1)


$\frac{5}{5}$ 
Subcontract No. 359636

Actuals through May 96

WBS: 1043.01.03 Technology Inlegration

Manager: Dr. John S. Wilson

Start Date: 6/27/95

End Date: $12 / 1 / 96$

Task Description: Provide support in eslablishing criteria for identifying risks to the public health and safety posed by conditions at the weapons complex facilities, evaluale the extent of these risks, determine the urgency and priorities for eliminating or minimizing the risks, and access the cost of activities required to meet applicable compliance agreements.

Cost Performance Summary:

\begin{tabular}{|c|c|c|c|}
\hline & \multicolumn{3}{|c|}{ Current Period } \\
\hline & Budget & Actuals & Variance \\
\hline Hours: & 2,328 & 3,216 & $-8 \overline{88}$ \\
\hline Price: & 247.120 & 283,077 & $-35,957$ \\
\hline
\end{tabular}

\begin{tabular}{|c|c|c|}
\hline \multicolumn{3}{|c|}{ Inception to Date } \\
\hline Budget & Actuals & Variance \\
\hline 24,054 & 16,419 & 7,635 \\
\hline $2,405,178$ & $1,396,857$ & $1,008,321$ \\
\hline
\end{tabular}

\begin{tabular}{|c|c|c|}
\hline \multicolumn{3}{|c|}{ At Complete } \\
\hline Budget & Estimate & Variance \\
\hline 33,367 & 25,732 & 7,635 \\
\hline $3,393,658$ & $2,385,337$ & $1,008,321$ \\
\hline
\end{tabular}

Monthly Financlal Recap:

\begin{tabular}{|c|c|c|c|c|c|c|c|c|c|c|c|c|}
\hline & Jun 95 & Jul 95 & Aug 95 & Sep 95 & Oct 95 & Nov 95 & Dec 95 & $\operatorname{Jan} 96$ & Feb 96 & Mar 96 & Apr 96 & May 96 \\
\hline \multicolumn{13}{|l|}{ Actuals: } \\
\hline Monthly Hours: & 1 & 1,339 & 1,972 & 2,117 & 608 & 450 & 664 & 1,036 & 1,196 & 1,453 & 2,370 & 3,216 \\
\hline Cumu Hours: & 1 & 1,340 & 3,312 & 5,428 & 6.036 & 6,486 & 7.150 & 8,185 & 9,381 & 10,834 & 13,203 & 16,419 \\
\hline Monthly Price: & 139 & 106,521 & 151,601 & 169,960 & 73,113 & 41,466 & 82,773 & 75,216 & 117,736 & 104,335 & 190,919 & 283,077 \\
\hline Cumu Price: & 139 & 106,660 & 258,261 & 428,221 & 501,334 & 542,800 & 625.574 & 700,790 & 818,526 & 922,860 & $1,113,780$ & $1,396,857$ \\
\hline
\end{tabular}

Budget:

\begin{tabular}{|c|c|c|c|c|c|c|c|c|c|c|c|c|}
\hline Monthly Hours: & 800 & 4,589 & 5,555 & $-5,515$ & 2,328 & 2,328 & 2,328 & 2,328 & 2,328 & 2,328 & 2,328 & 2,328 \\
\hline Cumu Hours: & 800 & $5, \overline{388}$ & 10,943 & 5,428 & 7,756 & 10,085 & 12,413 & 14.741 & 17,069 & $19, \overline{398}$ & 21,726 & 24,054 \\
\hline Monthly Price: & 54,170 & 299,639 & 356,729 & $-282,320$ & 247.120 & 247,120 & 247,120 & 247,120 & 247,120 & 247,120 & 247,120 & 247.120 \\
\hline
\end{tabular}


Subcontract No. 359636

Actuals through May 96

WBS: 1043.01 .03 Technology Integration

Manager: Dr. John S. Wilson

Start Date: 6/27/95

End Date: $12 / 1 / 96$

Task Description: Provide support in establishing criteria for identifying risks to the public health and safety posed by conditions at the weapons complex facilities, evaluate the extent of these risks, determine the urgency and priorities for eliminating or minimizing the risks, and access the cost of activities required to meel applicable compliance agreements.

Cost Performance Summary:

\begin{tabular}{|c|c|c|c|}
\hline & \multicolumn{3}{|c|}{ Current Period } \\
\hline & Budget & Actuals & Variance \\
\hline Hours: & 2,328 & 3,216 & -888 \\
\hline Price: & 247,120 & $\overline{283}, \overline{077}$ & $-35,957$ \\
\hline
\end{tabular}

\begin{tabular}{|c|c|c|}
\hline \multicolumn{3}{|c|}{ Inception to Date } \\
\hline Budget & Actuals & Variance \\
\hline $24, \overline{054}$ & 16.419 & 7,635 \\
\hline $2,405,178$ & $1,396,857$ & $1,008,321$ \\
\hline
\end{tabular}

\begin{tabular}{|c|c|c|}
\hline \multicolumn{3}{|c|}{ At Complete } \\
\hline Budget & Estimate & Variance \\
\hline 33,367 & 25,732 & 7,635 \\
\hline $3,393,658$ & $2,385,337$ & $1,008,321$ \\
\hline
\end{tabular}

Monthly Financial Recap:

\begin{tabular}{|c|c|c|c|c|c|c|c|c|c|c|c|c|}
\hline & Jun 96 & Jul 96 & Aug 96 & Sep 96 & Oct 96 & Nov 96 & Dec 96 & Jan 97 & Feb 97 & Mar 97 & Apr 97 & May 97 \\
\hline \multicolumn{13}{|l|}{ Actuals: } \\
\hline Monthly Hours: & 0 & 0 & 0 & 0 & 0 & 0 & & & & & & \\
\hline Cumu Hours: & 16,419 & 16,419 & 16.419 & 16,419 & 16,419 & 16,419 & & & & & & \\
\hline Monthly Price: & 0 & 0 & 0 & 0 & 0 & 0 & & & & & & \\
\hline Cumu Price: & $1,396,857$ & $1,396,857$ & $1,396,857$ & $1,396,857$ & $1,396,857$ & $1,396,857$ & & & & & & \\
\hline
\end{tabular}

Budget:

Monthly Hours:

Cumu Hours:

Monthly Price:

\begin{tabular}{|c|c|c|c|c|c|}
\hline 2,328 & 2,328 & 2,328 & 2,328 & 0 & 0 \\
\hline 26,382 & 28,711 & 31.039 & 33,367 & 33,367 & 33,367 \\
\hline 247,120 & 247,120 & 247.120 & 247,120 & 0 & 0 \\
\hline $2,652,298$ & $2,899,418$ & $3,146,538$ & $3,393,658$ & $3,393,658$ & $3,393,658$ \\
\hline
\end{tabular}

Cumu Price:

(1)


$\frac{1}{4}$ 
Actuals through May 96

WBS: 1043.01.04 Systems Engineering

Manager: Dr. John S. Wilson

Start Date: 2/1/96

End Date: 12/1/96

Task Description:

\section{Cost Performance Summary:}

\begin{tabular}{|c|c|c|c|}
\hline & \multicolumn{3}{|c|}{ Current Period } \\
\hline & Budget & Actuals & Variance \\
\hline Hours: & 162 & 0 & 162 \\
\hline Price: & 21,420 & 51 & 21,369 \\
\hline
\end{tabular}

\begin{tabular}{|c|c|c|}
\hline \multicolumn{3}{|c|}{ Inception to Date } \\
\hline Budget & Actuals & Variance \\
\hline 162 & 0 & 162 \\
\hline 21,420 & 51 & 21,369 \\
\hline
\end{tabular}

\begin{tabular}{|c|c|c|}
\hline \multicolumn{3}{|c|}{ At Complete } \\
\hline Budget & Estimate & Variance \\
\hline 1,134 & 972 & 162 \\
\hline 149,940 & 128,571 & 21,369 \\
\hline
\end{tabular}

Monthly Financial Recap:

\begin{tabular}{|c|c|c|c|c|c|c|c|c|c|c|c|c|}
\hline & Jun 95 & Jul 95 & Aug 95 & Sep 95 & Oct 95 & Nov 95 & Dec 95 & Jan 96 & Feb 96 & Mar 96 & Apr 96 & May 96 \\
\hline \multicolumn{13}{|l|}{ Actuals: } \\
\hline Monthly Hours: & 0 & 0 & 0 & 0 & 0 & 0 & 0 & 0 & 0 & 0 & 0 & 0 \\
\hline Cumu Hours: & 0 & 0 & 0 & 0 & 0 & 0 & 0 & 0 & 0 & 0 & 0 & 0 \\
\hline Monthly Price: & 0 & 0 & 0 & 0 & 0 & 0 & 0 & 0 & 0 & 0 & 0 & 51 \\
\hline Cumu Price: & 0 & 0 & 0 & 0 & 0 & 0 & 0 & 0 & 0 & 0 & 0 & 51 \\
\hline
\end{tabular}

Budget:
Monthly Hours:
Cumu Hours:

\begin{tabular}{|r|r|r|}
\hline 0 & 0 & 0 \\
\hline 0 & 0 & 0 \\
\hline 0 & 0 & 0 \\
\hline 0 & 0 & 0 \\
\hline
\end{tabular}

\begin{tabular}{|c|c|}
\hline \multicolumn{2}{|l|}{0} \\
\hline 0 & 0 \\
\hline & 0 \\
\hline & 0 \\
\hline
\end{tabular}

0
0
0

\begin{tabular}{|l|l|r|}
\hline 0 & 0 \\
\hline 0 & 0 & 0 \\
\hline 0 & 0 & 0 \\
\hline 0 & 0 & 0 \\
\hline 0 & 0 & 0 \\
\hline
\end{tabular}

\begin{tabular}{|c|c|c|c|c|}
\hline 0 & 0 & 0 & $\overline{0}$ & 162 \\
\hline 0 & 0 & $\overline{0}$ & 0 & 162 \\
\hline 0 & 0 & $\overrightarrow{0}$ & 0 & 21,420 \\
\hline 0 & 0 & $\overline{0}$ & 0 & 21.420 \\
\hline
\end{tabular}


Actuals through May 96

WBS: 1043.01.04 Syslems Engineering

Manager: Dr. John S. Wilson

\begin{abstract}
Start Date: 2/1/96
\end{abstract}
End Date: $12 / 1 / 96$

Task Description:

Cost Performance Summary:

\begin{tabular}{|c|c|c|c|}
\hline & \multicolumn{3}{|c|}{ Current Period } \\
\hline & Budget & Actuals & Variance \\
\hline Hours: & 162 & 0 & 162 \\
\hline Price: & 21,420 & 51 & 21,369 \\
\hline
\end{tabular}

Inception to Date
\begin{tabular}{|r|r|r|}
\hline Budget & Actuals & Varlance \\
\hline 162 & & 162 \\
\hline 21,420 & 0 & 21,369 \\
\hline
\end{tabular}

\begin{tabular}{|c|c|c|}
\hline \multicolumn{3}{|c|}{ At Complete } \\
\hline Budget & Estimate & Varlance \\
\hline 1,134 & 972 & 162 \\
\hline 149,940 & 128,571 & 21,369 \\
\hline
\end{tabular}

Monthly Financial Recap:

\begin{tabular}{|c|c|c|c|c|c|c|c|c|c|c|c|}
\hline Jun 96 & Jul 96 & Aug 96 & Sep 96 & Oct 96 & Nov 96 & Dec 96 & $\operatorname{Jan} 97$ & Feb 97 & Mar 97 & Apr 97 & May 97 \\
\hline
\end{tabular}

Actuals:

Monthly Hours:

Cumu Hours:

Monthly Price:

Cumu Price:

\begin{tabular}{|r|r|r|r|r|}
\hline 0 & 0 & 0 & 0 & 0 \\
\hline 0 & 0 & 0 & 0 \\
\hline 0 & 0 & 0 & 0 & 0 \\
\hline 51 & 0 & 0 & 0 & 0 \\
\hline 51 & 0 & 0 & 0 & 0 \\
\hline
\end{tabular}

(1)

Budget:

Monthly Hours:

Cumu Hours:

Monthly Price:

\begin{tabular}{|r|r|}
\hline 162 & 162 \\
\hline 324 & 162 \\
\hline 21,420 & 686 \\
\hline 42,840 & 648 \\
\hline 64,260 & 21,420 \\
\hline 85,680 \\
\hline
\end{tabular}



\footnotetext{
162
}

\author{
162
}

(1)

(1)


WASTE POLICY INSTITUTE MONTHLY REPORT TO THE EERC, JUNE 1996

\author{
APPENDIX C
}





\section{UNIVERSITY OF NORTH DAKOTA ENERGY AND ENVIRONMENTAL RESEARCH CENTER}

Monthly Report June, 1996

\section{TECHNOLOGY DEVELOPMENT INTEGRATION WPI SUBCONTRACT NUMBER



July 15,1996

Mr. John G. Hendrikson

Assistant to the Director

Energy and Environmental Research Center

University of North Dakota

15 North 23rd Street

Grand Forks, ND 58203

Subject: UNDEERC Fund No. 4624-0936, Technology Development Integration

WPI Subcontract No. 359636

Dear Mr. Hendrikson:

The Waste Policy Institute (WPI) is pleased to submit the enclosed report of activities conducted during the period of June 1, 1996 through June 30,1996, in compliance with Article VI and Appendix A of Subcontract Number 359636. A list of products developed during this period is provided as Attachment A to the activities report.

Through June 30, WPI has expended $\$ 11,048,418$. Our monthly cost and labor report provides the details of our costs to date. Although the current contract period extends through December 1, 1996, it should be noted that we anticipate the subcontract ceiling will be reached on or about September 20, 1996. This expenditure rate is consistent with our proposal for the new budget period.

Please do not hesitate to call me if you have any questions or require additional information.

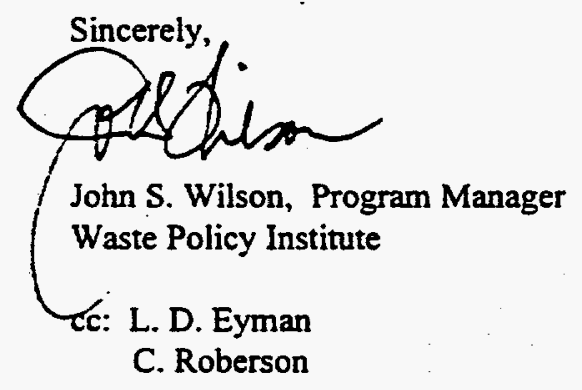


CONTRACTOR NAME: Waste Policy Institute 555 Quince Orchard Road

Suite 600

Gaithersburg, MD 20878-1437

CONTRACT PERIOD: $\quad 6 / 28 / 95-12 / 01 / 96$

\section{SUBCONTRACT DELIVERABLES:}

This report is submitted in fulfillment of requirements specified for the University of North Dakota Energy and Environmental Research Center (UNDEERC) Subcontract Number 359636. A list of products developed under this subcontract is provided as Attachment $A$.

\section{SUMMARY OF ACTIVITIES:}

The WPI team provided support for each focus area's program reviews with the Deputy Assistant Secretary that were conducted during the month.

\section{TASK A-TECHNOLOGY ASSESSMENT}

\section{TANKS FOCUS AREA (TFA)}

The staff provided technical support to the Managing Editor for the TFA Technology Summary (Rainbow Book) to resolve comments during the final stages of preparation including an additional field review. The Tanks Focus Area Rainbow Book was completed.

Staff members continued development of a Tanks Focus Area "Success Book". The book will present problems that have been addressed by new technologies, and explain the technologies.

Redevelopment of the TFA exhibit was begun. This exhibit travels to conferences and meetings all over the country. The current exhibit is very technical and works well at technical meetings or at meetings with an audience knowledgeable of DOE. The new exhibit will be oriented more towards the general public. It will be less technical, and assume the viewer has less knowledge of the DOE remediation requirements and technology development needs.

WPI team updated the FY95 TFA-Industry Partners map to show FY96 partnerships between TFA and industry and university partners around the United States, Russia and England. The map was part of the one-day review of the TFA conducted by Clyde Frank on June 21,1996 . It will also become a part of the TFA exhibit. 


\section{SUBSURFACE CONTAMINANTS FOCUS AREA (SCFA)}

Staff members drafted a review of close out documentation for milestone deliverable number 2A1 for TTP RL36PL21 Engineering Simulator - In Well Vapor Stripper (IWVS). The function of this review is to inform the program manager of new developments and accomplishments of this project and advise on the possible future actions for SCFA and this technology. Other sources reveal great promise for this technology: Fairchild AFB has installed a system, the City of Couer D'Alene, Idaho has signed a contract to have IWVS installed, and the city of Tucson, Arizona is planning to install a system.

A staff member provided a technical review of milestone deliverable D1 from TTP RL46PL41 - "In-Situ Gas Treatment Technology Demonstration Test Plan" to be conducted at the High Energy Laser System Test Facility (HELSTF) area within the White Sands Missile Range. Successful completion of the test will be of great use to DOE, other Federal Agencies and the private sector due to the wide spread problem of chromium contamination.

Technical background information for the Plumes and Landfill Stabilization Focus Area Winter Progress Report was developed. Review comments from SCFA team members were received and incorporated into the report. The report will be used by DOE-SR to prepare the SCFA Program Review.

A technical review and final draft of the treatability test to be conducted at the Hanford $100 \mathrm{~N}$-Springs was completed. If successful, this test would provide the basis for the construction of a 3000-foot barrier to prevent the migration of Sr90 into the Columbia River. This project will be the first demonstration by EM-50 of an in situ reactive barrier and will provide significant data to DOE-SR for conducting similar work. Successful completion of this project and implementation of the technology could be a very large success for the SCFA.

Staff members performed a technical review of 58 "quick win" proposals submitted to the SCFA during the month of June. The SCFA Lead Office requested that the TPOs submit quick win proposals which would be funded using FY96 project carryover. Technical evaluation criteria were developed and applied in a spreadsheet which summarized the evaluation. The assessment ranked technologies according to developed evaluation criteria and probability of success.

\section{DECONTAMINATION AND DECOMMISSIONING (D\&D) FOCUS AREA}

Two meetings of the Technology Selection Committee (TSC) for the CP-5 large scale demonstration project at ANL were attended by a WPI team member. The first meeting on June 5 focused primarily on identifying critical D\&D needs which could support demonstrations of innovative solutions and finalizing the selection methodology including 
decision criteria for evaluating individual technologies. On June 26 the TSC met again. This meeting focused on the evaluation of technologies for demonstration in several problem set areas. Technologies were evaluated in the problem set areas of Concrete/Surface Decontamination, Worker Protection, and Characterization and Monitoring Technologies. It was determined that additional data was needed prior to recommending specific technologies in the latter two problem set areas. For the Concrete/Surface Decontamination problem set, five technologies were recommended and efforts were initiated to develop technical proposals. These technologies include: Centrifugal Shot Blasting, $\mathrm{CO} 2$ Blasting, Flashlamp, Milling, and Laser Ablation.

A WPI team member attended a meeting with representatives of the Fernald Plant 1 TSC subgroup to develop a demonstration data requirements package. This subgroup, comprised of individuals from FERMCO, B\&W-NESI, Foster Wheeler, and USACE, were charged with the task of developing a data requirements package which could be used directly for the first four demonstrations scheduled for July and early-August. The data package accounts for all data elements necessary to evaluate the cost effectiveness of these first four technologies. In addition, it was designed to be easily modified to accommodate the data requirements for future demonstrations. The package was submitted to the full TSC on June 25 at FEMP where it was accepted unanimously.

In addition to reviewing the data requirements package, two technology proposals were reviewed at the June 25 meeting at FEMP. These technologies were: Personal Ice Cooled (PIC) Personal Protection Equipment (PPE) and Photogammetry/Laser Mapping. PIC was selected for demonstration and efforts were initiated to develop a Work Plan. The Photogammetry/Laser Mapping technology did not meet Fernald Plant 1 needs. The results of a preliminary technology screening were presented for a novel concrete decontamination technology developed in Japan. It was determined not to proceed with further efforts due to the immature state of the technology.

A meeting record was developed and delivered by a WPI team member to DOE for the May 23-24 Technology and Assessment Screening Team meeting for the C-Reactor. This meeting record also clearly laid out a plan and path forward for activities surrounding the technology selection process for the C-Reactor Large-scale Demonstration. WPI team solicited buy-in from site project personnel and METC which resulted in the meeting record acting as a project guidance document.

A June 11-12 meeting between DOE-METC, DOE-Richland, and the USACE was attended by a WPI team member. The WPI team provided valuable input to this meeting because of our extensive knowledge of the large-scale demonstration projects, particularly the lessons learned and unresolved issues surrounding the projects. Based on the team's earlier input and support during this meeting, the USACE now has clear direction and specific deliverable requirements concerning their large-scale demonstration support.

Development was continued by a WPI team member on a white paper concerning the recycle of radioactive scrap metal (RSM). The RSM recycle issue is controversial within 
the DOE Complex and WPI team is using its expertise to evaluate the issue in a clear and objective manner. The finished paper will assist the D\&DFA Board of Directors in their assessment of the value of future investments in the RSM recycle area.

WPI team met with the Savannah River Site's DOE D\&D Program Manager and successfully solicited SRS participation in the C-Reactor Large-Scale Demonstration. Hanford and SRS are the only two sites within the DOE Complex which have full-scale production reactors.

\section{MIXED WASTE FOCUS AREA (MWFA)}

Staff members coordinated the final review of the MWFA Rainbow Book and submitted comments to the technical editor.

Technology Development Requirements Document drafts for Non-destructive Examination for Radioactive Materials, Non-Destructive Examination for Hazardous Materials, Alpha Monitoring, Dioxin and Furan Monitoring and Salt Stabilization were submitted.

Members of the team reviewed these documents to support participation in DOE-ID meetings:

Combustor Rule

Mixed Waste Characterization Reference Document (draft)

Mixed Waste Focus Area Program System Requirements Document Technical Resource Document: Mixed Waste Characterization (draft) Technical Resource Document: Trial Burn for Mixed Waste Thermal Treatment Technologies (draft)

Information for final low-level mixed waste forms relating to regulatory criteria, waste form characteristics, and testing results was collected as part of the effort to select optimal final low-level mixed waste forms. This information was evaluated and submitted to DOE-ID in a matrix format.

The WPI team reviewed complex-wide Site Treatment Plans and Mixed Waste Inventory Report data to determine the final low-level mixed waste forms and volumes specified by mixed waste treatment systems. Treatment systems and waste forms are largely unspecified. This data was summarized in table format and provided it to DOE-ID.

Staff reviewed a White Paper written by DOE-ID on final waste forms and provided review comments to DOE-ID.

The Final Draft Independent Review Process Implementation Plan was submitted to DOEHQ for review and comment. 


\section{TASK B-PROJECT ASSESSMENT}

\section{TANKS FOCUS AREA (TFA)}

The team assisted the HQ and field program managers, and worked with PNNL, to prepare for the one-day review of the Tanks Focus Area by Clyde Frank. The focus area review included presentations from groups which have reviewed the focus area in the past year, including the Community Leaders Network, National Academy of Sciences; and Defense Nuclear Facilities Safety Board.

Staff participated in the Laser Ablation/Mass Spectrometry (LA/MS) and NIR program review meeting. The objective was to determine the current project direction to ensure completion and installation of the LAMMS system into Hanford hot cell facilities in FY96. Evaluation of NIR results was also discussed.

Staff participated in the Raman Spectrometer System Facilitated Decision Analysis Session at Hanford. The purpose of the meeting was to evaluate capabilities with respect to Hanford safety screening criteria and determine if the Raman-Cone Penetrometer system is designed to meet the needs. Some minor adjustments to the Raman system were identified by the users as needed before the system will be accepted. Specifically, the ability to quantify chemical components in situ is a major concern at Hanford. Meeting minutes were distributed to DOE-RL for review.

The staff prepared two monthly business reviews documenting program performance through March. The first was specifically tailored to the activities being conducted at the Hanford Site. The second included all activities being performed under the TFA. Each review summarized cost and schedule data in the PTS system, along with other programmatic information into a briefing on the performance of the technology development projects.

Contact with Tank Waste Retrieval System (TWRS) users was initiated by the WPI staff and the developers of an in situ hydrogen gas monitor. There is a need at Hanford for a hydrogen sensor with faster response time and a larger spectral bandwidth. The Characterization, Monitoring and Sensor Technology (CMST)-Crosscutting Program (CP) has developed and commercialized a technology with the desired specifications. CMST-CP has expressed interest in testing the technology at Hanford. The WPI team at Richland initiated contact between TWRS and the CMST-CP. TWRS lead engineers have agreed to allow lab testing of the technology in FY96. Final test plans are being developed and should be available by the end of July.

A draft memo for DOE/RL to transmit to Site Managers at each of the Tank Sites requesting their support for the TFA Program Execution Guidance and Multi-Year Program Plan Review was prepared by the WPI Team. 
Staff members assisted the Focus Area Lead in developing a revised agenda for the TFA one-day review in Gaithersburg on June 21, 1996. Staff prepared a fax memorandum and transmitted information to the attendees prior to the telecon and participated in the dry run telecon to talk-through the content of the presentations. Team members assisted DOE in coordinating with presenters to assure their input would be ready on the day of the review. Staff also prepared briefing materials and talking points for the review and coordinated inputs from Focus Area Lead, the Technical Implementation Team, as well as the WPI team on the content and format for the presentations.

Staff worked with the Focus Area Lead to compile a list of general program guidance fundamentals which will be useful for the Principal Investigators when developing their FY97 detailed scope. The objective was to circulate this information to the site representatives during the PEG review cycle to solicit any comments they might have before finalizing the PEG during the month of July.

A viewgraph was prepared by the staff for the TFA Lead to use at the TFA Workshop/Retreat held in Denver, Colorado, June 25-26, 1996. The slide was a graphic representation of the interface between DOE-RL, PNNL, and HQ.

The staff assisted the Focus Area Lead in scheduling and planning a workshop for team building in Denver, Colorado. As part of this effort, the staff identified a facilitator for the meeting and assisted the facilitator with interviews of all team members to be involved in the meeting. The staff also assisted in planning the logistics of the meeting, the agenda and format, and will prepare a wrap up report including observations and recommendations.

\section{SUBSURFACE CONTAMINANTS FOCUS AREA (SCFA)}

The WPI team evaluated the results of the scoring session for ranking FY97 Subsurface Contaminants Focus Area Work Packages, held on May 29-30, 1996. These results formed the basis for decisions by DOE-SR concerning the FY97 SCFA Program Execution Guidance. This scoring session applied the priority evaluation criteria resulting from the Atlanta meeting (May 22 \& 23) with Technical Program Officers. The package consisted of scoring tables, criteria lists, background information and meeting minutes and was utilized by DOE-SR as a reference for preparing the SCFA FY97 PEG.

Staff members supported the review of the FY97 SCFA Programmatic Execution Guidance (PEG). The PEGs are the guidance provided for the formation of the Technical Task Plans which are the contractual mechanism through which EM-50 research is funded.

Team members assisted in the preparation of the SCFA Program Review Presentation to Clyde Frank. This briefing highlighted the mission, accomplishments and financial standing of the focus area. 
Team members supported the SCFA in a meeting between the Office of Science and Technology and Office of Energy Research to discuss the roles as they related to basic research of environmental remediation technologies.

A review was conducted of all Subsurface Contaminants Focus Area milestones in PTS and those that did not meet the criteria of a milestone were deleted. The revised milestone list was transmitted to the site TPOs for comments and transmission to EM-54.

WPI team members prepared technical input for slides and briefing material for the June 6 , 1996 Office of Community Outreach Briefing. The material included the current technical status of Subsurface Contaminants Focus Area projects.

The team developed documentation to support the SCFA Decision Support Tool. Data requirements and responsibilities for data population of a software support system in support of the Program Planning in the Subsurface Contaminants Focus Area were defined.

Draft materials for the IRB presentation summarizing the technical status of New Project Status, Mortgages from previous years, and Deployment were prepared, as well as assumptions used to develop the material.

Members of the team developed a milestone status report for all projects in the Subsurface Contaminants Focus Area. This report was prepared to support a request from EM-50 to DOE-SR to provide a status of all ongoing tasks. The matrix is populated with all tasks and milestones contained in the SCFA TTPs with a status statement for all completed milestones as of March 1996.

Staff members provided technical input and a slide presentation along with a background material notebook for the 1996 Subsurface Contaminants Focus Area Program Review on June 24, 1996. The review included four major sections: Focus Area Management, Program Planning, Technology Systems, and the Business Review/Carryover. The WPI Team continued providing technical support for the development of a Decision Support System to aid the Focus Areas in program communication and in the prioritization of their technology development portfolios. Support in this area has included efforts to define the database structure, data requirements, and the parameters to be used in decision analysis.

\section{DECONTAMINATION AND DECOMMISSIONING (D\&D) FOCUS AREA}

A WPI team member provided input to develop a proposed responsibilities list for the Integrating Contractor Team at C-Reactor. This was delivered to DOE-Richland for comment. When completed, this document will direct the activities of the Integrating Contractor Team. 
DOE was assisted by a WPI Team member in determining specific technical task requirements for the US Army Corps of Engineers (USACE) in their support of the D\&DFA Large-Scale Demonstrations. WPI team provided input for the proposed technical tasking for USACE to DOE-METC.

A WPI team member attended meetings of the Fernald Plant 1 Large-scale Demonstration Integrating Contractor Team on May 30th and June 6th. A detailed meeting record was prepared for approval by the METC project manager.

The WPI team provided technical support to the developers of the CP-5 Strategic Alliance C-Reactor and Fernald Plant 1 homepages. The intent of this effort was not to prescribe a standardized homepage format, but rather to provide guidance on information requirements necessary to meet METC project support needs. In addition, this effort was to ensure that the necessary linkages were made between these two homepages and the D\&D Focus Area homepage.

Technical support was provided by the WPI Team to develop and communicate the individual roles and responsibilities for the development of the Innovative Technology Summary Reports (ITSR). These reports will be produced for each technology demonstrated within the D\&D Large-Scale Demonstration projects. The purpose of the ITSR documents is to convey the potential cost and benefits, in summary format, to potential users of the technology.

The WPI team provided D\&D programmatic support for the reporting of monthly cost and schedule information for all METC D\&D Focus Area projects to the Progress Tracking System (PTS).

Technical support was continued by the WPI team for the D\&D Focus Area's National Needs Prioritization Workshop to be held at METC on July $24 \& 25$. This effort has included developing a methodology for evaluating and scoring/prioritizing D\&D needs, as well as recording needs data received from the individual DOE sites. The needs data collected from each site has been entered into a database for the purpose of data handling and manipulation to facilitate the efforts at the workshop.

WPI team prepared a summary of the Progress Tracking System. The overview will be used to help ensure consistency in planning, measuring, and reporting work performed on the Office of Science and Technology's technical tasks. The information will also be used for analyzing cost and schedule information relating to technical tasks.

The WPI team reconciled electronic file copies and hard copies of the D\&D Focus Area Technical Task Plans (TTPs) and obtained the most current electronic versions of the TTPs from the Principal Investigators (PIs) in the field. A complete electronic set of the Focus Area TTPs was provided to the DOE Headquarters D\&D program managers, and to the WPI team program support staff. 
The WPI team conducted an analysis of FY96 carryover for the D\&D Focus Area's TTPs. The analysis included estimated carryover amounts, and the scope of work to be completed if the carryover is approved, for each project.

The Team provided technical input to and prepared the presentation transparencies for the D\&D Focus Area review on June 19 with the Deputy Assistant Secretary for Science and Technology, Clyde Frank.

Technical input was provided by the WPI team to the D\&D Focus Area Monthly Reports for the technical task work accomplished by the Focus Area Principal Investigators (PIs) in April and May, and assisted in the collection, review, and editing of monthly input from the PIs. This report informs interested parties of the monthly progress being made by the Focus Area.

\section{MIXED WASTE FOCUS AREA (MWFA)}

Staff members reviewed the following documents to support participation in DOE-ID meetings: Financial Authorization, Baseline and Actual Documents and Program Execution Guidance (June change packages).

The WPI team finalized the subcontract language to obtain the services for two technical resource team members under the WPI contract.

\section{TASK C-TECHNOLOGY INTEGRATION}

Members of the team drafted the WPI/METC Quality Assurance Plan and submitted it for internal review comments. Staff also updated the SAIC OCI Plan for the WPI contract and submitted for internal review.

Production of the U.S. Department of Energy (DOE) Focus Area Technology Summary books (Rainbow Books) continued. Crosscut information applicable to the Decontamination and Decommissioning (D\&D) Focus Area was incorporated into the D\&D Rainbow Book.

Rainbow Books for the Landfill Stabilization and Plumes Focus Areas were combined into one Book entitled Subsurface Contaminants Focus Area Technology Summary. This action was taken in response to a request from DOE Headquarters (HQ) to produce one book bearing the new title of the Focus Area. The overview was rewritten, and other sections were changed as appropriate for the new Book. For both Books, additional review cycles were completed. Comments from DOE Headquarters, DOE field offices, contractor leads, and WPI Blacksburg staff were incorporated. The complete set of Rainbow Books will reach a wide audience, including industry and the general public. The project also serves as an outreach activity as DOE shares its current information on technology development. 
Members of the staff provided meeting planning support for the Tanks Meeting, June 2526, 1996 at the Stouffer Concourse Hotel, Denver, Colorado.

WPI team provided meeting planning support for the In Situ Stabilization Workshop, June 26-27, 1996, Landmark Inn, Park City, Utah.

\section{TASK D-SYSTEMS ENGINEERING}

A WPI team member has begun production on a report covering a review of regulatory assumptions, changes in the waste inventory, downselection of systems in the INTS report and geographical dispersion of wastes to support cleanup facilities.

The WPI team reviewed Idaho National Engineering Laboratory (INEL) reports on treatment of mixed waste in the areas of selection of systems and subsystem components, and reviewed the assumptions in the areas of regulatory requirements, waste characterization, and waste characteristics. The purpose is to provide input to a full systems engineering assessment, being prepared by EERC and the WPI Team, of the INEL reports.

A draft report was prepared on the Evaluation of the Technical Approach to the INEL MLLW Treatment Studies. The draft analyzes the template being used and the application of the template to the reports. 


\section{ATTACHMENT A}

\section{PRODUCTS DELIVERED: TASK A - TECHNOLOGY ASSESSMENT}

\section{TANKS FOCUS AREA (TFA)}

- Map of the FY96 Tanks Focus Area industry and university partners

\section{SUBSURFACE CONTAMINANTS FOCUS AREA (SCFA)}

- Review of Quick Win Proposals

- LSFA-PFA Winter Progress Report

- Review of Milestone Deliverable A-1 of TTP RL\#-6-PL-41, "Complete Field Test Demonstration Design"

- Decision Support Tool

\section{DECONTAMINATION AND DECOMMISSIONING (D\&D) FOCUS AREA}

- Fernald Large-Scale Demonstration meeting record for May 30th meeting

- Fernald Large-Scale Demonstration meeting record for June 6th meeting

- C-Reactor Large-Scale Demonstration meeting record May 23-24th

- CP-5 Large-Scale Demonstration Technical Evaluations

- Fernald Large-Scale Demonstration meeting record for June 25th meeting MIXED WASTE FOCUS AREA (MWFA)

- Final Draft of the "Mixed Waste Characterization Treatment and Disposal Focus Area Rainbow Book".

- Draft Proposed MWFA DOE-ID Independent Review Process Implementation Plan.

- Five Technology Development Requirements Document Drafts:

Non-Destructive Assay of Hazardous Materials in Waste Containers

Non-Destructive Assay of Radioactive Materials in Waste Containers

Alpha Monitoring

Dioxin and Furan Monitoring

Salt Stabilization 


\section{PRODUCTS DELIVERED: TASK B: PROJECT ASSESSMENT}

\section{TANKS FOCUS AREA (TFA)}

- Draft memo for DOE-RL transmitting information about the TFA Retreat/Workshop in Denver, Colorado, June 25-26, 1996

- Meeting notes and action plans to support the TFA Retreat in Denver held June 25-26.

- Meeting notes from Laser Ablation/Mass Spectroscopy (LA/MS) and Near Infra-Red (NIR) probe program reviews, CMST/TFA conference call, and Raman spectrometer decision analysis session

- Draft memo for DOE Site Managers requesting their support of the TFA PEG/MYPP review

- Transmittal of memo for Program Review Dry-Run Telecon and Revised Agenda for DOE-RL

- Draft memorandum on Addendum to Radioactive Waste Tanks Focus Area Program Execution Guidance to Site Reps for DOE-RL

- Business Review (April 30, 1996 data)

- Fax transmittal with information regarding the TFA Program Review in Gaithersburg, MD on June 21, 1996

- Briefing for TFA Lead to present at the Program Review in Headquarters on June 21, 1996

- Viewgraph for DOE-RL to present a TFA Workshop/Retreat on June 25-26, 1996 in Denver, Colorado

\section{SUBSURFACE CONTAMINANTS FOCUS AREA (SCFA)}

- Scoring Results for FY97 Work Packages

- Technical Input into SCFA Program Review

- SCFA Program Plan

- SCFA Weekly Report for 5/31/96 
- IRB Support Data Summary Slides

- Consolidation of the Landfill Stabilization and Contaminant Plumes Focus Areas

- Technical Review of Milestone Deliverable D-1 of TTP RL4-6-PL-41, "In Situ Gas Treatment Technology Demonstration Plan"

- Subsurface Contaminant Focus Area Milestone/Task Status Matrix

- SCFA Milestone Review

DECONTAMINATION AND DECOMMISSIONING (D\&D) FOCUS AREA

- PTS Summary Overview

- Proposed Methodology for Decontamination and Decommissioning Prioritization Workshop

- Presentation for The Office of Science and Technology Program Review held June 19, 1996

MIXED WASTE FOCUS AREA (MWFA)

- May Monthly Report

PRODUCTS DELIVERED: TASK C: TECHNOLOGY INTEGRATION

- Briefing Materials for Office of Community Outreach on Status of SCFA Organization and Staffing 


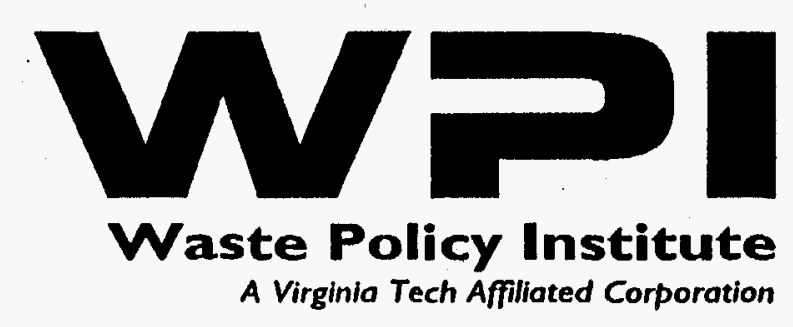

\section{MONTHLY \\ COST AND LABOR REPORT}

\section{UNIVERSITY OF NORTH DAKOTA ENERGY AND ENVIRONMENTAL RESEARCH CENTER}

Subcontract No. 359636

June, 1996 


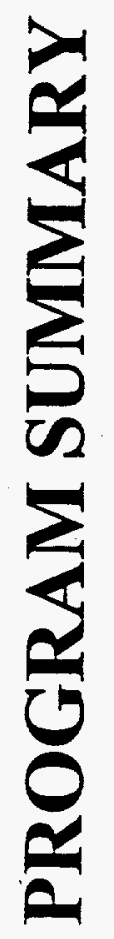


WPI Subcontract--EERC Coop. Agreement

$(\$ \times 1000)$

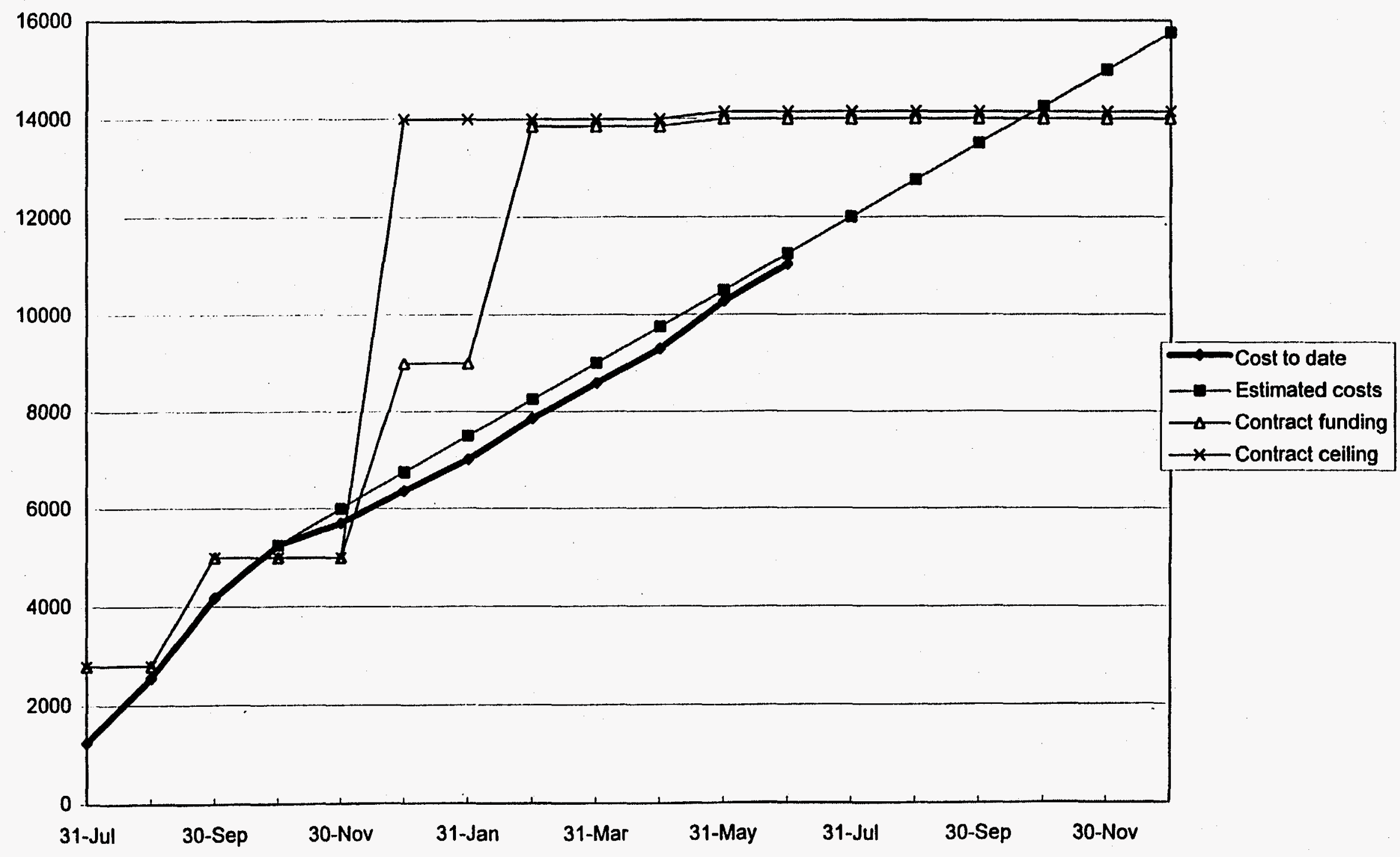

Page 1 
Subcontract No. 359636

Actuals through June 96

WBS: 1043 EERC

Manager: Dr. John S. Wilson

Start Date: 6/27/95

End Date: 12/1/96

Task Description: Provide assistance to EERC's conduct of lechnology development integration activities.

Cost Performance Summary:

\begin{tabular}{|c|c|c|c|}
\hline & \multicolumn{3}{|c|}{ Current Period } \\
\hline & Budget & Actuals & Variance \\
\hline Hours: & 10,668 & 8,786 & 1,882 \\
\hline Price: & 839.498 & 758,395 & 81,103 \\
\hline
\end{tabular}

\begin{tabular}{|c|c|c|}
\hline \multicolumn{3}{|c|}{ Inception to Date } \\
\hline Budget & Actuals & Variance \\
\hline 147,622 & 128,817 & 18,805 \\
\hline $11,583,490$ & $11,038,418$ & 545,072 \\
\hline
\end{tabular}

\begin{tabular}{|c|c|c|}
\hline \multicolumn{3}{|c|}{ At Complete } \\
\hline Budget & Estimate & Variance \\
\hline 179,950 & 161,145 & 18,805 \\
\hline $14,144,823$ & $13,599,752$ & 545,072 \\
\hline
\end{tabular}

Monthly Financial Recap:

\begin{tabular}{|c|c|c|c|c|c|c|c|c|c|c|c|c|}
\hline & Jun 95 & Jul 95 & Aug 95 & Sep 95 & Oct 95 & Nov 95 & Dec 95 & $\operatorname{Jan} 96$ & Feb 96 & Mar 96 & Apr 96 & May 96 \\
\hline \multicolumn{13}{|l|}{ Actuals: } \\
\hline Monthly Hours: & 149 & 15,710 & 17.723 & 19,161 & 10,639 & 6,367 & 6,669 & 6,932 & 8,057 & 8,562 & 8,653 & 11,408 \\
\hline Cumu Hours: & 149 & 15,859 & 33,582 & 52,743 & 63,382 & 69,749 & 76,418 & 83,350 & 91,408 & 99,970 & 108,623 & 120,031 \\
\hline Monthly Price: & 8,492 & $1,240,210$ & $1,300,381$ & $1,628,866$ & $1,072,629$ & 508,957 & 674,480 & 577,622 & 844,119 & 734,699 & 707.388 & 982,181 \\
\hline Cumu Price: & 8,492 & $1,248,702$ & $2,549,083$ & $4,177,949$ & $5,250,578$ & $5,759,535$ & $6,434,015$ & $7,011,637$ & $7,855,755$ & $8,590,455$ & $9,297,843$ & $10,280,023$ \\
\hline
\end{tabular}

Budgat:

\begin{tabular}{|c|c|c|c|c|c|c|c|c|c|c|c|c|}
\hline Monthly Hours: & 1,437 & 18,428 & 22,308 & 10,570 & 10.506 & 10,506 & 10,506 & 10,506 & 10,506 & 10,506 & 10,506 & 10,669 \\
\hline Cumu Hours: & 1,437 & 19,865 & 42,173 & 52,743 & 63,249 & 73,755 & 84,261 & 94,767 & 105,273 & 115,779 & 126,286 & 136,954 \\
\hline Monthly Price: & 89,294 & $1,251,829$ & $1,454,843$ & $1,381,982$ & 818,078 & 818,078 & 818,078 & 818,078 & 818,078 & 818,078 & 818,078 & 839,498 \\
\hline Cumu Price: & 89,294 & $1,341,124$ & $2,795,967$ & $4,177,949$ & $4,996,027$ & $5,814,106$ & $6,632,183$ & $7,450,261$ & $8,268,339$ & $9,086,417$ & $9,904,494$ & $10,743,992$ \\
\hline
\end{tabular}




\section{Subcontract No. 359636}

Actuals through June 96

WBS: 1043 EERC

Manager: Dr. John S. Wilson

Start Date: 6/27/95

End Date: 12/1/96

Task Description: Provide assistance to EERC's conduct of lechnology development integration activities.

Cost Performance Summary:

\begin{tabular}{|c|c|c|c|}
\hline & \multicolumn{3}{|c|}{ Current Period } \\
\hline & Budget & Actuals & Variance \\
\hline ours: & 10.668 & 8.786 & 1,882 \\
\hline Price: & 839,498 & 758,395 & 81,103 \\
\hline
\end{tabular}

\begin{tabular}{|c|c|c|}
\hline \multicolumn{3}{|c|}{ Inception to Date } \\
\hline Budget & Actuals & Variance \\
\hline 147,622 & 128,817 & 18,805 \\
\hline $11,583,490$ & $11,038,418$ & 545,072 \\
\hline
\end{tabular}

\begin{tabular}{|c|c|c|}
\hline \multicolumn{3}{|c|}{ At Complete } \\
\hline Budget & Estimate & Varlance \\
\hline 179,950 & 161,145 & $18, \overline{805}$ \\
\hline $14,144,823$ & $13,599,752$ & 545,072 \\
\hline
\end{tabular}

Monthly Financial Recap:

\begin{tabular}{|c|c|c|c|c|c|c|c|c|c|c|c|}
\hline Jun 96 & Jul 96 & Aug 96 & Sep 96 & Oct 96 & Nov 96 & Dec 96 & $\operatorname{Jan} 97$ & Feb 97 & Mar 97 & Apr 97 & May 97 \\
\hline
\end{tabular}

Actuals:

Monthly Hours:

Cumu Hours:

Monthly Price:

Cumu Price:

\begin{tabular}{|c|c|c|c|c|c|}
\hline B,786 & 0 & 0 & 0 & 0 & 0 \\
\hline 128,817 & 128,817 & 128,817 & 128,817 & 128,817 & 128,817 \\
\hline 758,395 & 0 & 0 & 0 & 0 & 0 \\
\hline $11,038,418$ & $11,038,418$ & $11,038,418$ & $11,038,418$ & $11,038,418$ & $11,038,418$ \\
\hline
\end{tabular}

(1)

Budget:

Monthly Hours:

Cumu Hours:

Monthly Price:

\begin{tabular}{|r|r|}
\hline 10,668 & 10,668 \\
\hline 147,622 & 158,290 \\
\hline 839,498 & 839,498 \\
\hline
\end{tabular}

$\begin{array}{r}10,668 \\ \hline 168,958 \\ \hline 839,498 \\ \hline\end{array}$

10,668

$\begin{array}{r}162 \\ 179.788 \\ \hline\end{array}$

162

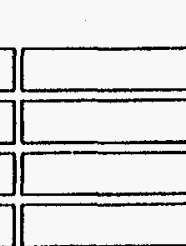

(1)

(1)

Cumu Price:

\begin{tabular}{|r|r|r|r|r|r|r|r|r|r|r|}
\hline $11,583,490$ & $12,422,988$ & $13,262,486$ & $14,101,983$ & $14,123,403$ & $14,144,823$ \\
\hline
\end{tabular}


$\frac{5}{5}$ 
End Date: 12/1/96

Task Description: Perform lechnical reviews of requirements, needs and assessments related to waste characterization, containment, in-situ and ex-situ treatment, wasle storage, disposal, robotics handling, monitoring, laboratory analysis, site characterization and remediation.

Cost Performance Summary:

\begin{tabular}{|c|c|c|c|}
\hline & \multicolumn{3}{|c|}{ Current Perlod } \\
\hline & Budget & Actuals & Variance \\
\hline Hours: & 5,474 & 3,103 & 2,371 \\
\hline Price: & 297,160 & 273,298 & 23.861 \\
\hline
\end{tabular}

Inception to Date
\begin{tabular}{r|r|r|}
\hline Budget & Actuals & Variance \\
\hline 71,034 & 55,303 & 15,732 \\
\hline $4,532,106$ & $5,072,545$ & $-540,439$ \\
\hline
\end{tabular}

\begin{tabular}{r|r|r|}
\multicolumn{3}{c}{ At Complete } \\
\hline \multicolumn{1}{c|}{ Budget } & Estimate & Varlance \\
\hline 87,456 & 71,724 & 15,732 \\
\hline $5,423,585$ & $5,964,024$ & $-540,439$ \\
\hline
\end{tabular}

Monthly Financlal Recap:

\begin{tabular}{|c|c|c|c|c|c|c|c|c|c|c|c|c|}
\hline & Jun 95 & Jul 95 & Aug 95 & Sep 95 & Oct 95 & Nov 95 & Dec 95 & Jan 96 & Feb 96 & Mar 96 & Apr 96 & May 96 \\
\hline \multicolumn{13}{|l|}{ Actuals: } \\
\hline Monthly Hours: & 50 & 6,255 & 7,504 & 7,961 & 6,453 & 4,330 & 3,138 & 2,600 & 3,300 & 3,479 & 2,963 & 4.168 \\
\hline Cumu Hours: & 50 & 6,305 & 13,809 & 21,770 & 28,224 & 32,553 & 35,691 & 38,291 & 41,591 & 45,069 & 48,032 & 52,200 \\
\hline Monthly Price: & 2,574 & 533,931 & 582,189 & 738,970 & 657,545 & 359,376 & 316,660 & 247,333 & 406,806 & 323,669 & 246,524 & 383,670 \\
\hline Cumu Price: & 2,574 & 536,505 & $1,118,694$ & $1,857,664$ & $2,515,209$ & $2,874,585$ & $3,191,245$ & $3,438,578$ & $3,845,383$ & $4,169,052$ & $4,415,577$ & $4,799,247$ \\
\hline \multicolumn{13}{|l|}{ Budget: } \\
\hline Monthly Hours: & 328 & 7,196 & 8,711 & 5,534 & 5,474 & 5,474 & 5,474 & 5,474 & 5,474 & 5,474 & 5,474 & 5,474 \\
\hline Cumu Hours: & 328 & 7,525 & 16,236 & 21,770 & 27,244 & 32,718 & 38,191 & 43,665 & 49,139 & 54,613 & 60,087 & 65,561 \\
\hline Monthly Price: & 14,090 & 498,386 & 570,555 & 774,636 & 297.160 & 297,160 & 297,160 & 297,160 & 297,160 & 297,160 & 297,160 & 297,160 \\
\hline Cumu Price: & 14,090 & 512,477 & $1,083,032$ & $1,857,668$ & $2,154,828$ & $2,451,988$ & $2,749,148$ & $3,046,308$ & $3,343,467$ & $3,640,627$ & $3,937,787$ & $4,234,946$ \\
\hline
\end{tabular}


章 
1043.01.02

Waste Policy Institute

Task Area Summary

Subcontract No. 359636

Actuals through June 96

WBS: 1043.01 .02 Project Management

Manager: Dr. John S. Wilson

Start Date: 6/27/95

End Date: 12/1/96

Task Description: Conduct reviews, analyze and develop strategies for program management systems for integration and control of programs, projects, tasks and documentation.

\begin{tabular}{|c|c|c|c|c|c|c|c|c|c|}
\hline \multicolumn{10}{|c|}{ Cost Performance Summary: } \\
\hline & Budget & Actuals & Variance & Budget & Actuals & Varlance & Budget & Estimate & Variance \\
\hline Hours: & 2,704 & 3,151 & .447 & 49,881 & 54,562 & $-4,681$ & 57.993 & 62,674 & $-4,681$ \\
\hline Price: & 273.798 & 264,458 & 9,340 & $4,356,246$ & $4,348,326$ & 7,919 & $5,177,640$ & $5,169,721$ & 7,919 \\
\hline
\end{tabular}

Monthly Financlal Recap:

\begin{tabular}{|c|c|c|c|c|c|c|c|c|c|c|c|}
\hline Jun 95 & Jul 95 & Aug 95 & Sep 95 & Oct 95 & Nov 95 & Dec 95 & Jan 96 & Feb 96 & Mar 96 & Apr 96 & May 96 \\
\hline
\end{tabular}

Actuals:

Monthly Hours:

Cumu Hours:

Monthly Price:

\begin{tabular}{|c|c|c|c|c|c|c|c|c|c|c|c|}
\hline 98 & 8.116 & 8,247 & 9.084 & 3,578 & 1,588 & 2,868 & 3,297 & 3.561 & 3.631 & 3,321 & 4.024 \\
\hline 98 & 8,214 & 16,462 & 25,545 & 29,123 & 30,711 & 33,578 & 36,875 & 40,436 & 44,067 & 47,388 & 51,412 \\
\hline 5,779 & 599,758 & 566,591 & 719,936 & 341,971 & 108,114 & 275,047 & 255,073 & 319,577 & 306,696 & 269,945 & 315,382 \\
\hline 5,779 & 605,537 & $1,172,128$ & $1,892,064$ & $2,234,035$ & $2,342,149$ & $2,617,196$ & $2,872,269$ & $3,191,846$ & $3,498,542$ & $3,768,486$ & $4,083,869$ \\
\hline
\end{tabular}

Cumu Price:

Budget:

Monthly Hours:

Cumu Hours:

Monthly Price:

\begin{tabular}{|r|r|r|r|r|}
\hline 309 & 6,643 & 8,042 & 10,551 & 2,704 \\
\hline 309 & 6,952 & 14,994 & 25,545 & 28,249 \\
\hline 21,034 & 453,804 & 527,559 & 889,666 & 273,798 \\
\hline 21,034 & 474,838 & $1,002,397$ & $1,892,063$ & $2,165,861$ \\
\hline
\end{tabular}

\begin{tabular}{|r|}
\hline 2,704 \\
\hline 273,953 \\
\hline $2,439,659$ \\
\hline
\end{tabular}

\begin{tabular}{|r|}
\hline 2,704 \\
\hline 33,657 \\
\hline 273,798 \\
\hline $2,713,457$ \\
\hline
\end{tabular}

\begin{tabular}{|r|}
\hline 2,704 \\
\hline 36,361 \\
\hline 273,798 \\
\hline $2,987,255$ \\
\hline 3,21 \\
\hline
\end{tabular}

\begin{tabular}{|r|r|r|r|}
\hline 2,704 & 2,704 & 2,704 & 2,704 \\
\hline 39,065 & 41,769 & 44,473 & 47,177 \\
\hline 273,798 & 273,798 & 273,798 & 273,798 \\
\hline $3,261,053$ & $3,534,852$ & $3,808,650$ & $4,082,448$ \\
\hline
\end{tabular}


Subcontract No. 359636

Actuals through May 96

WBS: 1043.01.02 Project Management

Manager: Dr. John S. Wilson

Start Date: 6/27/95

End Date: 12/1/96

Task Description: Conduct reviews, analyze and develop stralegies for program management systems for integration and control of programs, projects, tasks and documentalion.

Cost Performance Summary:

\begin{tabular}{|c|c|c|c|}
\hline & & Irrent Perioc & \\
\hline & Budget & Actuals & Variance \\
\hline Hours: & $2, \overline{704}$ & 3,151 & -447 \\
\hline Price: & 273,798 & 264,458 & 9,340 \\
\hline
\end{tabular}

\begin{tabular}{|c|c|c|}
\hline \multicolumn{3}{|c|}{ Inception to Date } \\
\hline Budget & Actuals & Variance \\
\hline 49,881 & 54,562 & $-4,681$ \\
\hline $4,356,246$ & $4,348,326$ & 7,919 \\
\hline
\end{tabular}

\begin{tabular}{|c|c|c|}
\hline \multicolumn{3}{|c|}{ At Complete } \\
\hline Budget & Estimate & Varlance \\
\hline 57,993 & 62,674 & $-4,681$ \\
\hline $5,177,640$ & $5,169,721$ & 7,919 \\
\hline
\end{tabular}

Monthly FInancial Recap:

\begin{tabular}{|c|c|c|c|c|c|c|c|c|c|c|c|c|}
\hline & Jun 96 & Jul 96 & Aug 96 & Sep 96 & Oct 96 & Nov 96 & Dec 96 & $\operatorname{Jan} 97$ & Feb 97 & Mar 97 & Apr 97 & May 97 \\
\hline \multicolumn{13}{|l|}{ Actuals: } \\
\hline Monthly Hours: & 3,151 & 0 & 0 & 0 & 0 & 0 & & & & & & \\
\hline Cumu Hours: & 54,562 & 54,562 & 54,562 & 54,562 & 54,562 & 54,562 & & & & & & \\
\hline Monthly Price: & 264,458 & 0 & 0 & 0 & 0 & 0 & & & & & & \\
\hline Cumu Price: & $4,348,326$ & $4,348,326$ & $4,348,326$ & $4,348,326$ & $4,348,326$ & $4,348,326$ & & & & & & \\
\hline
\end{tabular}

Budget:

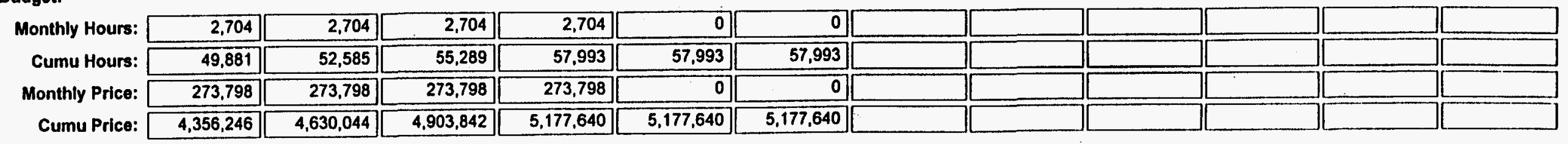


$\frac{1}{4}$ 


\section{Subcontract No. 359636}

Actuals through June 96

WBS: 1043.01 .03 Technology Integration

Manager: Dr. John S. Wilson

\section{Start Date: 6/27/95}

End Date: 12/1/96

Task Description: Provide support in establishing criteria for identitying risks to the public health and safety posed by conditions at the weapons complex facilities, evaluate the extent of these risks, determine the urgency and priorities for eliminating or minimizing the risks, and access the cost of activities required to meet applicable compliance agreements.

\section{Cost Performance Summary:}

\begin{tabular}{|c|c|c|c|}
\hline & \multicolumn{3}{|c|}{ Current Period } \\
\hline & Budget & Actuals & Variance \\
\hline urs: & $2 . \overline{328}$ & 2,533 & .204 \\
\hline Price: & 247,120 & 220,104 & 27,016 \\
\hline
\end{tabular}

\begin{tabular}{|c|c|c|}
\hline \multicolumn{3}{|c|}{ Inception to Date } \\
\hline Budget & Actuals & Variance \\
\hline 26,382 & 18,952 & 7,431 \\
\hline $2,652,298$ & $1,616,960$ & $1,035,338$ \\
\hline
\end{tabular}

\begin{tabular}{|c|c|c|}
\hline \multicolumn{3}{|c|}{ At Complete } \\
\hline Budget & Estimate & Variance \\
\hline 33,367 & 25,937 & 7,431 \\
\hline $3,393,658$ & $2,358,320$ & $1,035,338$ \\
\hline
\end{tabular}

Monthly Financial Recap:

\begin{tabular}{|c|c|c|c|c|c|c|c|c|c|c|c|}
\hline Jun 95 & Jul 95 & Aug 95 & Sep 95 & Oct 95 & Nov 95 & Dec 96 & $\operatorname{Jan} 96$ & Feb 96 & Mar 96 & Apr 96 & May 96 \\
\hline
\end{tabular}

\section{Actuals:}

Monthly Hours:

Cumu Hours:

Monthly Price:

Cumu Price:

\begin{tabular}{|c|c|c|c|c|c|c|c|c|c|c|c|}
\hline 1 & 1,339 & 1,972 & 2,117 & 608 & 450 & 664 & 1,036 & 1,196 & 1,453 & 2,370 & 3,216 \\
\hline 1 & 1,340 & 3,312 & 5.428 & 6,036 & 6,486 & 7.150 & 8,185 & 9,381 & 10,834 & 13,203 & 16.419 \\
\hline 139 & 106,521 & 151,601 & 169,960 & 73,113 & 41,466 & 82,773 & 75,216 & 117.736 & 104,335 & 190,919 & 283,077 \\
\hline 139 & 106,660 & 258,261 & 428,221 & 501,334 & 542,800 & 625,574 & 700,790 & 818,526 & 922,860 & $1,113,780$ & $1,396,857$ \\
\hline
\end{tabular}

Budget:

Monthly Hours:

Cumu Hours:

Monthly Price:

\begin{tabular}{|r|r|}
\hline 800 & 4,589 \\
\hline 800 & 5,388 \\
\hline 54,170 & 299,639 \\
\hline 54,170 & \\
\hline 353,809 & \\
\hline
\end{tabular}

\begin{tabular}{|r|r|r|r|r|}
\hline 5,555 & $-5,515$ & 2,328 & 2,328 & 2,328 \\
\hline 10,943 & 5,428 & 7,756 & 10,085 & 12,413 \\
\hline 356,729 & $-282,320$ & 247,120 & 247,120 & 247,120 \\
\hline 710,538 & 428,218 & 675,338 & 922,458 & $1,169,578$ \\
\hline
\end{tabular}

\begin{tabular}{|r|}
\hline 2,328 \\
\hline 14,741 \\
\hline 247,120 \\
\hline $1,416,698$ \\
\hline
\end{tabular}

\begin{tabular}{|r|r|r|r|}
\hline 2,328 & 2,328 & 2,328 & 2,328 \\
\hline 17,069 & 19,398 & 21,726 & 24,054 \\
\hline 247,120 & 247,120 & 247,120 & 247,120 \\
\hline $1,663,818$ & $1,910,938$ & $2,158,058$ & $2,405,178$ \\
\hline
\end{tabular}


Subcontract No. 359636.

Actuals through May 96

WBS: 1043.01 .03 Technology Inlegration

Manager: Dr. John S. Wilson

Start Date: 6/27/95

End Date: 12/1/96

Task Description: Provide support in establishing crileria for identifying risks to the public health and safety posed by conditions at the weapons complex facilities, evaluate the extent of these risks, determine the urgency and priorities for eliminating or minimizing the risks, and access the cost of activities required to meet applicable compliance agreements.

Cost Performance Summary:

\begin{tabular}{|c|c|c|c|}
\hline & \multicolumn{3}{|c|}{ Current Period } \\
\hline & Budget & Actuals & Variance \\
\hline Hours: & 2,328 & 2.533 & -204 \\
\hline Price: & 247,120 & 220,104 & 27,016 \\
\hline
\end{tabular}

\begin{tabular}{|c|c|c|}
\hline \multicolumn{3}{|c|}{ Inception to Date } \\
\hline Budget & Actuals & Variance \\
\hline 26,382 & 18,952 & 7.431 \\
\hline $2,652,298$ & $1,616,960$ & $1,035,338$ \\
\hline
\end{tabular}

\begin{tabular}{|c|c|c|}
\hline \multicolumn{3}{|c|}{ At Complete } \\
\hline Budget & Estimate & Varlance \\
\hline 33.367 & 25,937 & 7,431 \\
\hline $3,393,658$ & $2,358,320$ & $1,035,338$ \\
\hline
\end{tabular}

Monthly Financlal Recap:

\begin{tabular}{|c|c|c|c|c|c|c|c|c|c|c|c|c|}
\hline & Jun 96 & Jul 96 & Aug 96 & Sep 96 & Oct 96 & Nov 96 & Dec 96 & Jan 97 & Feb 97 & $\operatorname{Mar} 97$ & Apr 97 & May 97 \\
\hline Actuals: & & & & . & & & & & & & & \\
\hline Monthly Hours: & 2,533 & 0 & 0 & 0 & 0 & 0 & & & & & & \\
\hline Cumu Hours: & 18,952 & 18,952 & 18,952 & 18.952 & 18,952 & 18,952 & & & & & & \\
\hline Monthly Price: & 220,104 & 0 & 0 & 0 & 0 & 0 & & & & & & \\
\hline Cumu Price: & $1,616,960$ & $1,616,960$ & $1,616,960$ & $1,616,960$ & $1,616,960$ & $1,616,960$ & & & & & & \\
\hline
\end{tabular}

Budget:

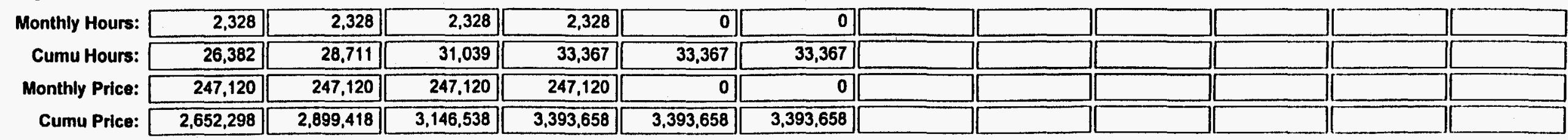


$\frac{1}{4}$ 
Subcontract No. 359636

Actuals through June 96

WBS: 1043.01.04 Systems Engineering

Start Date: 2/1/96

End Date: 12/1/96

Task Description:

Cost Performance Summary:

\begin{tabular}{|c|c|c|c|}
\hline & \multicolumn{3}{|c|}{ Current Period } \\
\hline & Budget & Actuals & Varlance \\
\hline ours: & 162 & 0 & 162 \\
\hline Price: & 21,420 & 535 & 20,885 \\
\hline
\end{tabular}

\begin{tabular}{|c|c|c|}
\hline \multicolumn{3}{|c|}{ Inception to Date } \\
\hline Budget & Actuals & Variance \\
\hline 324 & 0 & 324 \\
\hline 42,840 & 586 & 42,254 \\
\hline
\end{tabular}

\begin{tabular}{r|r|r|}
\multicolumn{3}{c}{ At Complete } \\
\hline Budget & \multicolumn{1}{c}{ Estimate } & \multicolumn{1}{c}{ Variance } \\
\hline 1,134 & 810 & 324 \\
\hline 149,940 & 107,686 & 42,254 \\
\hline
\end{tabular}

Monthly Financlat Recap:

\begin{tabular}{|c|c|c|c|c|c|c|c|c|c|c|c|c|}
\hline & Jun 95 & Jul 95 & Aug 95 & Sep 95 & Oct 95 & Nov 95 & Dec 95 & Jan 96 & Feb 96 & Mar 96 & Apr 96 & May 96 \\
\hline \multicolumn{13}{|l|}{ Actuals: } \\
\hline Monthly Hours: & 0 & 0 & 0 & 0 & 0 & 0 & 0 & 0 & 0 & 0 & 0 & 0 \\
\hline Cumu Hours: & 0 & 0 & 0 & 0 & 0 & 0 & 0 & 0 & 0 & 0 & 0 & $\overline{0}$ \\
\hline Monthly Price: & 0 & 0 & 0 & 0 & 0 & 0 & 0 & 0 & 0 & 0 & 0 & 51 \\
\hline Cumu Price: & 0 & 0 & 0 & 0 & 0 & 0 & 0 & 0 & 0 & 0 & 0 & 51 \\
\hline
\end{tabular}

Budget:

Monthly Hours: Cumu Hours:

Monthly Price:

\begin{tabular}{|r|}
\hline 0 \\
\hline 0 \\
\hline 0 \\
\hline 0 \\
\hline
\end{tabular}

\begin{tabular}{|l|l|}
\hline 0 \\
\hline 0 \\
\hline 0 \\
\hline 0 \\
\hline 0
\end{tabular}

\begin{tabular}{|r|r|}
\hline 0 \\
\hline 0 \\
0 \\
0 \\
0 \\
0
\end{tabular}

\begin{tabular}{l|l|}
0 & 0 \\
0 & 0 \\
0 & 0 \\
0 & 0 \\
\hline
\end{tabular}

\begin{tabular}{|c|c|c|c|}
\hline 0 & 0 & 0 & 0 \\
\hline 0 & 0 & 0 & 0 \\
\hline 0 & 0 & 0 & 0 \\
\hline 0 & 0 & 0 & 0 \\
\hline
\end{tabular}

\begin{tabular}{|l|r|r|r|}
\hline 0 & 0 & 162 \\
\hline 0 & 0 & 162 \\
\hline 0 & 0 & 0 \\
\hline 0 & 0 & 21,420 \\
\hline & 0 & 0 \\
\hline
\end{tabular}


WBS: 1043.01.04 Systems Engineering

Manager: Dr. John S. Wilson

Start Date: $2 / 1 / 96$

End Date: 12/1/96

Task Description:

Cost Performance Summary:

\begin{tabular}{|c|c|c|c|}
\hline & \multicolumn{3}{|c|}{ Current Period } \\
\hline & Budget & Actuals & Varlance \\
\hline Hours: & 162 & 0 & 162 \\
\hline Price: & 21,420 & 535 & 20,885 \\
\hline
\end{tabular}

\begin{tabular}{|c|c|c|}
\hline \multicolumn{3}{|c|}{ Inception to Date } \\
\hline Budget & Actuals & Variance \\
\hline 324 & 0 & 324 \\
\hline 42,840 & 586 & 42,254 \\
\hline
\end{tabular}

\begin{tabular}{r|r|r|}
\multicolumn{3}{c}{ At Complete } \\
\hline Budget & \multicolumn{1}{c}{ Estimate } & Varlance \\
\hline 1,134 & 810 & 324 \\
\hline 149,940 & 107.686 & 42,254 \\
\hline
\end{tabular}

Monthly Financial Recap:

\begin{tabular}{|c|c|c|c|c|c|c|c|c|c|c|c|}
\hline Jun 96 & Jul 96 & Aug 96 & Sep 96 & Oct 96 & Nov 96 & Dec 96 & Jan 97 & Fob 97 & Mar 97 & Apr 97 & May 97 \\
\hline
\end{tabular}

Actuals:

Monthly Hours:

Cumu Hours:

Monthly Price:

Cumu Price:

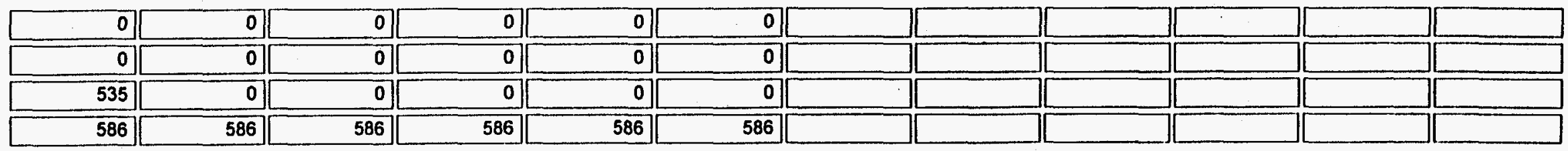

Budget:

Monthly Hours:

Cumu Hours:

Monthly Price:

\begin{tabular}{|r|r|r|r|}
\hline 162 & 162 & 162 \\
\hline 324 & 486 & 162 \\
\hline 21,420 & 648 & 810 \\
\hline 21,420 & 21,420 & 21.420 \\
\hline
\end{tabular}

810

162

(162]

Cumu Price: 42,840 64,260 85,680 107,100 128,520 149,940 

WASTE POLICY INSTITUTE MONTHLY REPORT TO THE EERC, JULY 1996 



\section{UNIVERSITY OF NORTH DAKOTA ENERGY AND ENVIRONMENTAL RESEARCH CENTER}

Monthly Report
July, 1996

\section{TECHNOLOGY DEVELOPMENT INTEGRATION WPI SUBCONTRACT NUMBER 359636}

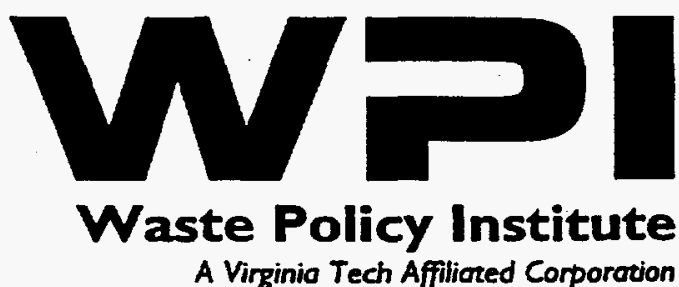



August 15, 1996

Mr. John G. Hendrikson

Assistant to the Director

Energy and Environmental Research Center

University of North Dakota

15 North 23rd Street

Grand Forks, ND 58203

Subject: UNDEERC Fund No. 4624-0936, Technology Development Integration WPI Subcontract No. 359636

Dear Mr. Hendrikson:

The Waste Policy Institute (WPI) is pleased to submit the enclosed report of activities conducted during the period of July 1, 1996 through July 31,1996, in compliance with Article VI and Appendix A of Subcontract Number 359636. A list of products developed during this period is provided as Attachment A to the activities report.

Through July 31 , WPI has expended $\$ 11,849,563$. Our monthly cost and labor report provides the details of our costs to date. Although the current contract period extends through December 1, 1996, it should be noted that we anticipate the subcontract ceiling will be reached on or about September 20, 1996. This expenditure rate is consistent with our proposal for the new budget period.

Please do not hesitate to call me if you have any questions or require additional information.

Sincerely,

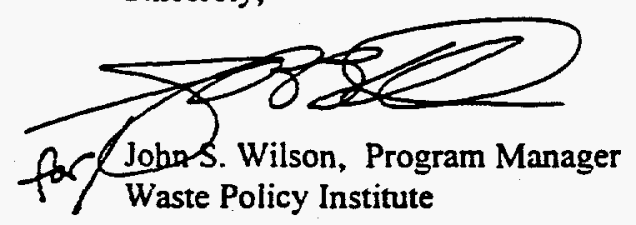

cc: L. D. Eyman

C. Roberson
Corporate Office: Blacksburg,VA

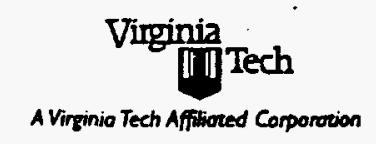


SUBCONTRACT NUMBER: 359636

Report Period: 7/1/96-7/31/96

CONTRACTOR NAME: Waste Policy Institute

555 Quince Orchard Road

Suite 600

Gaithersburg, MD 20878-1437

CONTRACT PERIOD: $\quad 6 / 28 / 95-12 / 01 / 96$

\section{SUBCONTRACT DELIVERABLES:}

This report is submitted in fulfillment of requirements specified for the University of North Dakota Energy and Environmental Research Center (UNDEERC)

Subcontract Number 359636. A list of products developed under this subcontract is provided as Attachment $\mathrm{A}$.

\section{SUMMARY OF ACTIVITIES:}

Members of the WPI team provided technical support to the development of the FY97 Program Execution Guidance (PEG) for all focus areas throughout the month. The effort culminated in the FY97 PEG Review Meeting of July 29 with Deputy Assistant Secretary for Science and Technology, Dr. Frank, and the Technology Development Council Meeting on July 30.

\section{TASK A-TECHNOLOGY ASSESSMENT}

\section{TANKS FOCUS AREA (TFA)}

Staff supported TFA in conducting a series of meetings between EM-50, EM-30, Westinghouse, PNNL, and other contractors to eliminate the proposed delay on the September scheduled deployment of the LDUA. Staff initiated an effort to form a database to keep track of all LDUA end effectors development activities as this issue is becoming more critical for the LDUA future and a daily reporting system for LDUA progress to monitor the events until delivery.

Members of the team prepared a trip report for the June 19-22, 1996 American Chemical Society (ACS) Northwest Regional meeting on Hazardous and Radioactive Waste for the DOE-RL TFA Lead and staff. The report highlighted pertinent technical development tasks from other areas of DOE that could be helpful for the TFA and offered recommendations to pursue discussions with the cognizant engineers.

Staff coordinated FY97 tank waste sampling requirements for DOE-RL. Hanford Tank AN-104 was sampled and any residual remaining after Tank Waste Retrieval System (TWRS) safety program sampling needs were met would be needed by TFA and Efficient Separations programs for cesium and technetium removal testing. 


\section{SUBSURFACE CONTAMINANTS FOCUS AREA (SCFA)}

Members of the team performed a technical review of draft reports: "Projected Performance of In-Well Vapor Stripping" (IWVS) and "Preliminary Performance Assessment of In-Well Vapor Stripping System" from TTP RL36PL21. The review was combined due to similarity in the content of these progress reports that are only separated by a few weeks. The IWVS System is already showing great promise for OST.

Technical information was provided on the Subsurface Contaminants Focus Area technologies relevant to the 10 Year Strategic Plan. The information included a cover letter, a table of selected site needs matched to the current SCFA projects that address the need, and a list of 1994-1998 actual or planned accomplishments, and was prepared for distribution to each site.

Team members developed a one-page fact sheet for each inquiry from an article in the March 1996 issue of Chemical Engineering regarding viscous liquid barrier technology.

The WPI team compiled a list of long-term, directed science needs that were determined to be the most relevant to the SCFA's mission. These identified needs were transferred to questionnaires, which are consistent with the format requested by EM-50. Each need was listed on a separate form, and included as much of the requested information concerning each need as could be obtained.

Technical review comments were provided on the report entitled "In Situ Remediation of DNAPL Compounds in Low Permeability Media: Fate/Transport, In Situ Control Technologies, and Risk Reduction."

Team members performed a technical review of the final report (deliverable 5-1 for TTP PE16PL41) entitled "Selective Polymer Separation Technologies for Removal of Inorganic Contaminants from Groundwater; Milestone Report." The review described the contents of the report, provided comments, and developed technical recommendations.

\section{DECONTAMINATION AND DECOMMISSIONING (D\&D) FOCUS AREA}

The WPI team submitted a technical research paper on the radioactive scrap metal recycling industry with recommendations for future investment by DOE. Activity this month included resolution of all peer review comments. The paper will be submitted to the OST Board of Directors.

A one-day meeting of the Fernald Large-Scale Demonstration Project Integrating Contractor Team at Fernald, Ohio on July 30, 1996 was attended by a WPI team member. In addition to monitoring the project for METC, the WPI member provides technical support to the IC team in the selection and demonstration of technologies. Preparation of 
a meeting record is in progress. The WPI team member participated in a side meeting of federal government representatives during the one-day meeting and prepared a memorandum for the record.

Team members prepared several sections of a review paper on the Idaho National Engineering Laboratory (INEL) reports on treatment of mixed waste in the areas of selection of systems and subsystem components. The sections covered the assumptions in the areas of regulatory requirements, waste characterization, and waste characteristics. The review paper is a systems engineering assessment of the INEL reports, being prepared by EERC and the WPI team.

A draft white paper on the status of depleted uranium hexafluoride (DU), including the extent of the problem, the DOE DU management program, the Programmatic Environmental Impact Statement for DU, and the possible technical solutions to the DU problem, was prepared by the WPI team. The paper will be submitted to the OST Board of Directors.

The WPI team has begun assisting METC with tasks related to the coordination of the review of the fourteen D\&D FY97-98 Large Scale Demonstration proposals. Activities included preparing copies of evaluation forms on diskettes and preparing summary tables about the proposals to assist METC in conducting the review.

The "Technical Peer Review Panel Report on the D\&D Focus Area Mid-Year Program Review" was completed by the WPI team. This report documents the comments and recommendations of the peer review panel, and provides their recommendations for future planning and work in the focus area.

A WPI team member collected and evaluated data to identify major costs associated with D\&D projects. Although little DOE information was available, the WPI team was able to assess actual and estimated costs stemming from the D\&D of commercial nuclear power facilities both in the United States and abroad. This data was evaluated to assist DOE in determining which technology investments have the greatest potential for substantial return.

The first C-Reactor Large Scale Demonstration IC Team meeting, held on July 24-25 in Richland, Washington, was attended by a WPI team member who actively participated in this meeting both in support of METC and to contribute field-experienced radiological professional expertise. A detailed record of the meeting, including a description of the technologies that were selected by the IC Team, was developed.

A WPI team member attended and participated in the C-Reactor Large-Scale Demonstration Technology Selection Committee meeting in Philadelphia on July 8th and 9 th. As a result of WPI team efforts, the project redirected their technology selection efforts towards those that would have the greatest potential to reduce mortgage associated with D\&D across the DOE Weapons Complex. 
Personnel developed the document detailing responsibilities of the C-Reactor Large Scale IC Team. After this document was reviewed by DOE-METC, DOE-Richland, and Bechtel-Hanford, it became the directing instrument of all C-Reactor IC Team efforts and was also used to assist other ongoing Large-Scale Demonstrations define their IC Team roles. The WPI team has enhanced project communication and has guarded METC's interests through the development of this document and previous documents, such as a CReactor Large-Scale Demonstration presentation which communicated METC's needs and clearly defined terms such as "innovative."

\section{MIXED WASTE FOCUS AREA (MWFA)}

A staff member completed the support of the Waste Form Initiative work with the DOEID MWFA and provided a final draft of all deliverables to DOE-ID, including the bibliography, which was updated in the beginning of July, 1996.

The WPI team revised Mixed Waste Focus Area Technology Development Requirements Documents (TDRD), and submitted a draft TDRD of the High Efficiency Particulate Air Filter.

Members of the team reviewed these documents to support participation in DOE-ID meetings:

-Integrated Thermal Treatment Systems Study (draft)

-Integrated Non-thermal Treatment Systems Study (draft)

-Comparison of Integrated Thermal Treatment Systems (draft)

-Integrated Non-thermal Treatment Systems for Mixed Low-Level Waste(draft)

-Requirements for Cleanable Steel High Efficiency Particulate Air Filter Derived from

Systems Analysis (draft)

-Technology Development Field Cost Estimating Guide (draft)

Members of the team provided technical research support related to steam reforming and plasma hearth off-gas processing.

The second draft of Site Regulatory Summaries was delivered.

The WPI team coordinated WPI legal and subcontractor review of EPA proposed changes to combustion rules.

Staff members investigated the background and prepared an evaluation of the Oak Ridge Operation office announcement for a procurement for Treatment for Disposition and Transportation of Low-Level Mixed Waste for the MWFA.

Team members prepared the draft and final paper for Spectrum ' 96 titled "ER-Related EM-Related International Technology Development Program at the Idaho National Engineering Laboratory" for the Mixed Waste Focus Area. 


\section{TASK B-PROJECT ASSESSMENT}

\section{TANKS FOCUS AREA (TFA)}

Staff developed a comparison of the costs to treat tank waste reported in the Baseline Environmental Management Report for 1996 to the costs reported in the Draft FY97-FY99 Multi-year Program Plan (MYPP). This information was incorporated into Appendix A of the MYPP.

The MYPP for the TFA was reviewed by the WPI team and comments were forwarded to DOE-RL. The TFA Lead requested the staff prepare an informal memo transmitting the MYPP to the Community Leaders Network (CLN) for review and comment.

Staff reviewed and commented on draft Program Execution Guidance (PEG) submittals from PNNL for DOE-RL. DOE-RL asked the WPI team to incorporate their comments with ours and submit one set of comments to PNNL for resolution. WPI staff entered complete PEG information into the TTP32c database and prepared a draft prioritized list of tasks. This information was then distributed for review and comment to PNNL, site representatives, and Technical Program Officers for DOE-RL. Staff prepared a Draft PEG Review Briefing outlining the FY97 program for the TFA Lead to present July 29, 1996 to Clyde Frank, DOE-HQ. Staff participated in the meeting to calculate carryover in the FY96 TFA budget and transmitted information to DOE-HQ for the TFA Lead.

The WPI team staff attended the D\&D105-C Reactor Large Scale Demonstration (LSD) Technologies Selection meeting in Richland July 24-25, 1996 in support of D\&D activities and the virtual office concept for WPI's new contract.

Talking points on the Light Duty Utility Arm (LDUA) were prepared by the staff to be used in a DOE-RL media event.

A dialogue between TFA and EM-30 for improving the coordination and communication on Hanford needs was established by the WPI team. This effort will be incorporated into the Site Technical Coordination Group (STCG) meeting activities.

Staff reviewed and commented on the proposed EM-50 Performance Measures (PMs) from the HQ Process Improvement Team and provided the comments to DOE-RL. Recommendations included simplifying the PMs and some type of measure of customer satisfaction.

The WPI team has begun drafting agendas for the weekly TFA teleconference by DOE$\mathrm{RL}$ and report on Updates and Actions from the previous week's call for the TFA. Draft agendas and updates/actions were submitted to DOE-RL for the month of July. 
Draft minutes from the TFA Workshop held in Denver, Colorado, June 25-26, 1996, were prepared by the WPI staff for DOE-RL, and transmitted electronically to attendees for review and comment by the WPI staff.

WPI staff prepared a Program Review briefing for the TFA Lead to present to DOE-RL management which discussed current cost/budget, milestones, accomplishments, and issues in the TFA. Staff incorporated much of the information into the monthly Business Review Briefing.

Staff provided input to the TFA Team on a strawman format for the FY97 TTPs. The draft TTP format will be shared with the other Focus Areas and Crosscutting programs to underscore commonalities.

Staff was directed by DOE-RL to coordinate a meeting and tour for Robyn Sweeny who is responsible for EM-30 High-Level Waste Team Integration at HQ. Ms. Sweeny provided some important insight regarding the Ten-Year Plan and highest priorities for DOE HLW from the complex-wide perspective.

\section{SUBSURFACE CONTAMINANTS FOCUS AREA (SCFA)}

Members of the team produced a preliminary table for referencing FY97 TTPs to site needs. The table was produced with timely turnaround using work in progress on FY96 TTPs and adding a column of FY97 TTPs from a crosswalk table.

Staff produced technical information and prepared a slide presentation for the Subsurface Contaminants Focus Area PEG Review on July 29, 1996 and the TD Council Meeting on July 30,1996

The SCFA Monthly Progress Reports for April and May 1996 were prepared with a total of four pictures (one from each deployment sector). The monthly report is based on the weekly progress reports and is utilized as a communications tool.

A WPI team member produced a memo requesting participation by TPO's in preparation of information for the PTS Monthly Business Review and explanation of cost/schedule variances which exceed $10 \%$ threshold.

Support was provided by staff members to the requirements definition for a decision support system for Subsurface Contaminants Focus Area management planning needs. The status report was produced for the month of July providing the current requirement definition. The team is currently finalizing the reporting requirements and the data sources. Final delivery of the system is estimated to be on schedule for the end of September. 
Members of the staff performed a technical review of the STCG technology needs compared them to current Focus Area requirements, and suggested supporting guidance for STCGs to provide technology needs information to the focus area.

\section{DECONTAMINATION AND DECOMMISSIONING (D\&D) FOCUS AREA}

The WPI team prepared the draft FY97 PEG for the D\&D Focus Area. Team members assisted METC to develop PEGs for new project starts as well as for FY96 continuing projects. TheWPI staff also prepared the presentation for the D\&D Focus Area FY97 PEG review on July 29. with the Deputy Assistant Secretary for Science and Technology, Dr. Clyde Frank. The PEGs will be revised based on comments that came out of that briefing.

The WPI team organized and supported the D\&D National Needs Workshop held at METC on July 24 and 25. This effort included collating site STCG inputs into 31 D\&D problem areas which were prioritized by representatives of the site STCGs, EM-40, EM-50, and EM-60. A workshop notebook and briefing materials was prepared for participants.

Technical input was provided by the WPI team to the D\&D Focus Area Monthly Report on the technical task work accomplished by the focus area Principal Investigators (PIs) in June, and assisted in the collection, review, and editing of input from the PIs. Following approval by the focus area team leader, WPI published the April and May D\&D Monthly Reports and distributed them to the METC approved mailing list. This report informs interested parties of the monthly progress being made by the D\&D Focus Area.

WPI team members prepared a D\&D Focus Area briefing for the "Seventh Annual Robotics Forum." This briefing will help METC to familiarize attendees with the D\&D related robotics development work being done by the D\&D Focus Area.

\section{MIXED WASTE FOCUS AREA (MWFA)}

Team members finalized organizational charts of the MWFA and its contractors and a master list of points of contact was prepared.

Staff members began compiling information for the Revised Technical Task Plan and started gathering information to connect multiple databases together into a single Technical Task Plan Summary sheet.

Team members reviewed these documents to support participation in DOE-ID meetings:

-Financial Authorization, Baseline and Actual Documents

-Program Execution Guidance (July change packages). 
The development of draft Gantt and PERT charts for the MWFA Request for Interest (RFI) to address the thirty deficiencies identified during the development of the Technical Baseline Document continued.

The WPI team provided DOE-ID support and input to determine Potential Organizational Conflicts of Interest (OCI) areas for the MWFA Request for Interest review process. Several table and chart ideas to implement and further define the nature of the responses to the RFI and allow an objective review of the potential $\mathrm{OCI}$ issue were developed.

Members of the staff attended several meetings with Dallas Hofer and Linda Hallum to discuss the RFI/RFP process, outline potential OCI issues and devise a working schedule for LITCO.

Staff members provided project management services for the technical resource team members under the WPI contract. Activities included reviewing weekly reports, evaluating cost and expenditure information, and obtaining travel approvals for necessary meetings by the members.

WPI team research obtained new information was on the ASME committee review process for incorporation into the Independent Review Process Implementation Plan.

The WPI team developed a revised Technical Task Plan summary sheet for DOE-ID, obtained DOE-ID comments, and revised the format accordingly.

\section{TASK C-TECHNOLOGYINTEGRATION}

The WPI team performed analysis on the FY97 PEG in relation to the 17 prioritized technology needs requested by Hanford. The information was produced in tables including related work packages, TTP, and funding.

Staff conducted an informal review of a DOE-METC proposed format for Innovative Technology Summary Reports, commonly known as the "green books."

A member of the team researched, reviewed, and analyzed EPA (40 C.F.R. Section 262.34 ) and 13 State hazardous waste accumulation requirements, provided guidance concerning potential changes in the combuster rulemaking schedule and relevant American Indian regulatory development (effort in EPA Region IX for State/Tribal cooperative determination of Clean Air Act issues).

Members of the staff provided technical support to the Oak Ridge TFA Program Manager for the following activities: a technical review and comments on the draft Memorandum of Understanding for the Oak Ridge Cesium Removal Demonstration (CsRD) and Savannah River Vitrification Demonstration, observation of the CsRD project site, participation in a brief status meeting and draft minutes of the meeting, and other activities as required. 
WPI team members completed the Rainbow Books for D\&D and SCFA and they were approved by the Office of Public Affairs and sent to the printer for reproduction. The complete set of Rainbow Books will reach a wide audience, including industry and the general public. The project also serves as an outreach activity as DOE shares its current information on technology development. The books will be available to participants at the SPECTRUM ' 96 Conference to be held in August, 1996.

WPI staff researched and tracked federal environment and technology legislation which may potentially impact the field, in particular, the National Defense Authorization Act for FY97.

Staff members researched, tracked and distributed quick-read reports on the status of the ongoing FY97 appropriations process as it impacts DOE's Environmental Management program and technology development issues at the field level.

Staff members continued with the development of a comprehensive and integrated schedule to show all major milestones for technologies for all focus and crosscut areas. Major milestones will correspond to the Gate model as much as possible and will include: complete bench-scale testing, complete pilot-scale testing, complete full-scale testing, available for transfer, complete technology performance report, and available for implementation. The focus of this project will be identifying where the current gaps of information are, particularly in the outyears, and in making the schedule information available in a more consistent format.

Members of the team organized and conducted a strategy session at METC for an Executive Seminar Series on expediting commercial use of EM-50 technologies

\section{TASK D-SYSTEMS ENGINEERING}

The WPI team submitted the final report, "Review of the Integrated Thermal and NonThermal Treatment System Studies," to the client. This study analyzed three systems engineering (SE) studies prepared by LITCO on treatment technologies for mixed lowlevel waste. Using a common framework or template for SE, the objective of the study was to evaluate the validity and completeness of the approach taken in each of the SE studies. 


\section{ATTACHMENT A}

\section{PRODUCTS DELIVERED: TASK A - TECHNOLOGY ASSESSMENT}

\section{TANKS FOCUS AREA (TFA)}

- Northwest Regional American Chemical Society Trip Report

- Light Duty Utility Arm (LDUA) Report

- Hanford Waste Sample Needs for FY97

- Status report of Grout at INEL

\section{SUBSURFACE CONTAMINANTS FOCUS AREA (SCFA)}

- Review of Draft Reports: "Projected Performance of In-Well Vapor Stripping" and "Preliminary Performance Assessment of In-Well Vapor Stripping System"

- Technical Information on SCFA Technologies as input to the ERWM 10 Year Strategic Plan

- One Page Fact Sheet and Cover Letter on Viscous Liquid/Barrier Technology from Chemical Engineering Inquiries

- Identified and Formatted SCFA Basic Science Needs

- Review of "In Situ Remediation of DNAPL Compounds in Low Permeability Media: Fate/Transport, In Situ Control Technologies, and Risk Reduction" Cover Letter and Table

\section{DECONTAMINATION AND DECOMMISSIONING (D\&D) FOCUS AREA}

- Radioactive Scrap Metal Recycling Report (Final Draft)

- D\&D Mid-Year Review Panel Report

- D\&D Cost Evaluation

- C-Reactor Large-Scale Demonstration IC Team Meeting Record MIXED WASTE FOCUS AREA (MWFA)

- Waste Forms Initiative Deliverables 



\section{PRODUCTS DELIVERED: TASK B: PROJECT ASSESSMENT}

\section{TANKS FOCUS AREA (TFA)}

- Reconciliation of TFA MYPP with BEMR 1996

- FY97 Draft TFA PEG Review Comments and Recommendations

- DSI (informal memo) transmitting FY97 MYPP to the CLN for review and comment

- Draft meeting minutes from the TFA Workshop held in Denver, CO, June 25-26, 1996

- Review and comments on the FY97 Multi-year Program Plan to DOE-RL

- DOE-RL PEG review comments incorporated with WPI comments and transmitted to PNNL

- Draft memorandum from DOE-RL on Revising the TFA Strategic and Management Plans

- PEG files and Prioritization Table

- Draft Business Review Briefing for TFA to DOE-RL management

- Draft memorandum from DOE-RL to TPOs and Site Representatives transmitting FY97 Draft PEG

- Draft PEG Review Briefing for DOE-RL, July 29, 1996

- Comments on proposed performance measures for TFA for FY97

- Agenda for 7/30/96 TFA telecon and Update/Actions from 7/23/96 call

- Strawman TTP format for TFA FY97 TTPs

- Notes from Robyn Sweeny's (EM-50) Visit/Tour of Hanford

SUBSURFACE CONTAMINANTS FOCUS AREA (SCFA)

- Spreadsheet containing FY97 TTPs Referenced to Applicable Site Needs

- Presentation Materials for SCFA PEG and TD Council Meetings on July $29 \& 30$. 
- Monthly Progress Reports for April and May

- May PTS Cost/Variance Explanations for the Monthly Business Review

- Draft Systems Report for Data Requirements and Responsibilities of a Support System for the Program Planning in SCFA

- SCFA Weekly Report June 7

- SCFA Weekly Report June 14

- SCFA Weekly Report June 28

- Review of STCG Statement on Technology Needs

DECONTAMINATION AND DECOMMISSIONING (D\&D) FOCUS AREA

- D\&D National Needs Workshop Notebook and D\&DFA briefings

- PEG Review Briefing

- April D\&D Focus Area Monthly Report

- May D\&D Focus Area Monthly Report

- D\&D Focus Area Robotics Forum Briefing

MIXED WASTE FOCUS AREA (MWFA)

- June Monthly Report

\section{PRODUCTS DELIVERED: TASK C: TECHNOLOGY INTEGRATION}

- Comments on Memo of Understanding for the Oak Ridge Cesium Removal Demonstration and Savannah River Vitrification Demonstration

- Minutes from Oak Ridge Cesium Removal Demonstration Project Site Visit, July 30, 1996

- Department of Energy Technology Summary Books, D\&D and SCFA 


\section{PRODUCTS DELIVERED: TASKD: SYSTEMS ENGINEERING}

- Draft report "Review of the Integrated Thermal and Nonthermal Treatment System Studies" 


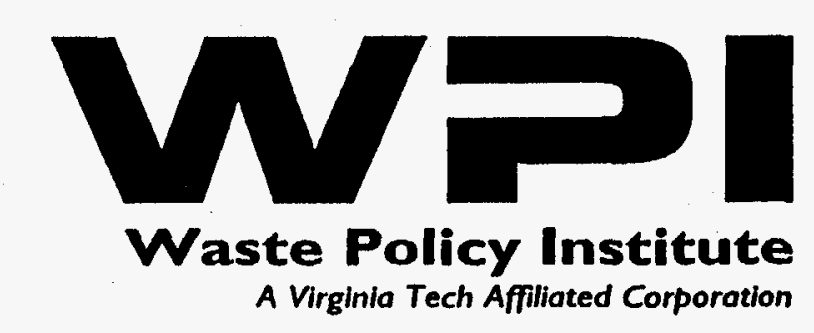

\section{MONTHLY \\ COST AND LABOR REPORT}

\section{UNIVERSITY OF NORTH DAKOTA ENERGY AND ENVIRONMENTAL RESEARCH CENTER}

Subcontract No. 359636

July, 1996 


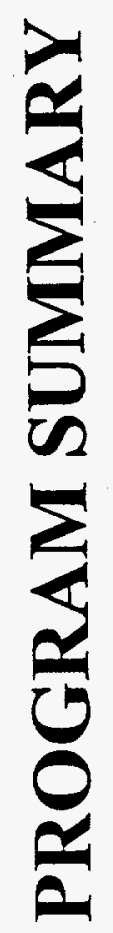


WPI Subcontract--EERC Coop: Agreement

(\$x1000)

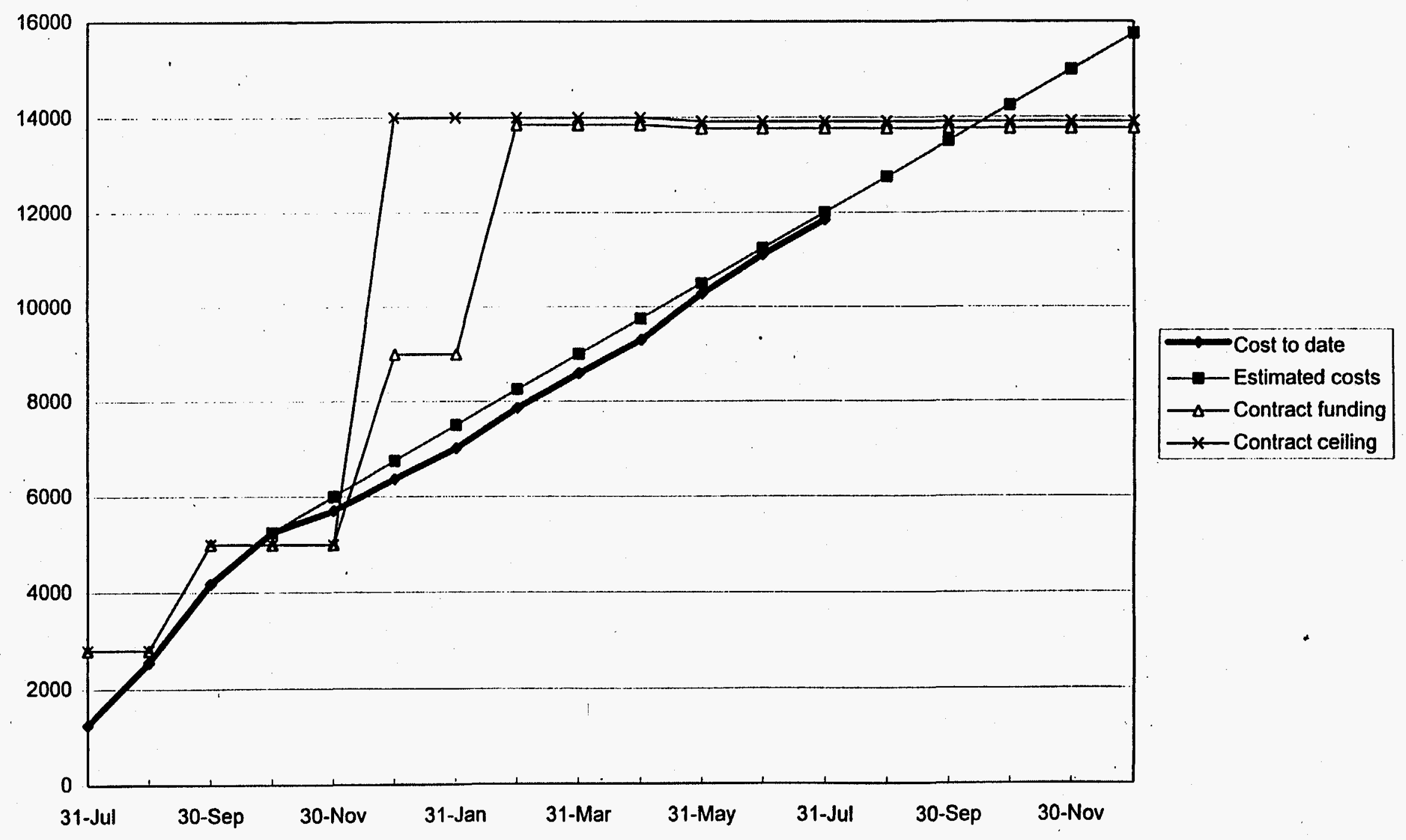


Subcontract No. 359636

Actuals through July 96

WBS: 1043 EERC

Manager: Dr. John S. Wilson

Start Date: 6/27/95

End Date: 12/1/96

Task Description: Provide assistance to EERC's conduct of technology development integration activities.

Cost Performance Summary:

\begin{tabular}{|c|c|c|c|}
\hline & \multicolumn{3}{|c|}{ Current Period } \\
\hline & Budget & Actuals & Variance \\
\hline Hours: & 10,668 & 10,309 & 359 \\
\hline Price: & 839,498 & 740,287 & 99,211 \\
\hline
\end{tabular}

\begin{tabular}{|c|c|c|}
\hline \multicolumn{3}{|c|}{ Inception to Date } \\
\hline Budget & Actuals & Variance \\
\hline 158,290 & 139,122 & 19,169 \\
\hline $12,422,988$ & $11,849,563$ & 573,425 \\
\hline
\end{tabular}

\begin{tabular}{|c|c|c|}
\hline \multicolumn{3}{|c|}{ At Complete } \\
\hline Budget & Estimate & Varlance \\
\hline 179,950 & 160,782 & 19,169 \\
\hline $14,144,823$ & $13,571,399$ & 573,425 \\
\hline
\end{tabular}

Monthly Financial Recap:

\begin{tabular}{|c|c|c|c|c|c|c|c|c|c|c|c|c|}
\hline & Jun 95 & Jul 95 & Aug 95 & Sep 95 & Oct 95 & Nov 95 & Dec 95 & Jan 96 & Feb 96 & $\operatorname{Mar} 96$ & Apr 96 & May 96 \\
\hline \multicolumn{13}{|l|}{ Actuals: } \\
\hline Monthly Hours: & 149 & 15,710 & 17,723 & 19,161 & 10,639 & 6,367 & 6,669 & 6,932 & 8,057 & 8,562 & 8,653 & 11,408 \\
\hline Cumu Hours: & 149 & 15,859 & 33,582 & 52,743 & 63,382 & 69,749 & 76,418 & 83,350 & 91,408 & 99,970 & 108,623 & 120,031 \\
\hline Monthly Price: & 8,492 & $1,240,210$ & $1,300,381$ & $1,628,866$ & $1,072,629$ & 508,957 & 674,480 & 577,622 & 844,119 & 734,699 & 707,388 & 982,181 \\
\hline Cumu Price: & 8,492 & $1,248,702$ & $2,549,083$ & $4,177,949$ & $5,250,578$ & $5,759,535$ & $6,434,015$ & $7,011,637$ & $7,855,755$ & $8,590,455$ & $9,297,843$ & $10,280,023$ \\
\hline \multicolumn{13}{|l|}{ Budget: } \\
\hline Monthly Hours: & 1,4397 & 18,428 & 22,308 & 10.570 & 10,506 & 10,506 & 10,506 & 10,506 & 10,506 & 10,506 & 10,506 & 10,669 \\
\hline Cumu Hours: & 1,437 & 19,865 & 42,173 & 52.743 & 63,249 & 73,755 & 84,261 & 94,767 & 105,273 & 115,779 & 126,286 & 136,954 \\
\hline Monthly Price: & 89,294 & $1,251,829$ & $1,454,843$ & $1,381,982$ & 818,078 & 818,078 & 818,078 & 818,078 & 818,078 & 818.078 & 818,078 & 839.498 \\
\hline Cumu Price: & 89,294 & $1,341,124$ & $2,795,967$ & $4,177,949$ & $4,996,027$ & $5,814,106$ & $6,632.183$ & $7,450,261$ & $8,268,339$ & $9,086,417$ & $9,904,494$ & $10,743,992$ \\
\hline
\end{tabular}




\section{Subcontract No. 359636}

Actuals through July 96

WBS: 1043 EERC

Manager: Dr. John S. Wilson

Start Date: 6/27/95

End Date: 12/1/96

Task Description: Provide assistance to EERC's conduct of technology development integration activities.

\section{Cost Performance Summary:}

\begin{tabular}{|c|c|c|c|}
\hline & \multicolumn{3}{|c|}{ Current Period } \\
\hline & Budget & Actuals & Varlance \\
\hline Hours: & 10,668 & 10,309 & 359 \\
\hline Price: & 839,498 & 740,287 & 99,211 \\
\hline
\end{tabular}

\begin{tabular}{|c|c|c|}
\hline \multicolumn{3}{|c|}{ Inception to Date } \\
\hline Budget & Actuals & Variance \\
\hline 158,290 & 139,122 & 19,169 \\
\hline $12,422,988$ & $11,849,563$ & 573,425 \\
\hline
\end{tabular}

\begin{tabular}{r|rr}
\multicolumn{3}{c}{ At Complete } \\
\hline Budget & Estimate & Varlance \\
\hline 179,950 & 160,782 & 19,169 \\
\hline $14,144,823$ & $13,571,399$ & 573,425 \\
\hline
\end{tabular}

Monthly Financial Recap:

\begin{tabular}{|c|c|c|c|c|c|c|c|c|c|c|c|}
\hline Jun 96 & Jul 96 & Aug 96 & Sep 96 & Oct 96 & Nov 96 & Dec 96 & Jan 97 & Feb 97 & Mar 97 & Apr 97 & May 97 \\
\hline
\end{tabular}

Actuals:

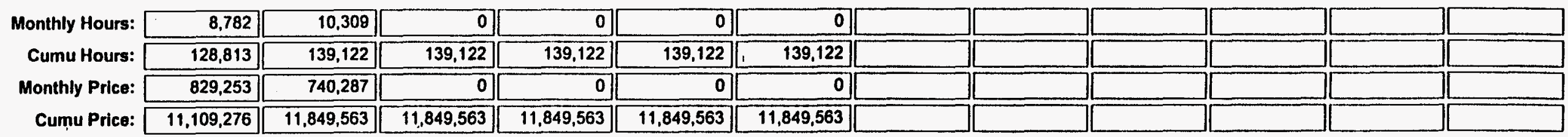

Budget:

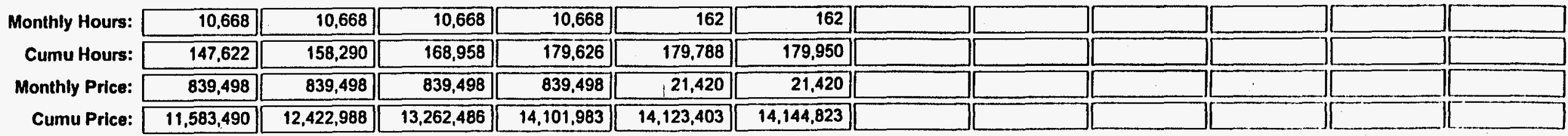



Actuals through July 96

WBS: 1043.01.01 Technology Management

Manager: Dr. John S. Wilson

Start Date: 6/27/95

End Date: 12/1/96

Task Description: Perform technical reviews of requirements, needs and assessments related to waste characterization, containment, in-situ and ex-situ treatment, waste storage, disposal, robotics handling, monitoring, laboratory analysis, sile characterization and remediation.

Cost Performance Summary:

Current Period

\begin{tabular}{|c|c|c|c|}
\hline & Budget & Actuals & Variance \\
\hline ou & 5,474 & 2,743 & 2,731 \\
\hline Price: & 297,160 & 219,262 & 77,898 \\
\hline
\end{tabular}

Inception to Date

\begin{tabular}{|c|c|c|}
\hline Budget & Actuals & Variance \\
\hline 76,508 & 58,041 & 18,467 \\
\hline $4,829,266$ & $5,335,908$ & $-506,642$ \\
\hline
\end{tabular}

\section{At Complete}

\begin{tabular}{|c|c|c|}
\hline Budget & Estimate & Variance \\
\hline 87,456 & 68,989 & 18,467 \\
\hline $5,423,585$ & $5,930,227$ & $-506,642$ \\
\hline
\end{tabular}

Monthly Financlai Recap:

\begin{tabular}{|c|c|c|c|c|c|c|c|c|c|c|c|c|}
\hline & Jun 95 & Jul 95 & Aug 95 . & Sep 95 & Oct 95 & Nov 95 & Dec 95 & Jan 96 & Feb 96 & Mar 96 & Apr 96 & May 96 \\
\hline \multicolumn{13}{|l|}{ Actuals: } \\
\hline Monthly Hours: & 50 & 6.255 & 7,504 & 7,961 & 6,453 & 4,330 & 3,138 & 2,600 & 3,300 & 3,479 & 2,963 & 4,168 \\
\hline Cumu Hours: & 50 & 6,305 & 13,809 & 21,770 & 28,224 & 32,553 & 35,691 & 38,291 & 41,591 & 45,069 & 48,032 & 52,200 \\
\hline Monthly Price: & 2,574 & 533,931 & 582.189 & 738.970 & 657,545 & 359,376 & 316,660 & 247,333 & 406,806 & 323,669 & 246,524 & 383,670 \\
\hline Cumu Price: & 2,574 & 536,505 & $1,118,694$ & $1,857,664$ & $2,515,209$ & $2,874,585$ & $3,191,245$ & $3,438,578$ & $3,845,383$ & $4,169,052$ & $4,415,577$ & $4,799,247$ \\
\hline
\end{tabular}

Budget:

Monthly Hours:

Cumu Hours:

Monthly Price:

\begin{tabular}{|r|r|}
\hline 328 & 7,196 \\
\hline 328 & 7,525 \\
\hline 14,090 & \\
\hline 14,090 & 598,386 \\
\hline
\end{tabular}

\begin{tabular}{|r|r|}
\hline 8,711 & 5,534 \\
\hline 16,236 & 21,770 \\
\hline 570,555 & 774,636 \\
\hline $1,083,032$ & $1,857,668$ \\
\hline
\end{tabular}

\begin{tabular}{|r|}
\hline 5,474 \\
\hline 27,244 \\
\hline 297,160 \\
\hline $2,154,828$ \\
\hline
\end{tabular}

\begin{tabular}{|r|r|}
\hline 5,474 & 5,474 \\
\hline 32,718 & 38,191 \\
\hline 297,160 & 297,160 \\
\hline $2,451,988$ & $2,749,148$ \\
\hline
\end{tabular}

\begin{tabular}{r|}
\hline 5,474 \\
\hline 43,665 \\
\hline $3,046,308,160$ \\
\hline
\end{tabular}

\begin{tabular}{|r|r|}
\hline 5,474 & 5,474 \\
\hline 49,139 & 54,613 \\
\hline 297,160 & 297,160 \\
\hline $3,343,467$ & $3,640,627$ \\
\hline
\end{tabular}

\begin{tabular}{|r|r|}
\hline 5,474 & 5,474 \\
\hline 60,087 & 65,561 \\
\hline 297,160 & 297,160 \\
\hline $3,937,787$ & $4,234,946$ \\
\hline
\end{tabular}


Subcontract No. 359636

Actuals through July 96

WBS: 1043.01.01 Technology Management

Manager: Dr. John S. Wilson

\section{Start Date: 6/27/95}

End Date: 12/1/96

Task Description: Perform lechnical reviews of requirements, needs and assessments related to waste characterization, containment, in-situ and ex-silu trealment, waste storage, disposal, robotics handling, monitoring, laboratory analysis, site characterization and remediation.

Cost Performance Summary:

\begin{tabular}{|c|c|c|c|}
\hline & \multicolumn{3}{|c|}{ Current Period } \\
\hline & Budget & Actuals & Variance \\
\hline Hours: & 5,474 & $2, \overline{743}$ & 2,731 \\
\hline Price: & 297.160 & 219,262 & $77, \overline{898}$ \\
\hline
\end{tabular}

\begin{tabular}{|c|c|c|}
\hline \multicolumn{3}{|c|}{ Inception to Date } \\
\hline Budget & Actuals & Variance \\
\hline 76,508 & 58,041 & 18.467 \\
\hline $4,829,266$ & $5,335,908$ & $-506,642$ \\
\hline
\end{tabular}

\begin{tabular}{r|r|r|}
\multicolumn{3}{c}{ At Complete } \\
\hline Budget & Estimate & Variance \\
\hline 87,456 & 68,989 & 18,467 \\
\hline $5,423,585$ & $5,930,227$ & $-506,642$ \\
\hline
\end{tabular}

Monthly Financial Recap:

\begin{tabular}{|c|c|c|c|c|c|c|c|c|c|c|c|c|}
\hline & Jun 96 & Jul 96 & Aug 96 & Sep 96 & Oct 96 & Nov 96 & Dec 96 & Jan 97 & Feb 97 & Mar 97 & Apr 97 & May 97 \\
\hline \multicolumn{13}{|l|}{ Actuals: } \\
\hline Monthly Hours: & 3,099 & 2,743 & 0 & 0 & 0 & 0 & & & & & & \\
\hline Cumu Hours: & 55,299 & 58,041 & 58,041 & 58,041 & 58,041 & 58,041 & & & & & & \\
\hline Monthly Price: & 317,399 & 219.262 & 0 & 0 & 0 & 0 & & & & & & \\
\hline Cumu Price: & $5,116,646$ & $5,335,908$ & $5,335,908$ & $5,335,908$ & $5,335,908$ & $5,335,908$ & & & & & & \\
\hline
\end{tabular}

Budget:

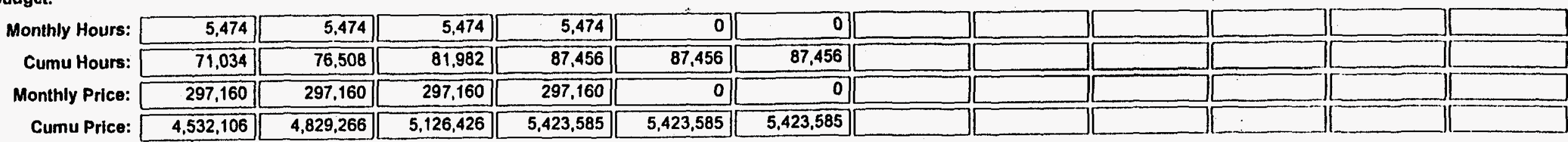


$\frac{1}{4}$ 
Subcontract No. 359636

Actuals through July 96

WBS: 1043.01.02 Projecl Management

Manager: Dr. John S. Wilson

Start Date: 6/27/95

End Date: 12/1/96

Task Description: Conduct reviews, analyze and develop strategies for program management systems for integration and control of programs, projects, tasks and documentation.

Cost Performance Summary:

\begin{tabular}{|c|c|c|c|}
\hline & \multicolumn{3}{|c|}{ Current Period } \\
\hline & Budget & Actuals & Varlance \\
\hline Hours: & 2,704 & 4,572 & $-1,868$ \\
\hline Price: & 273,798 & 305,344 & $-31,546$ \\
\hline
\end{tabular}

\begin{tabular}{l}
\multicolumn{3}{c}{ Inception to Date } \\
\begin{tabular}{r|r|r|}
\hline Budget & Actuals & Variance \\
\hline 52,585 & 59,134 & $-6,549$ \\
\hline $4,630,044$ & $4,665,270$ & $-35,226$ \\
\hline
\end{tabular}
\end{tabular}

\begin{tabular}{|c|c|c|}
\hline \multicolumn{3}{|c|}{ At Complete } \\
\hline Budget & Estimate & Varlance \\
\hline 57,993 & 64,542 & $-6,549$ \\
\hline $5,177,640$ & $5,212,866$ & $-35,226$ \\
\hline
\end{tabular}

Monthly Financial Recap:

\begin{tabular}{|c|c|c|c|c|c|c|c|c|c|c|c|}
\hline Jun 95 & Jul 95 & Aug 95 & Sep 95 & Oct 95 & Nov 95 & Dec 95 & $\operatorname{Jan} 96$ & Feb 96 & Mar 96 & Apr 96 & May 96 \\
\hline
\end{tabular}

Actuals:

\begin{tabular}{|c|c|c|c|c|c|c|c|c|c|c|c|c|}
\hline Monthly Hours: & 98 & 8,116 & 8,247 & 9,084 & 3,578 & 1,588 & 2,868 & 3,297 & 3,561 & 3,631 & 3,321 & 4,024 \\
\hline Cumu Hours: & 98 & 8,214 & 16,462 & 25,545 & 29,123 & 30,711 & 33,578 & 36,875 & 40,436 & 44,067 & 47,388 & 51,412 \\
\hline Monthly Price: & 5,779 & 599,758 & 566,591 & 719,936 & 341,971 & 108,114 & 275,047 & 255,073 & 319,577 & 306,696 & 269,945 & 315,382 \\
\hline
\end{tabular}
Budget:

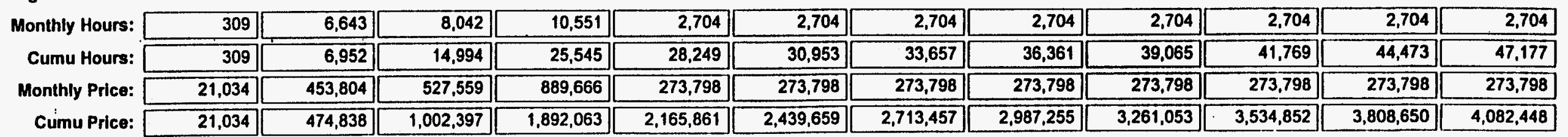


Subcontract No. 359636

Actuals through July 96

WBS: 1043.01.02 Project Management

Manager: Dr. John S. Wilson

Start Date: 6/27/95

End Date: 12/1/96

Task Description: Conduct reviews, analyze and develop strategies for program management systems for integration and control of programs, projects, tasks and documentation.

Cost Performance Summary:

\begin{tabular}{|c|c|c|c|}
\hline & \multicolumn{3}{|c|}{ Current Period } \\
\hline & Budget & Actuals & Variance \\
\hline ours: & 2,704 & 4.572 & -1.868 \\
\hline Price: & 273,798 & 305,344 & -31.546 \\
\hline
\end{tabular}

\begin{tabular}{|c|c|c|}
\hline \multicolumn{3}{|c|}{ Inception to Date } \\
\hline Budget & Actuals & Variance \\
\hline 52,585 & 59,134 & $-6,549$ \\
\hline $4,630,044$ & $4,665,270$ & $-35,226$ \\
\hline
\end{tabular}

\begin{tabular}{|c|c|c|}
\hline \multicolumn{3}{|c|}{ At Complete } \\
\hline Budget & Estimate & Variance \\
\hline 57.993 & 64,542 & -6.549 \\
\hline $5,177,640$ & $5,212, \overline{866}$ & $-35,226$ \\
\hline
\end{tabular}

Monthly Financial Recap:

\begin{tabular}{|c|c|c|c|c|c|c|c|c|c|c|c|c|}
\hline & Jun 96 & Jul 96 & Aug 96 & Sep 96 & Oct 96 & Nov 96 & Dec 96 & Jan 97 & Feb 97 & Mar 97 & Apr 97 & May 97 \\
\hline \multicolumn{13}{|l|}{ Actuals: } \\
\hline Monthly Hours: & 3,151 & 4,572 & 0 & 0 & 0 & 0 & & & & & & \\
\hline Cumu Hours: & 54,562 & 59,134 & 59,134 & 59,134 & 59,134 & 59,134 & & & & & & \\
\hline Monthly Price: & 276,057 & 305,344 & 0 & 0 & 0 & 0 & & & & & & \\
\hline Cumu Price: & $4,359,925$ & $4,665,270$ & $4,665,270$ & $4,665,270$ & $4,665,270$ & $4,665,270$ & & & & & & \\
\hline
\end{tabular}

Budget:

Monthly Hours:

Cumu Hours:

Monthly Price:

\begin{tabular}{|r|r|r|r|}
\hline 2,704 & 2,704 & 2,704 & 2,704 \\
\hline 49,881 & 52,585 & 55,289 & 57,993 \\
\hline 273,798 & 273,798 & 273,798 & 273,798 \\
\hline $4,356,246$ & $4,630,044$ & $4,903,842$ & $5,177,640$ \\
\hline
\end{tabular}

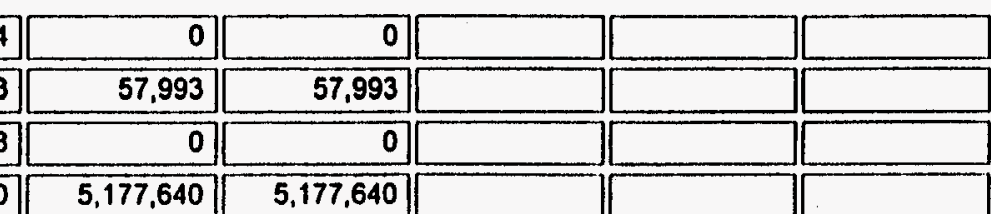

(1)


造 
Subcontract No. 359636

Actuals through July 96

WBS: 1043.01.03 Technology Integration

Manager: Dr. John S. Wilson

Start Date: 6/27/95

End Date: 12/1/96

Task Description: Provide support in establishing criteria for identifying risks to the public health and safety posed by conditions at the weapons complex facilities, evaluate the extent of these risks, determine the urgency and priorities for eliminating or minimizing the risks, and access the cost of activities required to meet applicable compliance agreements.

Cost Performance Summary:

\begin{tabular}{|c|c|c|c|}
\hline & \multicolumn{3}{|c|}{ Current Period } \\
\hline & Budget & Actuals & Variance \\
\hline ours: & 2,328 & 2,993 & -665 \\
\hline Price: & 247,120 & 215,115 & 32,005 \\
\hline
\end{tabular}

\begin{tabular}{|c|c|c|}
\hline \multicolumn{3}{|c|}{ Inception to Date } \\
\hline Budget & Actuals & Variance \\
\hline 28,711 & 21,945 & 6.766 \\
\hline $2,899,418$ & $1,842,120$ & $1,057,298$ \\
\hline
\end{tabular}

\begin{tabular}{|c|c|c|}
\hline \multicolumn{3}{|c|}{ At Complete } \\
\hline Budget & Estimate & Variance \\
\hline 33,367 & 26,601 & 6,766 \\
\hline $3,393,658$ & $2,336,361$ & $1,057,298$ \\
\hline
\end{tabular}

Monthly Financia! Recap:

\begin{tabular}{|c|c|c|c|c|c|c|c|c|c|c|c|}
\hline Jun 95 & Jul 95 & Aug 95 & Sep 95 & Oct 95 & Nov 95 & Dec 95 & $\operatorname{Jan} 96$ & Feb 96 & Mar 96 & Apr 96 & May 96 \\
\hline
\end{tabular}

Actuals:

\begin{tabular}{|c|c|c|c|c|c|c|c|c|c|c|c|c|}
\hline Monthly Hours: & 1 & 1,339 & 1.972 & 2,117 & 608 & 450 & 664 & 1,036 & 1,196 & 1,453 & 2,370 & 3,216 \\
\hline Cumu Hours: & 1 & 1,340 & 3,312 & 5,428 & 6,036 & 6,486 & 7,150 & 8,185 & 9,381 & 10,834 & 13,203 & 16.419 \\
\hline Monthly Price: & 139 & 106,521 & 151,601 & 169,960 & 73,113 & 41,466 & 82,773 & 75,216 & 117,736 & 104,335 & 190,919 & 283,077 \\
\hline Cumu Price: & 139 & 106,660 & 258,261 & 428,221 & 501,334 & 542,800 & 625,574 & 700,790 & 818,526 & 922,860 & $1,113,780$ & $1,396,857$ \\
\hline
\end{tabular}

Budget:

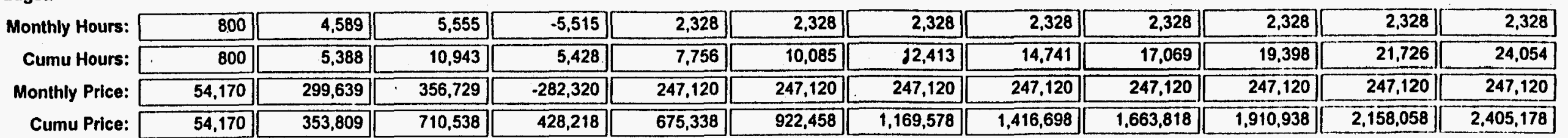


Subcontract No. 359636

Actuals through July 96

WBS: 1043.01.03 Technology Integration

Manager: Dr. John S. Wilson

Start Date: 6/27/95

End Date: 12/1/96

Task Description: Provide support in establishing criteria for identifying risks to the public health and safety posed by conditions at the weapons complex facilities, evaluate the extent of these risks, determine the urgency and priorities for eliminating or minimizing the risks, and access the cost of activities required to meet applicable compliance agreements.

Cost Performance Summary:

\begin{tabular}{|c|c|c|c|}
\hline & \multicolumn{3}{|c|}{ Current Period } \\
\hline & Budget & Actuals & Variance \\
\hline ours: & 2,328 & 2,993 & -665 \\
\hline Price: & 247,120 & 215,115 & $\overline{32.005}$ \\
\hline
\end{tabular}

Inception to Date
\begin{tabular}{r|r|r|}
\hline Budget & Actuals & Variance \\
\hline 28,711 & 21,945 & 6,766 \\
\hline $2,899,418$ & $1,842,120$ & $1,057,298$ \\
\hline
\end{tabular}

\begin{tabular}{|c|c|c|}
\hline \multicolumn{3}{|c|}{ At Complete } \\
\hline Budget & Estimate & Variance \\
\hline 33,367 & 26,601 & 6,766 \\
\hline $3,393,658$ & $2,336,361$ & $1,057,298$ \\
\hline
\end{tabular}

Monthly Financlal Recap:

\begin{tabular}{|c|c|c|c|c|c|c|c|c|c|c|c|}
\hline Jun 96 & Jul 96 & Aug 96 & Sep 96 & Oct 96 & Nov 96 & Dec 96 & Jan 97 & Feb 97 & Mar 97 & Apr 97 & May 97 \\
\hline
\end{tabular}

Actuals:

Monthly Hours:

Cumu Hours:

Monthly Price:

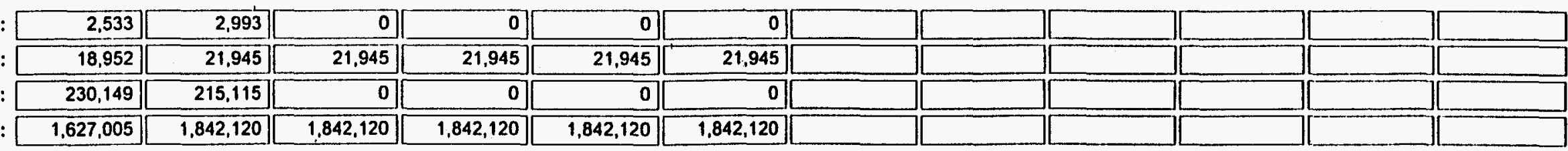

Cumu Price:

Budget:

Monthly Hours:

Cumu Hours:

Monthly Price:

\begin{tabular}{|r|r|}
\hline 2,328 & 2,328 \\
\hline 26,382 & 2,328 \\
\hline 247,120 & 28,711 \\
\hline 247,120 & 31,039 \\
\hline
\end{tabular}

$\left[\begin{array}{r}2,328 \\ 33,367\end{array}\right.$

Cumu Price:

$2,652,298 \quad 2,899,418 \quad 3,146,538$

\begin{tabular}{|r|r|}
\hline 33,36 \\
\hline 38 \\
\hline $3,393,658$ \\
\hline
\end{tabular}

\begin{tabular}{|r|r|r|r|}
\hline & 0 \\
\hline 33,367 & 33,367 \\
\hline $3,393,658$ & $3,393,658$ \\
\hline
\end{tabular}

(1)

(



1043.01.04

Waste Policy Institute

Task Area Summary

Subcontract No. 359636

Actuals through July 96

WBS: 1043.01.04 Systems Engineering

Manager: Dr. John S. Wilson

Start Date: 2/1/96

End Date: 12/1/96

Task Description:

Cost Performance Summary:

\begin{tabular}{|c|c|c|c|}
\hline & \multicolumn{3}{|c|}{ Current Period } \\
\hline & Budget & Actuals & Variance \\
\hline Hours: & 162 & 2 & 160 \\
\hline Price: & 21,420 & 565 & 20.855 \\
\hline
\end{tabular}

\begin{tabular}{|c|c|c|}
\hline \multicolumn{3}{|c|}{ Inception to Date } \\
\hline Budget & Actuals & Variance \\
\hline 486 & 2 & 484 \\
\hline 64,260 & 6,265 & 57,995 \\
\hline
\end{tabular}

\begin{tabular}{|c|c|c|}
\hline \multicolumn{3}{|c|}{ At Complete } \\
\hline Budget & Estimate & Variance \\
\hline 1,134 & 650 & 484 \\
\hline 149,940 & 91,945 & 57,995 \\
\hline
\end{tabular}

Monthly Financial Recap:

\begin{tabular}{|c|c|c|c|c|c|c|c|c|c|c|c|}
\hline Jun 96 & Jul 96 & Aug 96 & Sep 96 & Oct 96 & Nov 96 & Dec 96 & Jan 97 & Feb 97 & Mar 97 & Apr 97 & May 97 \\
\hline
\end{tabular}

Actuals:

Monthly Hours:

Cumu Hours:

Monthly Price:

Cumu Price:

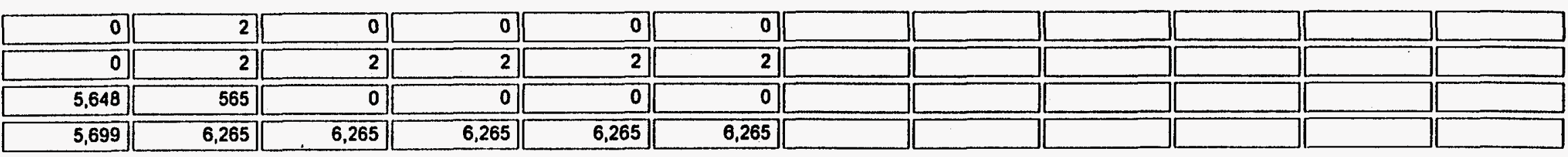

Budget:

Monthly Hours:

Cumu Hours:

Monthly Price:

\begin{tabular}{|r|r|}
\hline 162 & 162 \\
\hline 324 & 162 \\
\hline 21,420 & 486 \\
\hline 42,840 & 648 \\
\hline 64,260 & 620 \\
\hline
\end{tabular}

\begin{tabular}{|r|r|}
\hline 162 \\
\hline 810 \\
\hline 21,420 \\
\hline 107,100 \\
\hline 21,420 \\
\hline 128,520 \\
\hline
\end{tabular}

14,134

(1)


Subcontract No. 359636

Actuals through July 96

WBS: 1043.01.04 Systems Engineering

Manager: Dr. John S. Wilson

Start Date: 2/1/96

End Date: 12/1/96

Task Description:

Cost Performance Summary:

\begin{tabular}{|c|c|c|c|}
\hline & \multicolumn{3}{|c|}{ Current Period } \\
\hline & Budget & Actuals & Variance \\
\hline Hours: & 162 & 2 & 160 \\
\hline Price: & 21.420 & 565 & 20,855 \\
\hline
\end{tabular}

\begin{tabular}{|c|c|c|}
\hline \multicolumn{3}{|c|}{ Inception to Date } \\
\hline Budget & Actuals & Variance \\
\hline 486 & 2 & 484 \\
\hline 64,260 & 6,265 & 57,995 \\
\hline
\end{tabular}

\begin{tabular}{r|r|r|}
\multicolumn{3}{c}{ At Complete } \\
\hline Budget & Estimate & Varlance \\
\hline 1,134 & 650 & 484 \\
\hline 149,940 & 91,945 & 57,995 \\
\hline
\end{tabular}

Monthly Financial Recap:

\begin{tabular}{|c|c|c|c|c|c|c|c|c|c|c|c|c|}
\hline & Jun 95 & Jul 95 & Aug 95 & Sep 95 & Oct 95 & Nov 95 & Dec 95 & Jan 96 & Feb 96 & Mar 96 & Apr 96 & May 96 \\
\hline \multicolumn{13}{|l|}{ Actuals: } \\
\hline Monthly Hours: & 0 & 0 & 0 & 0 & 0 & 0 & 0 & 0 & 0 & 0 & 0 & 0 \\
\hline Cumu Hours: & 0 & $0]$ & 0 & 0 & 0 & 0 & 0 & 0 & 0 & 0 & 0 & 0 \\
\hline Monthly Price: & 0 & 0 & 0 & 0 & 0 & 0 & 0 & 0 & 0 & 0 & 0 & 51 \\
\hline Cumu Price: & 0 & 0 & 0 & 0 & 0 & 0 & 0 & 0 & 0 & 0 & 0 & 51 \\
\hline
\end{tabular}

Budget:

Morithly Hours:

Cumu Hours:

Monthly Price:

\begin{tabular}{r|r|}
\hline 0 & 0 \\
\hline 0 & 0 \\
\hline 0 & 0 \\
\hline 0 & 0 \\
\hline
\end{tabular}

\begin{tabular}{|c|c|c|c|c|}
\hline 0 & 0 & 0 & 0 & 0 \\
\hline & 0 & 0 & 0 & 0 \\
\hline & 0 & 0 & 0 & 0 \\
\hline & 0 & 0 & 0 & 0 \\
\hline
\end{tabular}

\begin{tabular}{l|r|}
0 & 0 \\
0 & 0 \\
0 & 0 \\
\hline 0 & 0
\end{tabular}

\begin{tabular}{|c|c|c|c|c|}
\hline 0 & 0 & 0 & 0 & 162 \\
\hline 0 & 0 & 0 & 0 & 162 \\
\hline 0 & 0 & 0 & 0 & 21,420 \\
\hline 0 & 0 & 0 & 0 & 21,420 \\
\hline
\end{tabular}


WASTE POLICY INSTITUTE MONTHLY REPORT TO THE EERC, AUGUST 1996

APPENDIX E 



\section{UNIVERSITY OF NORTH DAKOTA ENERGY AND ENVIRONMENTAL RESEARCH CENTER}

Monthly Report August, 1996

\section{TECHNOLOGY DEVELOPMENT INTEGRATION WPI SUBCONTRACT NUMBER 359636}

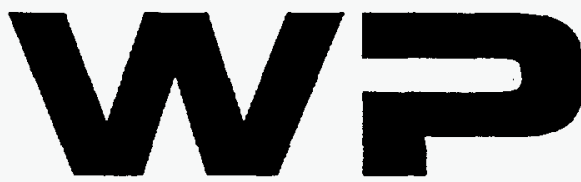

Waste Policy Institute A Virginia Tech Affilioted Corporation 

SUBCONTRACT NUMBER: 359636

Report Period: 8/1/96-8/31/96

CONTRACTOR NAME: Waste Policy Institute 555 Quince Orchard Road

Suite 600

Gaithersburg, MD 20878-1437

CONTRACT PERIOD: $\quad 6 / 28 / 95-12 / 01 / 96$

\section{SUBCONTRACT DELIVERABLES:}

This report is submitted in fulfillment of requirements specified for the University of North Dakota Energy and Environmental Research Center (UNDEERC) Subcontract Number 359636. A list of products developed under this subcontract is provided as Attachment A.

\section{SUMMARY OF ACTIVITIES:}

The WPI team provided support for each focus area's Ten Year Plans.

\section{TASK A-TECHNOLOGY ASSESSMENT}

\section{TANKS FOCUS AREA (TFA)}

\section{SUBSURFACE CONTAMINANTS FOCUS AREA (SCFA)}

Staff members created the presentation slides for the FY97 PEG Review. Included in this report were the FY96 carryover estimates, financial charts on funding levels by product line and TD funding per site over a three year period, the Workscope Priority List, the updated WBS for the FA including the new Product Line Managers and an analysis of the Quick Wins lost due to funds redistribution.

Members of the team created and delivered the Technology Council Meeting presentation to DOE-SR. The presentation addresses the PEG Funding Levels $(70,80$ and $85 \%)$ with the corresponding impacts of technologies delayed or concealed. The Ten Year Plan and the GAO Report response were also included in the presentation. Included in this product were talking notes to the letter to Gerald Boyd regarding the transfer of projects to the Mixed Waste Focus Area.

Draft input to a letter to Gerald Boyd regarding PFA/LSFA funding at the Savannah River Site was prepared. Analysis of funding trends and the technical basis for focus area funding at SRS was provided for the Fiscal Years FY1994 through FY1997. 


\section{DECONTAMINATION AND DECOMMISSIONING (D\&D) FOCUS AREA}

The WPI team conducted a review of Tecogen's Thermo Alpha Monitor Phase I Report and provided comments from that review. The WPI team provided a technical review of the theory underlying the proposed instrument as well as a needs analysis of the fully developed product.

The WPI team reviewed and provided comments for ESP PRDA Solicitation No. DERA21-95MC32195 Proposal Entitled "Removal of Contaminants from Equipment and Debris and Waste Minimization Using the TECHXTRACT TM Technology." Members of the team also assisted DOE in determining the need of this technology in the DOE D\&D Program and also reviewed the technical feasibility of the proposed process.

Staff members prepared a lesson plan and provided health physics instruction to D\&DFA personnel on August 26. This training was designed to assist DOE's D\&DFA Project Managers understand radiological issues surrounding surplus facilities and the D\&D program. This training was provided by WPI's certified health physicist.

The WPI team completed the status report on depleted uranium hexafluoride. This report will assist the D\&D Focus Area in assessing the need for R\&D related to uranium hexafluoride.

Members of the team participated in the 3-day workshop held with the Russian Delegation for the purpose of discussing possible research in support of the D\&D Focus Area.

\section{MIXED WASTE FOCUS AREA (MWFA)}

Staff members provided a review of a TTP deliverable schedule and incorporated information from MWFA FY96 TTPs into the schedule.

Background and inventory information was prepared and submitted to the MWFA to support a presentation developed by Richard Kimmel from the MWFA regulatory and stakeholder division.

The WPI team reviewed FY97 PEGs and condensed verbiage as part of a TTP status reporting project.

The1996 and 1997 PEGs and TTPs were reviewed to provide a crosswalk with the EM50 milestone project.

Staff members collected input from Principal Investigators and formatted and prepared a draft submittal for MWFA input for the1996 Office of Technology Development Annual Report to Congress. 
The WPI team participated in a meeting to brief Julie Conner on status of MWFA comments on Proposed Combustion Rule changes.

Work to assess EM-40 needs and prepare Preferred Alternative Matrices for complexwide EM-40 containerized wastes was initiated by team members.

The WPI team discussed strategy for finalizing the Draft Site Regulatory Summaries with Richard Kimmel. Draft Summaries are being reviewed by Dave Eaton (LMITCO) before being finalized, distributed, and placed on the MWFA Home Page by the end of September.

Team members revised MWFA Technology Development Requirements Documents.

The staff submitted a revised draft Technology Development Requirements Document for High Efficiency Particulate Air Filter.

These documents were reviewed to support participation in DOE-ID meetings:

Integrated Thermal Treatment Systems Study (draft)

Integrated Non-thermal Treatment Systems Study (draft)

Comparison of Integrated Thermal Treatment Systems and Integrated Non-

thermal Treatment Systems for Mixed Low Level Waste Report (draft)

Staff members assisted the team that conducted the technical review of the Integrated Non-thermal Treatment Systems Study and Comparison of Integrated Thermal Treatment Systems and Integrated Non-thermal Treatment Systems for Mixed Low Level Waste Report. A working summary of points raised during discussions was prepared and submitted.

\section{TASK B-PROJECT ASSESSMENT}

\section{TANKS FOCUS AREA (TFA)}

The staff prepared a TFA briefing package for the Manager of the Richland Field Office to use at the Office of Science and Technology Big-5 meeting. The meeting was a roundtable discussion about planned development operations across all sites. The package included materials about current and future development efforts of the TFA as well as an information package for FY97 technology development at the Hanford site.

The draft Program Execution Guidance (PEG) was prepared by the staff for DOE-RL with cooperation from the Battelle Pacific Northwest National Laboratory (PNNL) and transmitted to DOE-HQ. Attachment F, a prioritized list of Technical Task Plan (TTP) tasks, was also prepared and submitted with the PEG. After review of the draft, revisions to separate tasks put on hold were made to the PEG in accordance with guidance from DOE-HQ, and it was re-submitted with the changes. 
Staff completed a first draft of the Hanford EM-30 budgets for technology from FY95 to FY98. This was forwarded on to Jim Poppeti of EM-30. This will be combined with EM-50 budgets in order to develop a database to track technology development for tanks.

The staff prepared a Program Review briefing for the TFA to present to DOE-RL management which gave a current status of the program. Information about the Light Duty Utility Arm (LDUA), PEG, and Technical Team were included in the material.

A June Business Review was prepared by the staff for TFA to present to DOE-HQ containing current cost/budget, milestones, performance measures, accomplishments, and issues in the program.

Staff attended the International Topical Meeting on Nuclear and Hazardous Waste Management, Spectrum-96, in Seattle, Washington, August 18-22, 1996. Staff managed TFA exhibits and worked the sessions to support the meeting.

The team drafted a revised TFA Management Plan and met with DOE-RL to discuss a strategy for updating and distributing the plan. The strategy will include a formal review comment record, and a second distribution to the team for final comments before publication.

A draft formal response addressing all review comments regarding the TFA Management Plan was prepared by the staff. The responses were recorded in a table and provided to DOE-RL for distribution. Also, the staff drafted a memo to DOE-RL suggesting followon actions for the Management Plan including revising the Roles and Responsibilities document and final review by the Site Reps and the Technical Team.

Members of the team updated the Annual Report to Congress (ARC) for the Tanks Focus Area. Technologies to be included in the ARC were proposed to the TFA by the team, and one-page write ups for each were submitted to DOE-HQ.

The WPI team finalized meeting minutes and action items from the TFA Denver Workshop. A distribution memo was drafted along with the minutes and distributed to all attendees.

The team prepared a transmittal memo to DOE-RL for two TFA deliverables, one on the Raman Probe and the other on Ultrasound to improve sludge washing. It appears that TFA deliverables from other sites are still not being transmitted to DOE-RL.

The WPI team reviewed the Hanford Tanks Initiative (HTI) Program Plan, and met with DOE-RL to discuss a strategy for cooperative funding and management of the project between EM-50 and EM-30. An investigation of legal budgeting practices for funding the HTI was initiated. 
A tour agenda, list of upcoming Record of Decisions (RODs), and talking points for Carl Bauer's (EM-50) visit to Richland were prepared by the staff. Team assisted with various duties as DOE-RL hosted the tour on August 7, 1996.

The team developed inputs and comments from a review of the Ten Year Plan for Hanford and Savannah River Sites. The data will be used by DOE for development of a national program to clean up radioactive contaminated area. The review data was submitted to DOE-RL.

Staff prepared a draft of the Ten Year Plan TFA Budget Profile for the Focus Area and forwarded to the customer. The budget profile was only partially completed since the best data available was from the TFA MYPP which goes through FY99. Data for the Years FY00 through FY06 needs to be based upon innovative technology project definitions that respond to Ten Year Plan challenges or needs for breakthrough technologies. These have not yet been formulated for a variety of reasons.

\section{SUBSURFACE CONTAMINANTS FOCUS AREA (SCFA)}

The WPI team performed a technical review of the DOE Oak Ridge (OR) Operations Office Draft Ten Year Plan (TYP) to ensure that SCFA technology development activities have been appropriately included in the planning process. The team arrived at the conclusion that there is an insufficient level of detail in the document to ascertain whether or not SCFA technologies were considered when the DOE-OR TYP baseline was established. The WPI team created a database that identifies SCFA technologies that are potentially applicable to remediation problems at DOE-OR sites. The team will continue to review the remaining Ten Year Plans and will report the results separately as soon as the reviews are complete.

The WPI team performed a technical review of the DOE Richland Operations Office Draft TenYear Plan (TYP) focusing primarily on the extent to which SCFA technologies were considered and included in the TYP, what gaps exist, and where innovative technologies are needed, based on the site's needs identification process. There were some technology needs identified as high priority for remedial actions and are most relevant to the SCFA mission.

Team members prepared SCFA input into the Ten Year Plan presentation by DOE-SR for the visit by Al Alm. Information was provided for reviewing all Operations Offices Ten Year Plan input to Headquarters, modifying SCFA strategic plans, Basic Science needs, SCFA technologies address site needs and support for Ten Year Plan goals, and technology gaps.

The WPI team delivered input for a memo prepared from the SCFA Lead Office to the TPOs requesting that milestones in PTS that are currently classified as TYPE "PEG" be reclassified as TYPE "OTH" in accordance with the April 1996 EM-54 Memo (Quality of PTS Reported Data) from Gerald Boyd. 
The WPI team produced and delivered weekly reports for the Subsurface Contaminants Focus Area covering the weeks of June 21, July 5, July 12, July 26, and August 2.

Staff delivered the Subsurface Contaminants Focus Area Progress Reports for the Months of April and May.

Team members completed the Monthly Business Review briefing for Landfill and Plumes Focus Areas. One copy of a backup book with detailed information on cost variances, overdue milestones and copies of Program Manager's reports has also been prepared and delivered. Also, a copy of the July briefing on Carryover has been included with an updated slide to show changes in carryover data in August.

The WPI team generated a Performance Measure list from the Program Manager Measurement Tool (PMTT) which has been updated with the June PTS data. This list is provided to the Program Execution Manager for SCFA to assist in the confirmation of Performance Measures completed in FY96 for the Quarterly report.

\section{DECONTAMINATION AND DECOMMISSIONING (D\&D) FOCUS AREA}

A WPI team member prepared a meeting record of the Fernald Plant-1 Large Scale Demonstration Project meeting held on July 30, 1996. The WPI team member also serves as the coordinator for completion of outstanding action items by the Integrating Contractor Team.

The WPI team prepared a booklet capturing the results of the July 24-25, 1996 D\&D National Needs Assessment meeting held at METC. The booklet was used as supporting material for the August 7-8, 1996 D\&D basic research needs workshop held in Roanoke, Virginia.

The WPI team prepared four briefings for key D\&D Focus Area personnel for presentation at the August 7-8, 1996 workshop in Roanoke, Virginia. The briefings were crafted in coordination to guide the activities of the workshop entitled, "Defining Basic Research Needs."

A WPI team member attended the DOE National Decommissioning Meeting held on August 6 through August 8 in Oak Ridge, Tennessee. WPI actively participated in the meeting's dialogue and identified issued which effect the D\&DFA. Following the meeting, the team member developed and delivered a meeting record concerning D\&DFA-related topics.

A WPI team member provided a cost evaluation of C-Reactor disposition alternatives. This evaluation provided economic information and discussion on the following disposition alternatives: current-day one-piece removal; deferred one-piece removal; 
safe-storage with deferred one-piece removal; and safe-storage with deferred entombment.

A WPI team member resolved D\&DFA action items from the July C-Reactor IC Team meeting. These action items included data gathering on the following technologies: Liquid Gas Cutting; Metal Disintegration; Electro-kinetic Decon; and Microwave Decon. The results of the data gathering effort were provided to the project principal investigator in a memorandum dated August 21, 1996.

SPECTRUM ' 96 in Seattle, Washington was attended by a WPI team member. This week-long conference included environmental professionals from government, academia, and private industry. Each day included poster presentations by environmental technology developers and vendors; plenary sessions with briefings on ongoing environmental $R \& D$, remediation, and policy reform efforts; and a poster session highlighting ongoing R\&D by the DOE Office of Science and Technology. In support of the D\&D Focus Area, the team provided the technical and programmatic interface to the public for the D\&D Focus Area's Poster.

Following SPECTRUM ' 96 in Seattle, the D\&D Focus Area conducted a workshop with representatives from the National Commission of Atomic Energy (CNEA) of the Republic of Argentina. This workshop was attended by a team member. The purpose of this meeting was to outline and sign an agreement describing a path forward for cooperative technology demonstration between the D\&D Focus Area and CNEA. CNEA has a contaminated plutonium glovebox facility and they are seeking new and innovative technologies and techniques in order to decommission the facility. Over the next 12 to 15 months, the D\&D Focus Area will work with CNEA to characterize the problems at this facility, conduct a small-scale decontamination/dismantlement demonstration on a single glovebox, and then, if feasible, conduct a full-decommissioning of the NEA facility.

The WPI team provided technical support to the D\&D Focus Area in further refining its R\&D investment strategy. This project includes evaluation of identified technical needs relative to available commercial $D \& D$ technologies and ongoing technology $R \& D$ efforts. In addition, the focus area is assessing the site generated Ten Year Plans to verify the degree to which identified needs are documented, as well as to identify additional needs which may be elucidated within the Ten Year Plans. As one step in helping to plan and select R\&D projects for the D\&D Focus Area Technology Development Portfolio, WPI staff gathered information for the D\&D technology development investment opportunities assessment matrix in the areas of baseline technologies, commercially available technologies, and technologies in development.

WPI staff reviewed the environmental management Ten Year Plans for the Savannah River Site, Ohio Operations Office sites, and Albuquerque sites to find data related to the Large Scale Demonstration Projects (LSDs) that have been proposed by those sites. This information is needed to predict the schedule for implementation of D\&D at the facilities 
proposed by those sites, and to estimate the window of opportunity for conducting a D\&D LSD Project.

The WPI team analyzed 14 LSD proposals to abstract basic information to prepare data sheets, requested funding summary sheets, and summary fact sheets for use by the METC reviewers of the proposals. Team staff also prepared data summaries related to the contaminants and radiation levels in the LSDs and compared it to Title 10 of the Code of Federal Regulations - Part 835, or the Radiological Control Manual. We also prepared graphs to categorize the $14 \mathrm{LSD}$ proposals as predominantly demonstrating technologies for characterization, decontamination, dismantlement, material disposition, or D\&D support. This information will assist the reviewers and D\&D Focus Area staff in planning the distribution of LSD project types for the future.

The WPI team prepared the final copies of the Program Execution Guidance documents for FY97 for the D\&D Focus Area based on METC staff direction and input.

The staff provided technical input to the D\&D Focus Area Monthly Report of the technical task work accomplished by the Focus Area Principal Investigators (PIs) during June, and assisted in the collection, review, and editing of monthly input from the PIs. We also guided the production and distribution of the May Report. These reports inform interested parties of the monthly progress being made by the D\&D Focus Area.

\section{MIXED WASTE FOCUS AREA (MWFA)}

Team members supported the INTS/ITTS Stakeholder/Tribal meeting and Independent Peer Review Panel by assisting in planning the meeting, organizing computer and staff support, and providing materials for sessions at the Holiday Inn West Bank the week of August 5-9.

The WPI team supported the INTS/TTTS Stakeholder/Tribal meeting and Independent Peer Review Panel by providing a summary report of the meetings notes, conversations, and flip chart information.

Project management services for the technical resource team members under the WPI contract were performed. Activities included reviewing weekly reports, evaluating cost and expenditure information, and obtaining travel approvals for necessary meetings by the members.

\section{TASK C-TECHNOLOGY INTEGRATION}

The WPI team developed the slide presentation for the SPECTRUM ' 96 Conference in Seattle. Included were $35 \mathrm{~mm}$ slides and talking notes in the form of fact sheets for the eight featured technologies. The benefits of the consolidation were summarized and an overview of the product lines and the goals of the SCFA was prepared and preceded the technology section. 
Staff members completed an analysis of the SCFA program for items significant to the Council of Energy Resource Tribes (CERT). The team identified areas for potential input by CERT members and prepared these findings as view graphs for the CERT Meeting on August 26-27 in Denver, CO.

A screening of the inventory of the Subsurface Contaminants Focus Area technologies was conducted and those that are mature enough for commercialization were identified. A list of these technologies was compiled and sent by e-mail to GETE.

The WPI team coordinated and conducted the Product Line Manager Transition Meeting which was held at Savannah River on August 6, 1996. The team then produced a record of all meeting activities noting that there are several action items which will need to be addressed by the Lead Office in the near future.

A report summarizing work toward development of a decision support software system (DSS) was produced. This included defining the data requirements and responsibilities of the system to support program planning in the SCFA as well as, providing guidance to the group developing the EM-50 DSS under a METC contract.

A Top 20 TTP Hit List was published with the Office of Science and Technology's June Progress Tracking System (PTS) Summary Notes. The TTPs on this list exceeded the cost and/or schedule variance thresholds and the PTS narratives did not fully explain the variances or provide corrective action. The team contacted the field offices and notified them of the TTPs within their areas that appeared on the list and the corrective action that DOE required. The team is helping to ensure that corrective actions are taken to correct the problems and assisting in the clean-up of the problems where appropriate.

Staff members participated in providing assistance to the Subsurface Contamination Focus Area in health and safety issues related to taking samples at an Environmental Restoration site, the TSF-1 injection well operable unit.

The WPI team prepared a mailing list with name, title, telephone, fax and e-mail addresses of the Community Leaders Network (CLN) Tanks Working Group representatives for DOE-RL to use in distributing TFA program information to stakeholders.

Members of the staff assisted with the screening of Robotics Technology Development Crosscutting Program Coordinator's Reports for milestones completed, and to support compilation of a list of completed milestones for subsequent comparison with completions reported in the Progress Tracking System (PTS).

The staff assisted with the completion of an updated list of Robotics Technology Development Crosscutting Program acronyms and abbreviations. This activity was in 
response to frequent informal field comments requesting definitions of acronyms used in robotics correspondence and Coordinator's Reports.

Team members assisted with the development of a draft table entitled Private Sector/Other Government Agencies Cost Share relative to Robotics technologies. For each technology, the table included the leveraging partner, the service provided by that partner, a description of the data resulting from the technology, and an indication of the technology's inclusion in a Program Research and Development Announcement, Cooperative Research and Development Agreement, or Business Agreement.

WPI team members assisted with the development of a Robotics Milestones table to be used in developing a Long-Term Project Schedule for DOE Field and Headquarters (EM54) use.

The staff reviewed the draft Ten Year Plans for Albuquerque and Carlsbad to identify Efficient Separations Crosscut Program technology related issues.

The team assisted in the review of the Federal Register, Environment Reporter, and the DOE Newsclips to identify environment, safety, health, and quality issues of potential or actual impact on OST.

Team members provided assistance with the tracking and analysis of legislative and regulatory actions on environment, safety, and health matters of interest to OST.

WPI team members supported the development of narrative for the Monthly EM National Environmental Policy Act (NEPA) Report.

The staff commenced support for identifying technologies which may qualify for participation in the Environmental Protection Agency's Project XL reinvention program.

The Site Ten Year Plan submittals to evaluate the use of TFA innovative technologies in achieving cost savings and risk reduction were reviewed.

The staff provided assistance with the development and updating of Program Execution Guidance for Domestic Technology Systems Applications. Activities included attending meetings, writing draft guidance, editing documents, and researching information and changes.

Team members assisted with the gathering, assembling and organization of two separate batches of documentation on numerous technologies currently under development. These documents were collected and passed on to Information for Decisions for incorporation on various electronic home pages. 
The WPI team prepared miscellaneous briefing visuals on the subject of integrating technology development into DOE decision-making for presentation to METC at a meeting which was held on August 14, 1996.

The staff provided support for updating the Decision Paper on Priority Setting Recommendations to the OST Council.

Team members compiled data on SBIR and STTR activities for FY93 through FY96.

WPI team members researched and analyzed relevant state legislative and regulatory activity, and wrote and distributed the August "State Environmental Watch."

The staff researched and tracked Federal environment and technology legislation potentially impacting the field, particularly the National Defense Authorization Act for FY97 and the Energy and Water Development Appropriations Act for FY97.

The staff provided assistance with the researching, tracking and distribution of quick-read reports on the status of the ongoing FY97 appropriations process as it impacts DOE's Environmental Management program and technology development issues at the field level.

Team members researched follow-up information requested by the Aiken office on DOE's announced plans to privatize WETO.

The staff provided assistance with the research of information requested by the Richland office on privatization support service contractor language in the Defense Authorization Conference Report.

The team forwarded relevant BNA articles of interest to field.

The staff provided technical support for the Oak Ridge Tanks Focus Area (OR TFA) Program Manager.

Members of the team participated in the Cesium Removal Demonstration Project Weekly Team Meeting and reported on status of the project.

The staff conducted technical reviews, provided comments, met with other team members, gathered group comments, prepared and submitted summary of comments on the revised and final draft Memorandum of Understanding for the Oak Ridge Cesium Removal Demonstration and Savannah River Vitrification Demonstration.

The WPI team participated in the Site Technology Coordination Group (STCG) Subgroup Leaders' Meeting and STCG Meeting and drafted highlights of meetings. 
The staff coordinated with OR Operations and Savannah River Site management on project activities.

Team members provided assistance with the completion of the report on needs assessments conducted within the DOE Focus Areas. This report delineated processes for collecting and addressing Focus Area needs. Observations and suggestions on integrating and standardizing activities were included for potential value added.

\section{TASK D- SYSTEMS ENGINEERING}

Following an analysis of the INEL reports, the Systems Engineering Template was completed and supporting explanation strengthened and amplified by the team.

A member of the team attended the review of LITCO presentations at INCOSE in Boston and provided a critical review of that Systems Engineering Process as compared to the template.

WPI team reviewed the draft final report and provided suggested wording changes, organizational points, and suggestions regarding final report presentation. 
ATTACHMENT A

PRODUCTS DELIVERED: TASK A - TECHNOLOGY ASSESSMENT

TANKS FOCUS AREA (TFA)

SUBSURFACE CONTAMINANTS FOCUS AREA (SCFA)

- Slide Presentation FY97 PEG Review

- Slide Presentation and delivery for Technology Council Meeting to DOE-SR

- Draft Input to Letter to Gerald Boyd, re: PFA/LSFA Funding at Savannah River

DECONTAMINATION AND DECOMMISSIONING (D\&D) FOCUS AREA

- Review of Thermo Alpha Monitor (TAM) Phase I Report (8/8/96)

- Review of Techxtract Proposal (8/21/96)

- Status Report on Depleted Uranium Hexafluoride

MIXED WASTE FOCUS AREA (MWFA)

- Annual Report to Congress (draft)

- Mixed Waste Focus Area Technology Development Overview

\section{PRODUCTS DELIVERED: TASK B: PROJECT ASSESSMENT}

TANKS FOCUS AREA (TFA)

- Review of MWFA Comments on TFA Waste Form TTPs

- DOE-RL Monthly Program Review.

- Talking points and viewgraphs on Recent and Upcoming Hanford Record of Decisions for TFA presentation to C. Bauer, DOE-HQ

- Review of deliverables from TTP RL36WT41, Complete Draft Report on Caustic Leaching Improvement Tests, and TTP RL46WT21, Raman CPT Probe

Radiation/Chemical Impact Test 
- FY 1997 TFA Program Execution Guidance (PEG), Attachment F (Prioritized List of TTP Tasks), and draft transmittal memorandum to DOE-HQ from TFA

- Draft Ten Year Plan Budget Profile for TFA funding

- Review comments for Richland and Savannah River Ten Year Plans

- Matrix of TFA TTP tasks, need numbers, and users

- Briefing Book for Office of Science and Technology (OST) Board Meeting

- Hanford EM-30 Budget for Technology

- Business Review Briefing (June 1996)

- Statement of Work for Third Party Review for TFA

- Draft TTP Guidance Memorandum for DOE-RL

- Tanks Focus Area Management Plan, Revision 4.0

- Agendas and Updates/Actions from TFA teleconferences (August)

SUBSURFACE CONTAMINANTS FOCUS AREA (SCFA)

- Technical Review DOE-OR Operations Office Ten Year Plan

- Technical Review DOE-RL Operations Office Ten Year Plan

- Slide Presentation by DOE-SR to Al Alm re: Ten Year Plan Input for memo from SCFA Lead Office to TPOs re: PEG Type Reclassification from "PEG" to "OTH"

- Weekly Reports - June 21 through August 2

- SCFA Progress Reports for April and May

- Monthly Business Review Briefing for LSFA and PFA

- Performance Measure List from PMTT

DECONTAMINATION AND DECOMMISSIONING (D\&D) FOCUS AREA

- Fernald Plant-1 Large Scale Demonstration Project Meeting Record

- Results of the 1996 D\&D National Needs Assessment, July 24-25, 1996 
- Four briefings in support of the D\&D Workshop, "Defining Basic Research Needs"

- DOE National Decommissioning Committee Meeting Highlights (8/14/96)

- C-Reactor Disposition Alternatives Cost Comparison (8/27/96)

- Response to July C-Reactor IC Team Action Items

- D\&D Focus Area Monthly Report - May

- Final D\&D Focus Area FY97 Program Execution Guidance documents MIXED WASTE FOCUS AREA (MWFA)

- July Monthly Report

\section{PRODUCTS DELIVERED: TASK C: TECHNOLOGY INTEGRATION}

- Community Leaders Network mailing list

- Suggested narrative for inclusion in the monthly EM NEPA report.

- Updated List of Robotics Acronyms and Abbreviations

- Miscellaneous briefing visuals for METC briefing held on August 14, 1996.

- Minutes from Oak Ridge Cesium Removal Demonstration Project Weekly Team Meeting held on August 14, 1996.

- Tanks Focus Area Weekly Teleconference Minutes, dated August 13, 1996.

- Comments on the Revised Memorandum of Understanding for the Oak Ridge Cesium Removal Demonstration and Savannah River Vitrification Demonstration, held on August 9, 1996.

- Minutes from Oak Ridge Site Technology Coordination Group Meeting, August 8, 1996.

- Site Technology Coordination Group Subgroup Leaders' Meeting Minutes, August 6, 1996. 
- Tanks Focus Area Weekly Teleconference Meeting Minutes, August 6, 1996.

- Slide Presentation for Spectrum '96 for SCFA

- Presentation Materials in support of the meeting with Council of Energy Resource Tribes

- Identification list of technologies available for commercialization in the SCFA

- Meeting Record PLM Transition Meeting

- Report Summarizing Work for Development of a Decision Support Software System (DSS) 


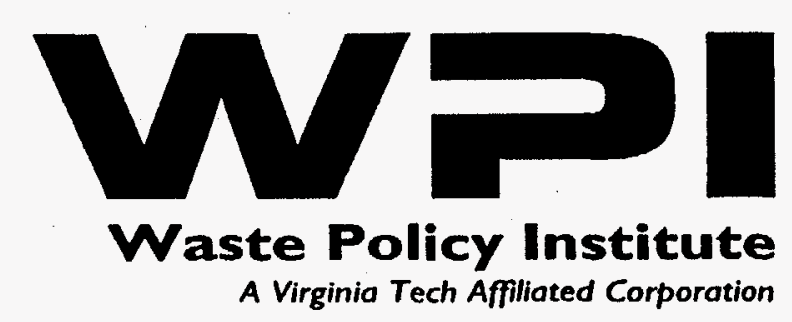

\section{MONTHLY \\ COST AND LABOR REPORT}

\section{UNIVERSITY OF NORTH DAKOTA ENERGY AND ENVIRONMENTAL RESEARCH CENTER}

Subcontract No. 359636

August, 1996 


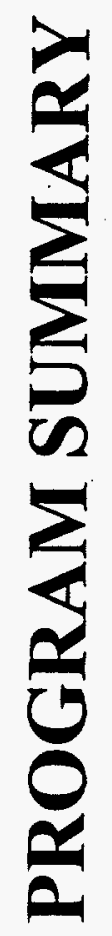




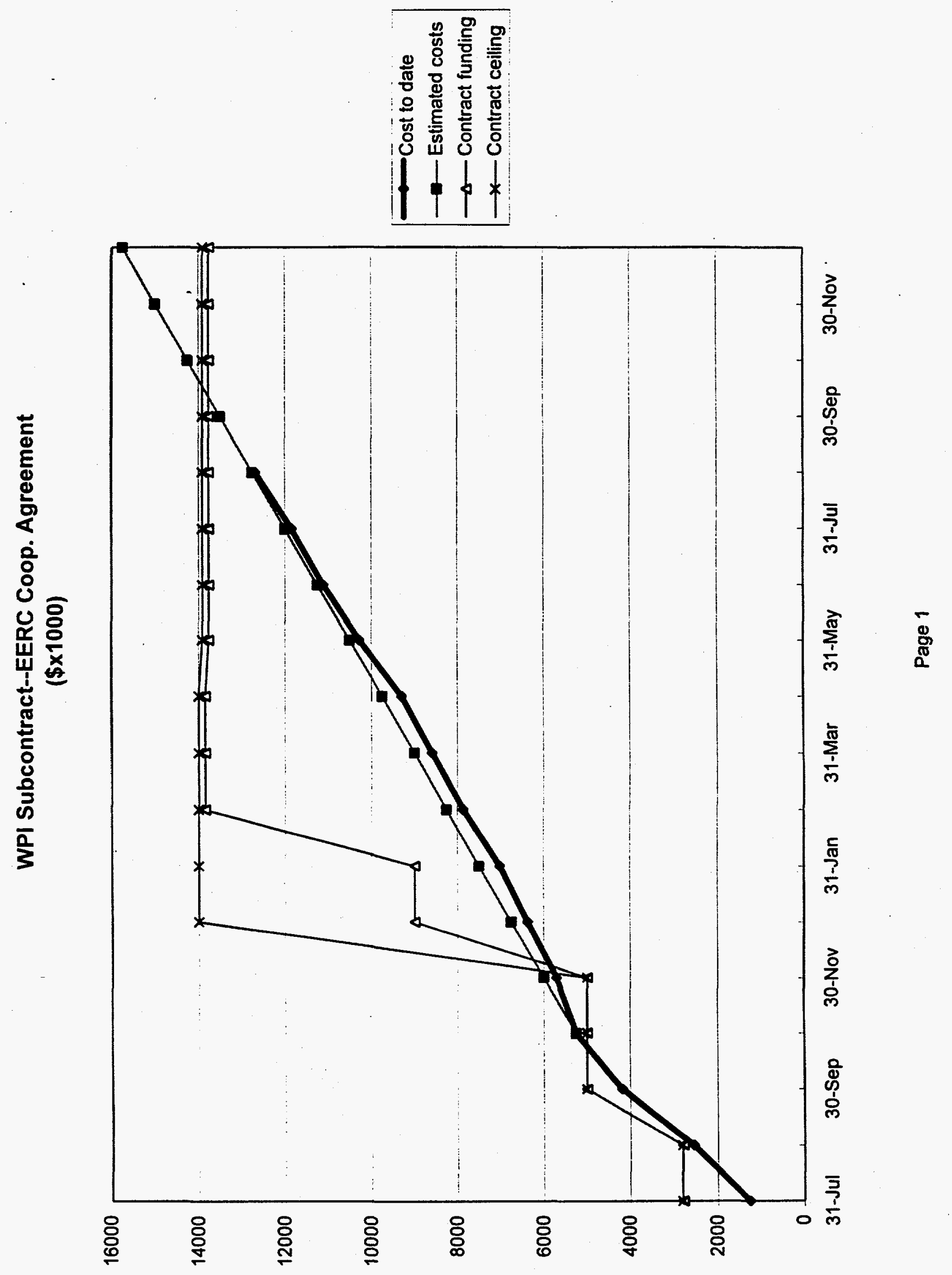


Subcontract No. 359636

Actuals through August 96

WBS: 1043 EERC

Manager: Dr. John S. Wilson

Start Date: $6 / 27 / 95$

End Date: 12/1/96

Task Description: Provide assistance to EERC's conduct of technology development integration activities.

Cost Performance Summary:

\begin{tabular}{|c|c|c|c|}
\hline & \multicolumn{3}{|c|}{ Current Period } \\
\hline & Budget & Actuals & Variance \\
\hline ours: & 10,668 & 11,071 & -402 \\
\hline Price: & 839,498 & 835,492 & $4, \overline{006}$ \\
\hline
\end{tabular}

\begin{tabular}{|c|c|c|}
\hline \multicolumn{3}{|c|}{ Inception to Date } \\
\hline Budget & Actuals & Variance \\
\hline 168,958 & 150.192 & 18,766 \\
\hline $13,262,486$ & $12,685,055$ & 577,431 \\
\hline
\end{tabular}

\begin{tabular}{|c|c|c|}
\hline \multicolumn{3}{|c|}{ At Complete } \\
\hline Budget & Estimate & Variance \\
\hline 179,950 & 161,184 & 18,766 \\
\hline $14,144,823$ & $13,567,393$ & 577,431 \\
\hline
\end{tabular}

Monthly Financial Recap:

\begin{tabular}{|c|c|c|c|c|c|c|c|c|c|c|c|}
\hline Jun 95 & Jul 95 & Aug 95 & Sep 95 & Oct 95 & Nov 95 & Dec 95 & Jan 96 & Feb 96 & Mar 96 & Apr 96 & May 96 \\
\hline
\end{tabular}

Actuals:

Monthly Hours:

Cumu Hours:

Monthly Price:

\begin{tabular}{|c|c|c|c|c|c|c|c|c|c|c|c|}
\hline 149 & 15,710 & 17.723 & 19,161 & 10,639 & 6,367 & 6,669 & 6,932 & 8,057 & 8,562 & 8,653 & 11,408 \\
\hline 149 & 15,859 & 33,582 & 52,743 & 63,382 & 69,749 & 76,418 & 83,350 & 91,408 & 99,970 & 108,623 & 120,031 \\
\hline 8,492 & $1,240,210$ & $1,300,381$ & $1,628,866$ & $1,072,629$ & 508,957 & 674,480 & 577,622 & 844.119 & 734,699 & 707,388 & 982,181 \\
\hline 8,492 & $1,248,702$ & $2,549,083$ & $4,177,949$ & $5,250,578$ & $5,759,535$ & $6,434,015$ & $7,011,637$ & $7,855,755$ & $8,590,455$ & $9,297,843$ & $10,280,023$ \\
\hline
\end{tabular}

Budget:

Monthly Hours:

Cumu Hours:

Monthly Price:

\begin{tabular}{|r|r|}
\hline 1,437 & 18,428 \\
\hline 1,437 & 19,865 \\
\hline 89,294 & $1,251,829$ \\
\hline 89,294 & $1,341,124$ \\
\hline
\end{tabular}

\begin{tabular}{|c|c|c|}
\hline 22,308 & 10,570 & 10,506 \\
\hline 42,173 & 52,743 & 63,249 \\
\hline $1,454,843$ & $1,381,982$ & 818,078 \\
\hline
\end{tabular}

$10,506]$

10,506

$$
10,506
$$

10,506

\begin{tabular}{|r|r|}
\hline 10,506 & 10,669 \\
\hline 126,286 & 136,954 \\
\hline 818,078 & 839,498 \\
\hline $9,904,494$ & $10,743,992$ \\
\hline
\end{tabular}

Cumu Price: \begin{tabular}{lll}
89,294 & $1,341,124$ & $2,795,967$ \\
$4,177,949$ & $4,996,027$ \\
\hline
\end{tabular}

\begin{tabular}{r|r|}
\hline 818,078 & 818,078 \\
\hline $5,814,106$ & $6,632,183$ \\
\hline
\end{tabular}

94,767

105,273

$\begin{array}{r}10,506 \\ \hline 115,779 \\ \hline 818,078 \\ \hline 9,086,417 \\ \hline\end{array}$

$8,268,339$

743,992 
Subcontract No. 359636

Actuals through August 96

Start Date: 6/27/95

End Date: 12/1/96

Task Description: Provide assistance to EERC's conduct of technology development integration activities.

Cost Performance Summary:

\begin{tabular}{|c|c|c|c|}
\hline & \multicolumn{3}{|c|}{ Current Period } \\
\hline & Budget & Actuals & Variance \\
\hline ours: & 10,668 & 11,071 & -402 \\
\hline Price: & 839,498 & 835,492 & 4,006 \\
\hline
\end{tabular}

\section{Inception to Date}

\begin{tabular}{|c|c|c|}
\hline Budget & Actuals & Variance \\
\hline 168,958 & 150,192 & 18,766 \\
\hline $13,262,486$ & $12,685,055$ & 577,431 \\
\hline
\end{tabular}

\begin{tabular}{|c|c|c|}
\hline \multicolumn{3}{|c|}{ At Complete } \\
\hline Budget & Estimate & Variance \\
\hline 179,950 & 161,184 & 18,766 \\
\hline $14,144,823$ & $13,567,393$ & 577,431 \\
\hline
\end{tabular}

Monthly Financiai Recap:

\begin{tabular}{|c|c|c|c|c|c|c|c|c|c|c|c|c|}
\hline & Jun 96 & Jul 96 & Aug 96 & Sep 96 & Oct 96 & Nov 96 & Dec 96 & Jan 97 & Feb 97 & Mar 97 & Apr 97 & May 97 \\
\hline \multicolumn{13}{|l|}{ Actuals: } \\
\hline Monthly Hours: & 8,782 & 10,309 & 11,071 & 0 & 0 & 0 & & & & & & \\
\hline Cumu Hours: & 128,813 & 139,122 & 150,192 & 150,192 & 150,192 & 150,192 & & & & & & \\
\hline Monthly Price: & 829,253 & 740,287 & 835,492 & 0 & 0 & 0 & & & & & & \\
\hline Cumu Price: & $11,109,276$ & $11,849,563$ & $12,685,055$ & $12,685,055$ & $12,685,055$ & $12,685,055$ & & & & & & \\
\hline
\end{tabular}

Budget:

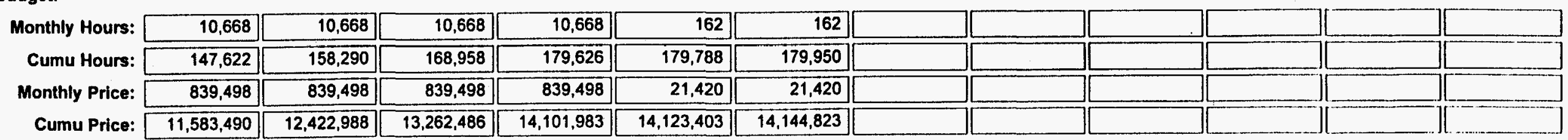


$\frac{4}{4}$ 
Subcontract No. 359636

Actuals through August 96

WBS: 1043.01.01 Technology Management

Manager: Dr. John S. Wilson

Start Date: 6/27/95

End Date: 12/1/96

Task Description: Perform technical reviews of requirements, needs and assessments related to waste characterization, containment, in-situ and ex-situ treatment, wasle storage,

disposal, robotics handling, monitoring, laboratory analysis, site characterization and remediation.

Cost Performance Summary:

\begin{tabular}{|c|c|c|c|}
\hline & \multicolumn{3}{|c|}{ Current Period } \\
\hline & Budget & Actuals & Variance \\
\hline Hours: & 5.474 & 2,528 & 2.946 \\
\hline Price: & 297,160 & 250,563 & 46,597 \\
\hline
\end{tabular}

\begin{tabular}{|c|c|c|}
\hline \multicolumn{3}{|c|}{ Inception to Date } \\
\hline Budget & Actuals & Varlance \\
\hline 81,982 & 60,569 & 21,413 \\
\hline $5,126,426$ & $5,586,471$ & $-460,045$ \\
\hline
\end{tabular}

\begin{tabular}{r|r|r|}
\multicolumn{3}{c}{ At Complete } \\
\hline \multicolumn{1}{|c|}{ Budget } & \multicolumn{1}{c}{ Estimate } & \multicolumn{1}{c}{ Variance } \\
\hline 87,456 & 66,043 & 21,413 \\
\hline $5,423,585$ & $5,883,630$ & $-460,045$ \\
\hline
\end{tabular}

Monthly Financial Recap

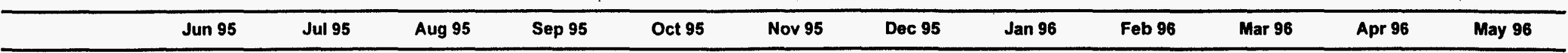

Actuals:

\begin{tabular}{|c|c|c|c|c|c|c|c|c|c|c|c|c|}
\hline Monthly Hours: & 50 & 6,255 & 7,504 & 7,961 & 6,453 & 4,330 & 3,138 & 2,600 & 3,300 & 3,479 & 2,963 & 4,168 \\
\hline Cumu Hours: & 50 & 6,305 & 13,809 & 21,770 & 28,224 & 32,553 & 35,691 & 38,291 & 41,591 & 45,069 & 48,032 & 52,200 \\
\hline Monthly Price: & 2,574 & 533,931 & 582,189 & 738,970 & 657,545 & 359,376 & 316,660 & 247,333 & 406,606 & 323,669 & 246,524 & 383,670 \\
\hline Cumu Price: & 2,574 & 536,505 & $1,118,694$ & $1,857,664$ & $2,515,209$ & $2,874,585$ & $3,191,245$ & $3,438,578$ & $3,845,383$ & $4,169,052$ & $4,415,577$ & $4,799,247$ \\
\hline
\end{tabular}

Budget:

\begin{tabular}{|c|c|c|c|c|c|c|c|c|c|c|c|c|}
\hline Monthly Hours: & 328 & 7,196 & 8,711 & 5,534 & 5,474 & 5,474 & 5,474 & 5,474 & 5,474 & 5,474 & 5,474 & 5,474 \\
\hline Cumu Hours: & 328 & 7,525 & 16,236 & 21,770 & 27,244 & 32,718 & 38,191 & 43,665 & 49,139 & 54,613 & 60,087 & $\overline{65,561}$ \\
\hline Monthly Price: & 14,090 & 498,386 & 570,555 & 774,636 & 297,160 & 297,160 & 297,160 & 297,160 & 297,160 & 297,160 & 297,160 & 297,160 \\
\hline Cumu Price: & 14,090 & 512,477 & $1,083,032$ & $1,857,668$ & $2,154,828$ & $2,451,988$ & $2,749,148$ & $3,046,308$ & $3,343,467$ & $3,640,627$ & $3,937,787$ & $4,234, \overline{946}$ \\
\hline
\end{tabular}


Subcontract No. 359636

Actuals through August 96

WBS: 1043.01.01 Technology Management

Manager: Dr. John S. Wilson

Start Date: 6/27/95

End Date: 12/1/96

Task Description: Perform technical reviews of requirements, needs and assessments related to waste characterization, containment, in-situ and ex-situ treatment, waste storage, disposal, robotics handling, monitoring, laboratory analysis, site characterization and remediation.

Cost Performance Summary:

\begin{tabular}{|c|c|c|c|}
\hline & \multicolumn{3}{|c|}{ Current Period } \\
\hline & Budget & Actuals & Variance \\
\hline Hours: & 5,474 & 2,528 & $2 . \overline{946}$ \\
\hline Price: & 297,160 & 250,563 & 46.597 \\
\hline
\end{tabular}

Inception to Date
\begin{tabular}{|r|r|r|}
\hline Budget & Actuals & Varlance \\
\hline 81,982 & 60,569 & 21,413 \\
\hline $5,126,426$ & $5,586,471$ & $-460,045$ \\
\hline
\end{tabular}

\begin{tabular}{|c|c|c|}
\hline \multicolumn{3}{|c|}{ At Complete } \\
\hline Budget & Estimate & Variance \\
\hline 87,456 & 66,043 & 21,413 \\
\hline $5,423,585$ & $5,883,630$ & $-460,045$ \\
\hline
\end{tabular}

Monthly Financial Recap:

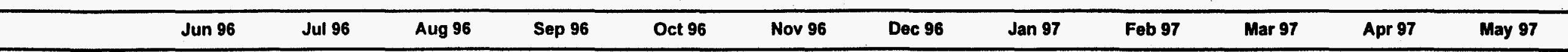

Actuals:

Monthly Hours:

Cumu Hours:

Monthly Price:

\begin{tabular}{|r|r|r|}
\hline 3,099 & 2,743 & 2,528 \\
\hline 55,299 & 58,041 & 60,569 \\
\hline 317,399 & 219,262 & 250,563 \\
\hline $5,116,646$ & $5,335,908$ & $5,586,471$ \\
\hline
\end{tabular}

\begin{tabular}{|r|r|r|r|}
\hline 0 & 0 & \\
\hline 60,569 & 60,569 & 60,569 & \\
\hline 0 & 0 & 0 \\
\hline $5,586,471$ & $5,586,471$ & $5,586,471$ \\
\hline
\end{tabular}

(1)

Budget:

Monthly Hours:

Cumu Hours:

Monthly Price:

\begin{tabular}{|r|r|r|}
\hline 5,474 & 5,474 & 5,474 \\
\hline 71,034 & 76,508 & 81,982 \\
\hline 297,160 & 297,160 & 297,160 \\
\hline $4,532,106$ & $4,829,266$ & $5,126,426$ \\
\hline
\end{tabular}

\begin{tabular}{r|r|r|}
\hline 5,474 & 0 \\
\hline 87,456 & 87,456 \\
\hline 297,160 & 0 \\
\hline $5,423,585$ & $5,423,585$ \\
\hline
\end{tabular}

re



(1)


$\frac{1}{4}$ 
Subcontract No. 359636

Actuals through August 96

WBS: 1043.01.02 Project Management

Manager: Dr. John S. Wilson

Start Date: 6/27/95

End Date: $12 / 1 / 96$

Task Description: Conduct reviews, analyze and develop strategies for program management systems for integration and control of programs, projects, tasks and documenlation.

Cost Performance Summary:

\begin{tabular}{|c|c|c|c|}
\hline & \multicolumn{3}{|c|}{ Current Period } \\
\hline & Budget & Actuals & Variance \\
\hline Hours: & 2,704 & 5,327 & $-2,623$ \\
\hline Price: & 273,798 & 361,463 & $-87,665$ \\
\hline
\end{tabular}

\begin{tabular}{|c|c|c|}
\hline \multicolumn{3}{|c|}{ Inception to Date } \\
\hline Budget & Actuals & Variance \\
\hline 55,289 & 64,461 & $-9,172$ \\
\hline $4,903,842$ & $5,026,733$ & $-122,891$ \\
\hline
\end{tabular}

\begin{tabular}{|c|c|c|}
\hline \multicolumn{3}{|c|}{ At Complete } \\
\hline Budget & Estimate & Varlance \\
\hline 57,993 & 67,165 & $-9,172$ \\
\hline $5,177,640$ & $5,300,531$ & $-122,891$ \\
\hline
\end{tabular}

Monthly Financiai Recap:

\begin{tabular}{|c|c|c|c|c|c|c|c|c|c|c|c|c|}
\hline & Jun 95 & Jul 95 & Aug 95 & Sep 95 & Oct 95 & Nov 95 & Dec 95 & Jan 96 & Feb 96 & Mar 96 & Apr 96 & May 96 \\
\hline \multicolumn{13}{|l|}{ Actuals: } \\
\hline Monthly Hours: & 98 & 8,116 & 8,247 & 9,084 & 3,578 & 1,588 & 2,868 & 3,297 & 3,561 & 3,631 & 3,321 & 4,024 \\
\hline Cumu Hours: & 98 & 8,214 & 16,462 & 25,545 & 29,123 & 30,711 & 33,578 & 36,875 & 40,436 & $44, \overline{067}$ & 47,388 & $51, \overline{412}$ \\
\hline Monthly Price: & 5,779 & 599,758 & 566,591 & 719,936 & 341,971 & 108,114 & 275,047 & 255,073 & 319,577 & 306,696 & 269,945 & 315,382 \\
\hline Cumu Price: & 5,779 & 605,537 & $1,172,128$ & $1,892,064$ & $2,234,035$ & $2,342,149$ & $2,617,196$ & $2,872,269$ & $3,191,846$ & $3,498,542$ & $3,768,486$ & $4, \overline{083,869}$ \\
\hline
\end{tabular}
Budget:

\begin{tabular}{|c|c|c|c|c|c|c|c|c|c|c|c|c|}
\hline Monthly Hours: & 309 & 6,643 & 8,042 & 10.551 & 2,704 & 2,704 & 2,704 & 2,704 & 2,704 & 2,704 & 2,704 & 2,704 \\
\hline Cumu Hours: & 309 & 6,952 & 14,994 & 25,545 & 28,249 & 30,953 & 33,657 & 36,361 & 39,065 & 41,769 & 44,473 & 47.177 \\
\hline Monthly Price: & 21,034 & 453,804 & 527,559 & 889,666 & 273,798 & 273,798 & 273,798 & 273,798 & 273,798 & 273,798 & 273,798 & $273, \overline{798}$ \\
\hline Cumu Price: & 21,034 & 474,838 & $1,002.397$ & $1,892,063$ & $2,165,861$ & $2,439,659$ & $2,713,457$ & $2,987,255$ & $3,261,053$ & $3,534, \overline{852}$ & $3,808,650$ & $4,082,448$ \\
\hline
\end{tabular}


Subcontract No. 359636

Actuals through August 96

WBS: 1043.01.02 Project Management

Manager: Dr. John S. Wilson

Start Date: 6/27/95

End Date: $12 / 1 / 96$

Task Description: Conduct reviews, analyze and develop strategies for program management systems for integration and control of programs, projects, tasks and documentation.

Cost Performance Summary:

\begin{tabular}{|c|c|c|c|}
\hline & \multicolumn{3}{|c|}{ Current Period } \\
\hline & Budget & Actuals & Variance \\
\hline Hours: & 2,704 & 5,327 & -2.623 \\
\hline Price: & 273,798 & 361,463 & $-87,665$ \\
\hline
\end{tabular}

Inception to Date
\begin{tabular}{r|r|r|}
\hline \multicolumn{1}{c}{ Budget } & \multicolumn{1}{c}{ Actuals } & Variance \\
\hline 55,289 & 64,461 & $-9,172$ \\
\hline $4,903,842$ & $5,026,733$ & $-122,891$ \\
\hline
\end{tabular}

\begin{tabular}{|c|c|c|}
\hline \multicolumn{3}{|c|}{ At Complete } \\
\hline Budget & Estimate & Variance \\
\hline 57,993 & 67,165 & $-9,172$ \\
\hline $5,177,640$ & $5,300,531$ & $-122,891$ \\
\hline
\end{tabular}

Monthly Financial Recap:

\begin{tabular}{|c|c|c|c|c|c|c|c|c|c|c|c|}
\hline Jun 96 & Jul 96 & Aug 96 & Sep 96 & Oct 96 & Nov 96 & Dec 96 & $\operatorname{Jan} 97$ & Feb 97 & Mar 97 & Apr 97 & May 97 \\
\hline
\end{tabular}

Actuals:

Monthly Hours:

Cumu Hours:

Monthly Price:

\begin{tabular}{|c|c|c|c|}
\hline 3,151 & 4,572 & 5,327 & 0 \\
\hline 54,562 & 59,134 & 64,461 & 64,461 \\
\hline 276,057 & 305,344 & 361,463 & 0 \\
\hline $4,359,925$ & $4,665,270$ & $5,026,733$ & $5,026,733$ \\
\hline
\end{tabular}

$0[0] \quad 0]$

Cumu Price:

$4,359,925 \quad 4,665,270$



64,461

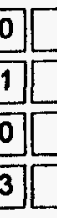

(1)



Budget:

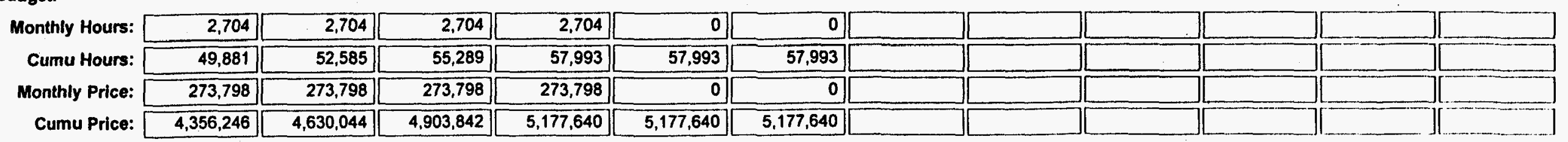


$\frac{0}{4}$ 
Subcontract No. 359636

Actuals through August 96

WBS: 1043.01.03 Technology Integration

Manager: Dr. John S. Wilson

Start Date: 6/27/95

End Date: 12/1/96

Task Description: Provide support in establishing criteria for identifying risks to the public health and safety posed by conditions at the weapons complex facilities, evaluate the extent of these risks, determine the urgency and priorities for eliminating or minimizing the risks, and access the cost of activities required to meet applicable compliance agreements.

Cost Performance Summan:

\begin{tabular}{|c|c|c|c|}
\hline & \multicolumn{3}{|c|}{ Current Period } \\
\hline & Budget & Actuals & Variance \\
\hline Hours: & 2,328 & 3,210 & -882 \\
\hline Price: & 247,120 & $21 \overline{8,378}$ & $28, \overline{742}$ \\
\hline
\end{tabular}

\begin{tabular}{|c|c|c|}
\hline \multicolumn{3}{|c|}{ Inception to Date } \\
\hline Budget & Actuals & Variance \\
\hline 31,039 & 25,155 & 5,884 \\
\hline $3,146,538$ & $2,060,498$ & $1,086,040$ \\
\hline
\end{tabular}

\begin{tabular}{|c|c|c|}
\hline \multicolumn{3}{|c|}{ At Complete } \\
\hline Budget & Estimate & Varlance \\
\hline 33,367 & 27,483 & 5,884 \\
\hline $3,393,658$ & $2,307,618$ & $1, \overline{086,040}$ \\
\hline
\end{tabular}

Monthly Financial Recap:

\begin{tabular}{|c|c|c|c|c|c|c|c|c|c|c|c|}
\hline Jun 95 & Jul 95 & Aug 95 & Sep 95 & Oct 95 & Nov 95 & Dec 95 & Jan 96 & Feb 96 & Mar 96 & Apr 96 & May 96 \\
\hline
\end{tabular}

Actuals:

\begin{tabular}{|c|c|c|c|c|c|c|c|c|c|c|c|c|}
\hline Monthly Hours: & 1 & 1,339 & 1,972 & 2,117 & 608 & 450 & 664 & 1,036 & 1,196 & 1.453 & 2,370 & $3, \overline{216}$ \\
\hline Cumu Hours: & 1 & 1,340 & 3,312 & 5,428 & 6,036 & 6,486 & 7,150 & 8,185 & 9,381 & 10,834 & 13,203 & 16,419 \\
\hline Monthly Price: & 139 & 106,521 & 151,601 & 169,960 & 73,113 & 41,466 & 82,773 & 75,216 & 117.736 & 104,335 & 190,919 & 283,077 \\
\hline Cumu Price: & 139 & 106,660 & 258,261 & 428,221 & 501,334 & 542,800 & 625,574 & 700,790 & 818,526 & 922,860 & $1,113,780$ & $1,396,857$ \\
\hline
\end{tabular}

Budget:

\begin{tabular}{|c|c|c|c|c|c|c|c|c|c|c|c|c|}
\hline Monthly Hours: & 800 & 4,589 & 5,555 & $-5,515$ & 2,328 & 2,328 & 2,328 & 2,328 & 2,328 & 2,328 & 2,328 & 2,328 \\
\hline Cumu Hours: & 800 & 5,388 & 10,943 & 5,428 & 7,756 & 10,085 & 12,413 & 14,741 & 17,069 & 19.398 & 21,726 & $24, \overline{054}$ \\
\hline Monthly Price: & 54,170 & 299,639 & 356,729 & $-282,320$ & 247,120 & 247,120 & 247,120 & 247,120 & 247,120 & 247,120 & 247,120 & 247,120 \\
\hline Cumu Price: & 54,170 & 353,809 & 710,538 & 428,218 & 675,338 & 922,458 & 1.169 .578 & $1,416,698$ & $1,663,818$ & $1,910.938$ & $2,158,058$ & $2,405,178$ \\
\hline
\end{tabular}


$\frac{1}{4}$ 
Actuals through August 96

WBS: 1043.01.04 Systems Engineering

Manager: Dr. John S. Wilson

Start Date: 2/1/96

End Date: 12/1/96

Task Description:

Cost Performance Summary:

\begin{tabular}{|c|c|c|c|}
\hline & \multicolumn{3}{|c|}{ Current Period } \\
\hline & Budget & Actuals & Variance \\
\hline Hours: & 162 & 5 & 157 \\
\hline Price: & 21,420 & 5,089 & $16, \overline{331}$ \\
\hline
\end{tabular}

Inception to Date
\begin{tabular}{r|r|r|}
\hline \multicolumn{1}{|c}{ Budget } & \multicolumn{1}{c}{ Actuals } & Variance \\
\hline 648 & \multicolumn{1}{|c|}{} & 641 \\
\hline 85,680 & 7 & \\
\hline & 11,354 & 74,326 \\
\hline
\end{tabular}

\begin{tabular}{|c|c|c|}
\hline \multicolumn{3}{|c|}{ At Complete } \\
\hline Budget & Estimate & Variance \\
\hline 1,134 & 493 & 641 \\
\hline 149,940 & 75,614 & 74,326 \\
\hline
\end{tabular}

Monthly Financial Recap:

\begin{tabular}{|c|c|c|c|c|c|c|c|c|c|c|c|c|}
\hline & Jun 95 & Jul 95 & Aug 95 & Sep 95 & Oct 95 & Nov 95 & Dec 95 & Jan 96 & Feb 96 & Mar 96 & Apr 96 & May 96 \\
\hline \multicolumn{13}{|l|}{ Actuals: } \\
\hline Monthly Hours: & 0 & 0 & 0 & 0 & 0 & 0 & 0 & 0 & 0 & 0 & 0 & 0 \\
\hline Cumu Hours: & 0 & 0 & 0 & 0 & 0 & 0 & 0 & 0 & 0 & 0 & 0 & 0 \\
\hline Monthly Price: & 0 & 0 & 0 & 0 & 0 & 0 & 0 & 0 & 0 & 0 & 0 & 51 \\
\hline Cumu Price: & 0 & 0 & 0 & 0 & 0 & 0 & 0 & 0 & 0 & 0 & 0 & 51 \\
\hline
\end{tabular}

Budget:

Monthly Hours:

Cumu Hours:

Monthly Price:

Cumu Price:

\begin{tabular}{|r|r|r|r|}
\hline 0 & 0 & 0 & 0 \\
\hline 0 & 0 & 0 & 0 \\
\hline 0 & 0 & 0 & 0 \\
\hline 0 & 0 & 0 & 0 \\
\hline
\end{tabular}

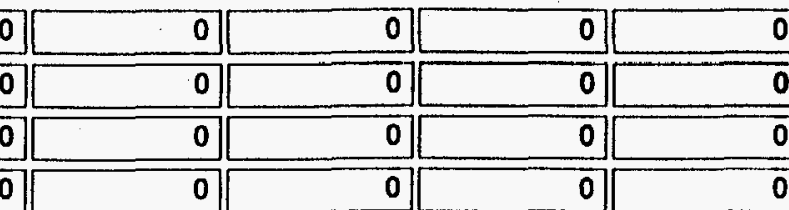

\begin{tabular}{|c|c|c|c|c|}
\hline 0 & 0 & 0 & 0 & 162 \\
\hline 0 & 0 & 0 & 0 & 162 \\
\hline 0 & 0 & 0 & 0 & 21,420 \\
\hline 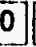 & 0 & 0 & 0 & 21,420 \\
\hline
\end{tabular}


Actuals through August 96

WBS: 1043.01.04 Systems Engineering

Manager: Dr. John S. Wilson

\begin{abstract}
Start Date: 2/1/96
\end{abstract}
End Date: 12/1/96

Task Description:

Cost Performance Summary:

\begin{tabular}{|c|c|c|c|}
\hline & \multicolumn{3}{|c|}{ Current Period } \\
\hline & Budget & Actuals & Variance \\
\hline Hours: & 162 & 5 & $15 \overline{7}$ \\
\hline Price: & 21,420 & $5, \overline{089}$ & 16,331 \\
\hline
\end{tabular}

\begin{tabular}{|c|c|c|}
\hline \multicolumn{3}{|c|}{ Inception to Date } \\
\hline Budget & Actuals & Variance \\
\hline 648 & 7 & 641 \\
\hline $85, \overline{680}$ & 11,354 & 74,326 \\
\hline
\end{tabular}

\begin{tabular}{|c|c|c|}
\hline \multicolumn{3}{|c|}{ At Complete } \\
\hline Budget & Estimate & Variance \\
\hline 1,134 & 493 & 641 \\
\hline 149,940 & 75,614 & 74,326 \\
\hline
\end{tabular}

Monthly Financial Recap:

\begin{tabular}{|c|c|c|c|c|c|c|c|c|c|c|c|c|}
\hline & Jun 96 & Jul 96 & Aug 96 & Sep 96 & Oct 96 & Nov 96 & Dec 96 & Jan 97 & Feb 97 & Mar 97 & Apr 97 & May 97 \\
\hline \multicolumn{13}{|l|}{ Actuals: } \\
\hline Monthly Hours: & 0 & 2 & 5 & 0 & 0 & 0 & & & & & & \\
\hline Cumu Hours: [ & 0 & 2 & 7 & 7 & 7 & 7 & & & & & & \\
\hline Monthly Price: [ & 5,648 & 565 & 5,089 & 0 & 0 & 0 & & & & & & \\
\hline Cumu Price: [ & 5,699 & 6,265 & 11,354 & 11,354 & 11,354 & 11,354 & & & & & & \\
\hline
\end{tabular}

\title{
Budget:
}

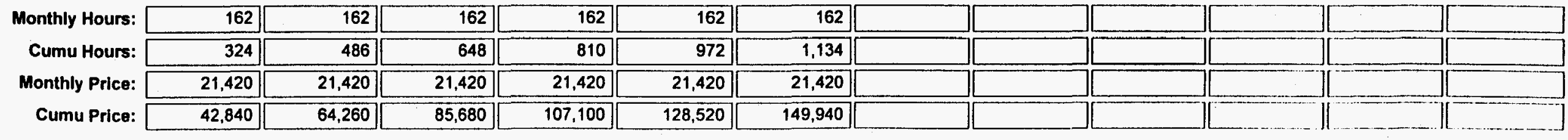



WASTE POLICY INSTITUTE MONTHLY REPORT TO THE EERC, SEPTEMBER 1996

APPENDIX F 



\section{UNIVERSITY OF NORTH DAKOTA ENERGY AND ENVIRONMENTAL RESEARCH CENTER}

\section{Monthly Report}

September, 1996

\section{TECHNOLOGY DEVELOPMENT INTEGRATION WPI SUBCONTRACT NUMBER 359636}

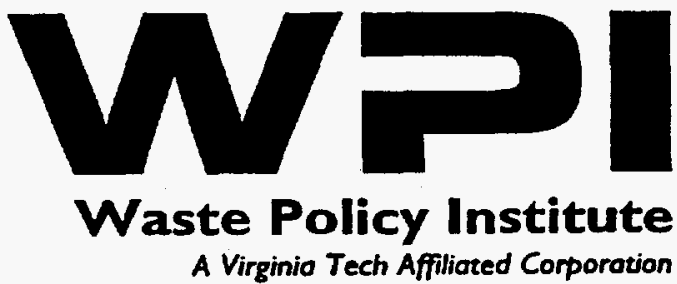


CONTRACTOR NAME: Waste Policy Institute 555 Quince Orchard Road

Suite 600

Gaithersburg, MD 20878-1437

CONTRACT PERIOD: $\quad 6 / 28 / 95-12 / 01 / 96$

\section{SUBCONTRACT DELIVERABLES:}

This report is submitted in fulfillment of requirements specified for the University of North Dakota Energy and Environmental Research Center (UNDEERC) Subcontract Number 359636. A list of products developed under this subcontract is provided as Attachment $A$.

\section{SUMMARY OF ACTIVITIES:}

A significant level of activity related to the review of site Ten Year Plans was a highlight of September's work.

\section{TASK A-TECHṄOLOGY ASSESSMENT}

\section{TANKS FOCUS AREA (TFA)}

Staff participated in the Integrated Contractors (IC) Team September teleconference for the C-Reactor Large Scale D\&D Demonstration. Action items relevant to the selection of technologies for demonstration were discussed.

The team prepared Fact Sheets on Crystalline Silico- Titanate (CST) for cesium removal and the clean salt process for reducing the volume of Hanford low activity waste. These were to be used by DOE-RL during a visit by Mr. Alm from HQ to emphasize technology development with respect to high level waste treatment at Hanford and the Ten Year Plan (TYP).

Staff developed the Near Infrared Spectrometer (NIR) Innovative Technology Summary Report (ITSR) input for DOE-RL. This ITSR is a summary of the NIR technology developed by Westinghouse Hanford Company (WHC). The technology is undergoing final testing and is awaiting a decision by the Hanford safety program managers for acceptance as part of the Hanford baseline for chemical analysis. The material was presented to DOE-RL. The final copy was forwarded to the Colorado Center for Environmental Management for publication.

A feasibility paper regarding disposition issues with the clean salt process developed by WHC was drafted by the team. The information contained in the feasibility paper 
included onsite and offsite options for salt reuse and the regulatory criteria for each reuse option. Also, the paper included information regarding paths to circumvent any regulatory restrictions associated with the salt. This is most important for offsite salt disposition options. A draft was sent to DOE-RL and other cognizant personnel for review.

A graphic depicting the top-level functions in the high level waste treatment process was prepared by the staff. The process flow included waste storage, characterization. pretreatment, HLW and LLW immobilization, interim storage, and ultimate disposal.

\section{SUBSURFACE CONTAMINANTS FOCUS AREA (SCFA)}

Team members completed a review of the August 1, 1996 Draft Ten-Year Plan (TYP) for the Richland Operations Office. The focus was primarily on the extent to which SCFA technologies were considered and included in the TYP, what gaps exist, and where innovative technologies are needed, based on the site's needs identification process.

An analysis was performed for the following technologies: LASAGNA, ACT-DE-CON, Hot Spot Removal, and Solution Mining. The technologies were evaluated against the Gate Criteria to determine whether they were ready for progression to the next stage of technology development. This information will be used to determine whether new Gate Criteria should be adopted. The accuracy of the analyses is variable because of the different degree of supporting information by which the team's evaluation was made.

The team provided comments on two systems engineering flow charts. The comments will be incorporated to insure the flow charts are accurate and can be easily understood.

A teleconference was planned utilizing DOE-SR's teleconferencing capabilities. Pointsof-Contact were established and submitted to DOE.

\section{DECONTAMINATION AND DECOMMISSIONING (D\&D) FOCUS AREA}

The WPI team provided a summary review of projects and associated technologies for the D\&D of plutonium-contaminated glovebox facilities. This review was conducted as a follow on to the meeting held August 23 in Seattle, Washington between the D\&D Focus Area and representatives from the National Commission of Atomic Energy (CNEA) of the Republic of Argentina. The purpose of this meeting was to outline and sign an agreement describing a path forward for cooperative technology demonstration between the D\&D Focus Area and CNEA. CNEA has a contaminated plutonium glovebox facility where they are seeking new and innovative technologies and techniques in order to decommission the facility. Over the next 12 to 15 months, the D\&D Focus Area will work with CNEA to characterize the problems at this facility, conduct a small-scale decontamination/dismantlement demonstration on a single glovebox, and then, if feasible, conduct a full-decommissioning of the facility. 
A technical review of five proposals submitted under a METC Research Opportunity Announcement in the area of Decontamination and Decommissioning was provided by the WPI team.

The WPI team prepared an assessment of currently available strippable coating technologies. This review provided background information, uses, application processes, vendor information, and performance specifications for currently available strippable coatings. This review was developed to support a request from the Russian D\&D Workshop.

A WPI team senior chemist contacted the reviewers selected for the Phase I review of the F2 Associates project, Laser Ablation of Contaminants from Concrete and Metal Surfaces, and provided information on the project, an agenda for the review meeting, and a questionnaire to be completed by each reviewer following the on-site review planned for September 26, 1996 in Albuquerque, NM. The reviewers' inputs will be used by the DOE/METC Project Manager to decide the future of the Laser Ablation project, including schedule and funding.

\section{MIXED WASTE FOCUS AREA (MWFA)}

The WPI team revised the Mixed Waste Focus Area Technology Development Requirements Documents.

Draft EM-40 Tables on Waste Treatment Options for Containerized Low-Level Waste were prepared.

\section{TASK B-PROJECT ASSESSMENT}

\section{TANKS FOCUS AREA (TFA)}

Staff developed a Technology Roadmap for FY97 that provides the dates and locations of technology demonstrations to be conducted by TFA. Information included the EM-30 target projects. Staff also provided input and support information, as requested by DOE-HQ/EM-54, by developing TFA milestone GANTT charts.

A draft highlight was prepared by the staff on the Light Duty Utility Arm (LDUA) for the WPI Initiatives in Environmental Technology Investment publication.

Staff prepared narratives describing technology demonstrations and implementations completed by the TFA in FY96 for input to the EM-50 Annual Report to Congress.

The team edited DOE-RL's TYP summaries for Tanks, D\&D, and Environmental Restoration and incorporated EM-30's comments into the Technology Tables for DOE-RL. The staff prepared talking points for DOE-RL and DOE-HQ to use in leading discussion of site TYPs during the weekly TFA Management Teleconference. Staff also prepared a brief on the TYP for John Wagoner, DOE-RL Field Office Manager, to 
present to the OST Board of Directors on September 17, 1996. The TFA is funding 145 technology solutions to support Richland, Idaho, Savannah River, and Oak Ridge. The technology solutions reflect technology needs that have been identified by the Site Technology Coordination Group (STCG).

The team completed a first draft of Tables 1,2, and 3 for the TFA for the Richland. SRS. Idaho, and Oak Ridge TYPs. Staff provided the draft to PNNL for review and assistance. Estimates of cost savings from TFA technologies for Table 3 are still being developed. Staff developed comments from the TFA on the TYP data submittal for Oak Ridge and Idaho and submitted copies to DOE-RL, DOE-OR and DOE-ID. The comments reviewed areas where technologies are available or are being developed to support the Oak Ridge and Idaho TYPs.

Performance Objectives, Measures, and Expectations for TFA Technical Team Performance were drafted by the staff for DOE-RL.

Staff prepared a list of TFA developed technologies that have been full-scale demonstrated and/or field tested and remain in use for DOE-HQ/EM-50 to respond to a request for information from EM-30. A table on DOE Technology Achievements was also prepared. This information answered a call from HQ and will be used for planning purposes and the fiscal year-end roll up.

Staff reviewed the TTP RL36WT51, "Retrieval Process Development" milestone 2.6-1 deliverable, "Draft Report: Pilot Scale Pulsed Air Test Results/Recommendations," and submitted comments and recommendations to DOE-RL.

The Memorandum of Understanding (MOU) for the Cesium Removal/Vitrification Demonstration was reviewed by the team for DOE-RL. The objective of this MOU is to define the roles and responsibilities for the Oak Ridge Cesium Removal Demonstration (CRD) and for the partners to agree to a specified scope for the amount of waste to be vitrified at SRS. Since the result of this demonstration is implementation at Oak Ridge and other sites, it was recommended that additional items might be added that address goals and responsibilities for technology transfer to EM-30 at DOE sites.

The team drafted a budget for technology development for TFA from FY97 to FY06 and provided recommendations to DOE-RL to answer a call from HQ. The budget required for HLW tank technology development was expected to remain at a level similar to FY98 through FY05. In FY06, the projection drops approximately $25 \%$ because several tanks have been retrieved at each of the sites, and the retum on investment for additional technology development is reduced.

The team prepared the TFA FY97 Performance Plan Technology Worksheets and Planning Tables 1, 2 and Attachment $\mathrm{H}$ and submitted them to DOE-HQ, DOE-RL, and PNNL. The Performance Plan will track the gate progress of technologies through 
transfer and the associated costs for each. Supporting documentation was provided in a matrix for all technologies being tracked (Attachment $\mathrm{H}$ ).

The TFA Program Review Briefing for presentation to DOE-RL management was prepared by the staff. This briefing is a review of the program to upper DOE-RL management by the TFA. It brings valuable insight into the program that can be incorporated into high-level decisions being made for the Hanford site.

Staff prepared the draft agenda, updates, and actions for the TFA Teleconference for the month of September. This involved being part of the teleconference and taking minutes to status the call.

\section{SUBSURFACE CONTAMINANTS FOCUS AREA (SCFA)}

Staff members provided a technical analysis and support to facilitate transition of needs determination information from EnviroIssues to Permanent Records Storage in the SCFA. Also described actions to integrate with developing SCFA capabilities such as TechInvest. A presentation was developed detailing the analysis and actions and was provided to SCFA on July 19, 1995.

Staff performed an analysis of the SCFA program to identify successes in technology development, team performance and industry partnership. From this analysis, we have developed an 8 -foot by 10 -foot full color exhibit for use at conferences. To support the exhibit we also developed fact sheets for the technologies highlighted. All of these materials were shipped to the SPECTRUM Conference on August 18, 1996. The transportable display has been retained in our facility at Savannah River Research Campus. A calendar is kept for its use at other conferences and outreach events.

The WPI team performed a technical analysis of SCFA activities and determined work processes and interfaces for effective coordination between the Stakeholder Coordinator and the Product Line Managers (PLM). The analysis was documented as a slide presentation and was presented at the PLM meeting held on September 10-11, 1996 at Savannah River Site.

The WPI team proposed a review process for the SCFA Long Form TTPs with resource loading which we developed in meetings with DOE and WSRC. The information includes scope of the review activities with travel requirements and resource loading. This process has already been informally provided and was implemented by the WPI team to perform the review according to DOE requirements.

Staff members produced information and coordinated presentation material for the Product Line Managers Strategy Meeting, re: FY97 PEG Slides. This included sorting and subtotaling 97 PEG by Product Line and making slides of each Product Line with subtotals. Identified TTPs which had funds, were put on hold or partial hold. 
Revisions to the SCFA Program Plan were completed in the area of graphics. After completion, the Program Plan was submitted to DOE for approval.

An information package was prepared to help inform the new DOE-PLMs and the TPOs on TTP work scope to be accomplished in the remainder of FY96. A TTP schedule, which has been updated with June PTS data, has been printed out for all Landfill and Plumes TTPs and will be sorted into Product Line or Site packages as appropriate. A list of problem TTPs was also included to focus attention on TTPs which require close monitoring to insure the appropriate action is initiated prior to the end of September, i.e.. Termination or continue scope with close-out funds. A list of TTPs that while active during FY 1996, are to be closed out in September was also included.

An SCFA information booklet was compiled and submitted. All information concerns the TTPs for FY96. A new package will be required to provide information for FY97 TTPs. The booklet contained: Information booklet, Fin plan spreadsheet with 3 month comparison, July Fin Plan, Aug. Fin Plan, Sept. Fin Plan, and TTP schedules for Landfill and Plumes.

Members of the team provided technical information that is to be used for the SCFA contribution to DOE's Annual Report to Congress. The information includes descriptions of SCFA technologies that have been demonstrated during FY96. Further information is being gathered for this report by DOE-HQ personnel. The Annual Report to Congress is used by DOE to convey to Congress the successes of it's Environmental Restoration programs which include the development of innovative technologies where no satisfactory baseline technologies exist.

The WPI team produced the SCFA FY96 Annual Performance Plan. The Plan includes a Technology Investment Profile, Performance Measure Planning table, Program Area Technology Summary Matrix, a Statement of Non-Federal Participation, a Performance Measures Improvement Initiative, and Technology Stage Worksheets. The Plan will assist the Office of Science and Technology in meeting their objective to plan performance measurement targets that support and justify OST's FY 1998 Congressional Budget Request.

Team members produced a Gantt Chart and a Technology Roadmap for SCFA significant activities in the FY97 Program: 1) datafile and printout in Microsoft Project of significant activities and 2) datafile and printout in Microsoft Excel of technology roadmap with demonstrations and dates.

\section{DECONTAMINATION AND DECOMMISSIONING (D\&D) FOCUS AREA}

Technical support was provided by the WPI team to the D\&D focus area in developing an $R \& D$ investment strategy. This project will include the evaluation of identified technical needs relative to available commercial $D \& D$ technologies and ongoing technology $R \& D$ efforts. In addition, the focus area will assess the site generated TYPs to verify the 
degree to which identified needs are described, as well as to identify additional needs which may be elucidated within the TYPs.

The WPI team provided monthly technical and performance status update to the Project Tracking System for FY95 METC D\&D Technical Tasks.

Technical support was provided by the WPI team for the development of a "Lessons Learned" document describing the process, feedback, and recommendations for conducting Needs Assessments within the D\&D Focus Area.

The WPI team prepared a Meeting Record for a CP-5 Large-Scale Demonstration Teleconference held on August 30,1996. The teleconference was used as a method to provide LSD status information to stakeholders in the CP-5 project.

The WPI team assisted in the Opportunities Assessment Project. They also reviewed TYPs and developed a short summary of all reviewed TYPs for DOE review.

Assistance was given by the WPI team in preparing a meeting agenda for the Large-Scale Demonstration Project combined meeting/DDFA Fiscal Year 1997 Kick-Off.

The WPI team began development of the 1996 Fiscal Year Annual Report for the DDFA.

Assistance was given in providing responses to the Technical Peer Review Panel Report by the WPI team. Responses were directed to specific concerns noted in the report.

The WPI team continued to provide support for the analysis of the 14 LSDP proposals for FY97 and FY98. The goals was to abstract and summarize additional information to prepare graphical data sheets depicting proposed schedules and budgets for the proposed projects, grouped by type of facility requiring D\&D. This information will assist the reviewers and D\&D Focus Area staff in planning the distribution of LSDP types for the future.

Technical input was provided by the WPI team to the D\&D Focus Area Monthly Report of the technical task work accomplished by the Focus Area Principal Investigators (PIs) during July, and assisted in the collection, review, and editing of monthly input from the PIs. We also guided the production and distribution of the June Report. These reports inform interested parties of the monthly progress being made by the D\&D Focus Area.

Program support staff on the WPI team provided input to the development of an Operations and Implementation Plan for the METC Environmental and Waste Management (EWM) Division. This Plan will define the role of the EWM Division under the new consolidated METC/PETC, known as the Federal Energy Technology Center (FETC).

The WPI team developed a plan for and initiated the D\&D Technology Development Investment Opportunities Assessment for the focus area. This assessment will support 
the strategic planning effort for technology investment by the focus area and was approved by the D\&D Focus Area lead. A formal project plan will be delivered in October. The assessment is being performed along two concurrent research paths. The first path will clearly define the DOE D\&D program using the site TYPs. The second path assesses baseline and commercially available technologies, and technologies in development to address D\&D program problem areas. The result of the assessment will be identification of the gaps in and opportunities for technology development to support the D\&D program.

The WPI team staff.prepared a proposed D\&D focus area response to the Technical Peer Review Panel comments from the program mid-year review.

A meeting of the Fernald Plant-1 Large-Scale Demonstration (LSD) Integrating Contractor (IC) Team on September 5, 1996 was attended by WPI staff. A meeting record was prepared and distributed.

The WPI team staff planned the FY97 LSD kickoff meeting and IC Team information exchange to be held in Cincinnati, Ohio on October 4, 1996. The effort included planning the technical agenda and arranging logistics. One member of the team will attend to facilitate the meeting and prepare a meeting record.

\section{MIXED WASTE FOCUS AREA (MWFA)}

Staff members completed design of TTP summary profile sheets, constructed database and report format, tested format with condensed long-form TTP data, and reviewed results with the DOE customer. The customer was pleased with the results, and will use this information to be kept advised of changes to scope, milestones, and funding as they occur.

Team members reviewed these documents to support participation in DOE-ID meetings:

Mixed Waste Focus Area Waste Form Strategy (draft)

Mixed Waste Focus Area FY 1997 Performance Plan (draft)

Mixed Waste Focus Area Program Management Plan (draft)

Mixed Waste Focus Area Test Plan Guidance (draft)

Members of the team reviewed these documents to support participation in DOE-ID meetings:

Configuration Change Reports (change Packages)

Cost/Performance Variance Analysis Reports

Financial Plans

Progress Tracking System Reports 


\section{TASK C-TECHNOLOGY INTEGRATION}

A review of Attachment IV of the 11 Draft TYPs for all DOE field sites was completed. The results of the review and the assumptions that were used to develop this information was included.

Staff attended the Mixed Waste Focus Area Community Leaders Network meetings.

The WPI team prepared and submitted working papers on non-thermal treatment projects and on technical deficiency matching projects.

A member of the staff assisted the Aiken office with the completion of a draft of the Subsurface Contaminants Focus Area Stakeholder Communication Plan.

Staff members assisted in the analysis of the Robotics FY96 (July) Financial Plan and Cost Schedule Variance Report, and developed explanatory text for schedule and cost variances.

Staff members assisted with the revision of the list of Robotics Technology Development Crosscutting Program acronyms and abbreviations, which included acronyms from previous Technology Summaries. This was in response to frequent informal field comments requesting definitions of acronyms used in robotics correspondence and Coordinators' Reports.

Staff members assisted with the development of Robotics technology information for a draft table entitled "DOE Technology Achievements Database". Technologies included those that have been demonstrated or are commercially available and/or implemented.

Staff members assisted with the preparation of the draft Robotics input to the FY96 Office of Science and Technology Annual Report to Congress. Support included compiling field inputs, formatting and editing of the initial draft, and the editing of subsequent drafts produced by the Graphics Department.

The staff assisted with the planning for cost savings activities for FY97 by identifying technologies which needed a cost savings analysis performed, and were sufficiently developed and tested to have yielded data necessary to support a valid cost and cost savings estimate. Staff members also assisted in preparing the draft input to guidance for performing cost estimates.

Staff members assisted in the development of Gantt charts and a technology roadmap for the Efficient Separations Crosscutting Program, and Gantt charts of project milestones for the MWFA. 
The staff assisted with the preparation and updating of an integrated long-term schedule which showed major milestones for all focus and crosscut areas.

Staff members assisted with the review of the TYP for the Ohio Field Office sites. This review focused on identifying specific OST technologies which would meet the site's needs and reduce costs compared to the baseline technology.

Staff members assisted with the revision of draft summaries on needs assessment processes and implementation results within the DOE Focus Areas. These summaries were distributed to Focus Areas for review and comment.

Staff members participated in weekly teleconferences with Focus Area leads and shared updates, discussed issues, offered suggestions on improvements, and aided in integrating activities.

Staff members assisted by providing E-mail regulatory updates to WPI team field offices on environmental regulatory activity. Updates included the impact of recent Land Disposal Restrictions (LDR) and the management of hazardous wastes in surface impoundments; EPA's draft compliance assurance monitoring (CAM) rule; EPA's consolidated regulatory impact assessment concerning potential revision of the national ozone and particulate matter air quality standards; the comment period on DOE's no-migration determination for the Waste Isolation Pilot Plant (WIPP); EPA's RCRA/21 initiative; EPA's Waste Minimization Prioritization Team's project; and Federally recognized American Indian tribes.

The staff assisted with the review of the Federal Register, LEXIS, and relevant environmental literature to remain current with regulatory developments which have the potential to impact the missions of the WPI team field offices.

A member of the staff assisted with the research and tracking of Federal environment and technology legislation potentially impacting the field, particularly the National Defense Authorization Act for FY97 and the Energy and Water Development Appropriations Act for FY97.

A member of the staff assisted with the researching, tracking and distribution of quick-read reports on the status of the ongoing FY97 appropriations process as it impacts DOE's Environmental Management program and technology development issues at the field level.

A WPI team member attended the September 5, 1996 Senate hearing on DOE Cleanup Costs and distributed the summary of this hearing.

A member of the staff assisted with the forwarding of relevant BNA articles of interest to the field, which included the September 9, 1996 article on the NRC report on Hanford cleanup options. 
Staff members assisted with the review of the draft TYPs submitted by DOE Field Offices to identify proposed remedial approaches and related technologies. Staff members identified potential opportunities for application of new, innovative technologies under development by EM 50, and initiated preparation of a list of new: technologies for which a cost savings analysis had been completed. Staff members assisted with the drafting of input to guidance for Focus Area review of the TYPs.

Staff members assisted with the planning for cost savings activities for FY97 and identified technologies. which needed a cost savings analysis performed. Staff members also provided draft input to guidance for performing cost estimates.

A member of the WPI team assisted with the research and analysis of relevant state legislative and regulatory activity, and assisted with the writing and distribution of the September "State Environmental Watch."

\section{TASK D-SYSTEMS ENGINEERING}

There was no activity under this task during September 


\section{ATTACHMENT A}

\section{PRODUCTS DELIVERED: TASK A - TECHNOLOGY ASSESSMENT}

\section{TANKS (TFA) FOCUS AREA}

- Crystalline Silico-titanates (CSTs) and Clean Salt Fact Sheets

- High Level Waste Process Flow Briefing

- Technology Summary Book: Near Infrared (NIR) Spectroscopy System

\section{SUBSURFACE CONTAMINANT (SCFA) FOCUS AREA}

- Review Richland Operations Office Draft TYP

- Proposed Technical Team Activities Work Activity 2.3-2.5

- Performed Analysis for Four SCFA Technologies

-LASAGNA

-ACT-DE-CON

-Hot Spot Removal

-Solution Mining

- Video Teleconference Points-of-Contact

- Comments for Systems Engineering Flow Charts

DECONTAMINATION AND DECOMMISSIONING (D\&D) FOCUS AREA

- Technical reviews for five D\&D ROA proposals

- Interim draft summary document describing projects and associated technologies for the D\&D of plutonium-contaminated glovebox facilities

- Report entitled “Strippable Coatings" (8/25/96)

\section{PRODUCTS DELIVERED: TASK B: PROJECT ASSESSMENT}

\section{TANKS (TFA) FOCUS AREA}

- Draft input forAnnual Report to Congress for Tanks Focus Area

- Summary Pages and Comment Incorporation for Richland's TYP 
- Memorandum of Understanding for Cesium Removal/Vitrification Review

- TYP Talking Points

- TFA Technical Implementation Team FY97 Performance Objectives, Measures. and Expectations

- Milestone 2.6-1, Draft Report Pilot Scale Pulsed Air Test Results/Recommendations Review

- TFA Technology Achievements Table

- TFA GANTT Chart and Technology Roadmap for FY97

- Office of Science and Technology Board of Director's Briefing

- Draft memorandum regarding TFA Kickoff Meeting, October 7-9, 1996

- Draft memorandum distributing first draft of FY97 TFA TTPs

- Briefing, "What TFA Does Well, Nẹeds Improvement, and Lessons Learned" for Focus Area Lead meeting on September 30, 1996

- FY97 Performance Plan for the TFA

- TFA Program Review Briefing

- Agendas, updates and actions for the TFA teleconferences during the month of September

\section{SUBSURFACE CONTAMINANT (SCFA) FOCUS AREA}

- FY97 PEG Slides (by Product Line)

- SCFA Draft Program Plan

- Information Package for TPOs and PLMs to Assist in Tracking and Close-out of FY96 TTPs

- SCFA Portfolio

-Information Booklet

-Fin Plan Spreadsheet w/3 Month Comparison

-July, August, September Fin Plans

-TTP Schedules for Landfill and Plumes 
- Technical Information - SCFA Contribution to DOE's Annual Report to Congress

- SCFA FY96 Annual Performance Plan

- Gantt Chart and Technology Roadmap for SCFA FY97 Program

- Analysis of the SCFA Program to Identify Success in Technology Development, Team Performance, and Industry Partnership.

- Technical Analysis of SCFA Activities between Stakeholder Coordinator and the Product Line Managers (PLMs)

- Technical Analysis and Support to Facilitate Transition of Needs Determination Information from EnviroIssues to Permanent Records Storage in SCFA

\section{DECONTAMINATION AND DECOMMISSIONING (D\&D) FOCUS AREA}

- CP-5 August 30 Teleconference Meeting Record

- Proposed D\&D Focus Area Response to Technical Peer Review Panel Comments

- Meeting Record-Fernald Plant-1 Large-Scale Demonstration (LSD) Integrating Contractor (IC) Team, September 5, 1996

- Agenda- FY97 LSD Kickoff Meeting and IC Team Information Exchange, October 4, 1996

- D\&D Focus Area Monthly Report - June

- F2 Associates Laser Ablation Project Phase I Review Questionnaire

- Large Scale Demonstration Project Proposal Summary Graphs

MIXED WASTE (MWFA) FOCUS AREA

- Draft EM-40 Tables on Waste Treatment Options for Containerized Low-Level Waste

- August Monthly Report

PRODUCTS DELIVERED: TASK C: TECHNOLOGY INTEGRATION

- Review of Attachment IV of the 11 Draft TYP 


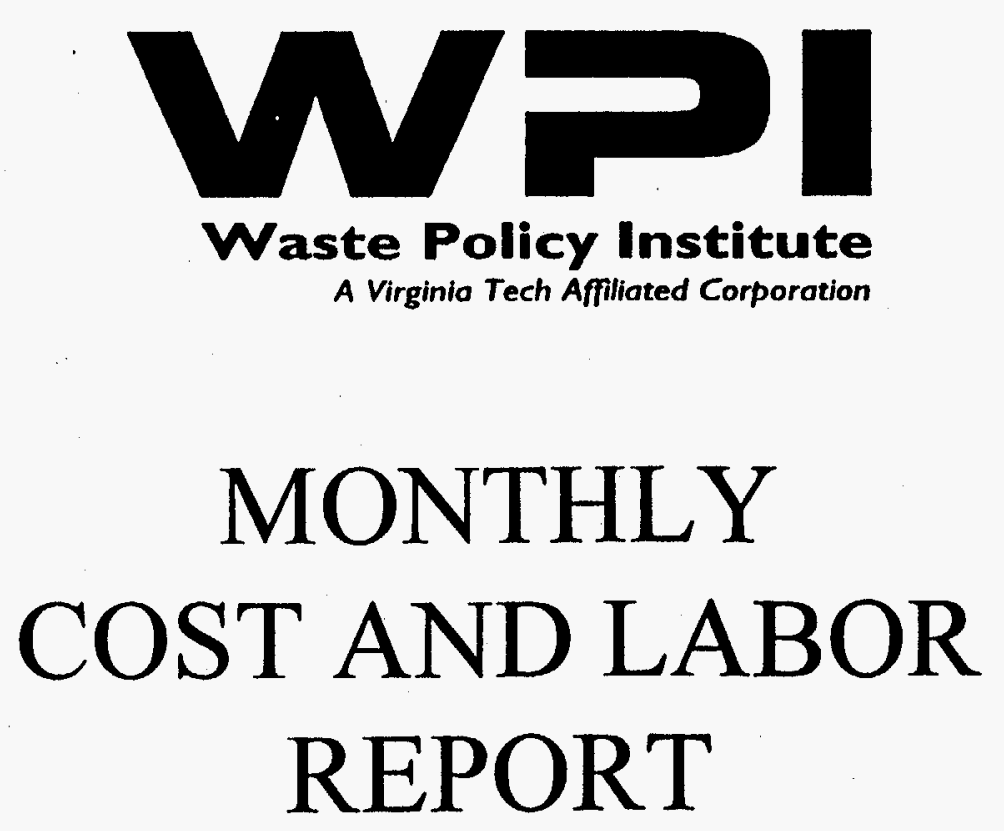

UNIVERSITY OF NORTH DAKOTA ENERGY AND ENVIRONMENTAL RESEARCH CENTER

Subcontract No. 359636

September, 1996 

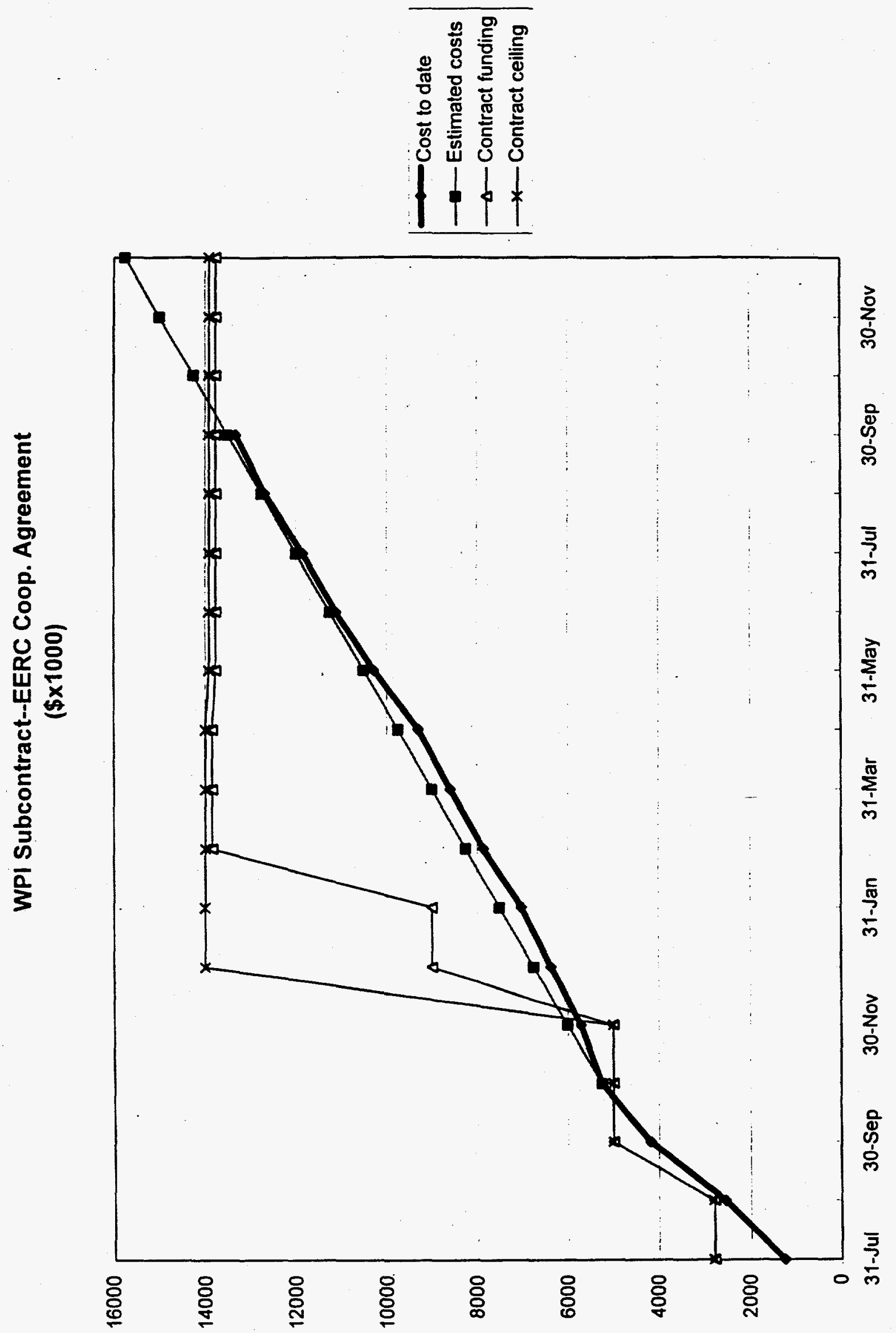


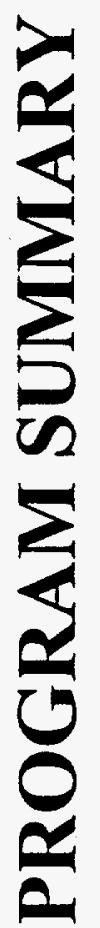


Subcontract No. 359636

Actuals through Sept 96

WBS: 1043 EERC

Manager: Dr. John S. Wilson

Start Date: 6/27/95

End Date: 12/1/96

Task Description: Provide assistance to EERC's conduct of technology development integration activities.

Cost Performance Summary:

\begin{tabular}{|c|c|c|c|}
\hline & \multicolumn{3}{|c|}{ Current Period } \\
\hline & Budget & Actuals & Variance \\
\hline Hours: & 10,668 & 8.052 & 2.617 \\
\hline Price: & 839.498 & $\overline{6} 3 \overline{0} \overline{73}$ & 208.765 \\
\hline
\end{tabular}

\begin{tabular}{|c|c|c|}
\hline \multicolumn{3}{|c|}{ Inception to Date } \\
\hline Budget & Actuals & Variance \\
\hline 179,626 & $1 5 \longdiv { 2 4 4 }$ & $\overrightarrow{21,383}$ \\
\hline $14,101,983$ & $13,31 \overline{5,788}$ & $786,19 \overline{5}$ \\
\hline
\end{tabular}

\begin{tabular}{|c|c|c|}
\hline \multicolumn{3}{|c|}{ At Complete } \\
\hline Budget & Estimate & Varlance \\
\hline 179,950 & 158,568 & $21, \overline{383}$ \\
\hline $1 \overline{14,144,823}$ & $13,358,628$ & 786,195 \\
\hline
\end{tabular}

Monthly Financial Recap:

\begin{tabular}{|c|c|c|c|c|c|c|c|c|c|c|c|c|}
\hline & Jun 96 & Jul 96 & Aug 96 & Sep 96 & Oet 96 & Nov 96 & Dec 96 & $\operatorname{Jan} 97$ & Feb 97 & Mar 97 & Apr 97 & May 97 \\
\hline \multicolumn{13}{|l|}{ Actuals: } \\
\hline Monthly Hours: & 8.782 & 10,309 & 11.071 & 8,052 & 0 & 0 & & & & & & \\
\hline Cumu Hours: & 128,813 & 139,122 & 150,192 & 158,244 & 158,244 & 158,244 & & & & & & \\
\hline Monthly Price: & 829,253 & 740,287 & 835,492 & $630, \overline{733}$ & 0 & $\overline{0}$ & & & & & & \\
\hline Cumu Price: & $11,109,276$ & $11,849,563$ & $12,685,055$ & $13,315,788$ & $13,315,788$ & $13,315,788$ & & & & & & \\
\hline
\end{tabular}

Budget:

Monthly Hours:

Cumu Hours:

Monthly Price:

\begin{tabular}{|c|c|c|c|}
\hline 10,668 & 10,668 & 10,668 & 10,668 \\
\hline$\overline{147,622}$ & 158,290 & 168,958 & 179,626 \\
\hline 839,498 & 839,498 & 839,498 & 839,498 \\
\hline $11,583,490$ & $12,422,988$ & $13,262,486$ & $14,101,983$ \\
\hline
\end{tabular}

\begin{tabular}{|r|r|}
\hline 162 & 162 \\
\hline 179,788 & 179,950 \\
\hline 21,420 & 21,420 \\
\hline $14,123,403$ & $14,144,823$ \\
\hline
\end{tabular}

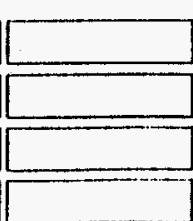

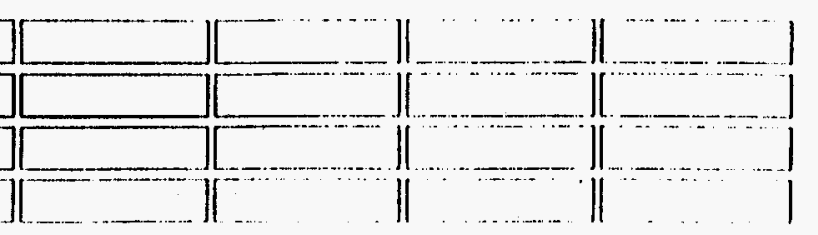


$\frac{4}{4}$ 
Actuals through Sept 96

WBS: 1043.01.01 Technology Management

Manager: Dr. John S. Wilson

Start Date: 6/27/95

End Date: $12 / 1 / 96$

Task Description: Perform technical reviews of requirements, needs and assessments related to waste characterization, containment, in-situ and ex-situ treatment, wasle storage, disposal, robotics handling, monitoring, laboration analysis, site characterization and remediation.

Cost Performance Summary:

\begin{tabular}{|c|c|c|c|}
\hline & \multicolumn{3}{|c|}{ Current Period } \\
\hline & Budget & Actuais & Variance \\
\hline Hours: & $5 . \overline{474}$ & $\overline{2}, \overline{0} \overline{6}$ & 3.448 \\
\hline Price: & 297.160 & 147,660 & 149,500 \\
\hline
\end{tabular}

\begin{tabular}{|c|c|c|}
\hline \multicolumn{3}{|c|}{ Inception to Date } \\
\hline Budget & Actuals & Varlance \\
\hline 87.456 & 62,595 & 24,861 \\
\hline $5,423,585$ & $5,734,130$ & $-310,545$ \\
\hline
\end{tabular}

\begin{tabular}{|c|c|c|}
\hline \multicolumn{3}{|c|}{ At Complete } \\
\hline Budget & Estimate & Varlance \\
\hline 87,456 & 62,595 & $\overrightarrow{24}, \overrightarrow{86} \bar{i}$ \\
\hline $5,4 \overline{33}, \overline{85}$ & $5, \overline{734}, 1 \overline{30}$ & $-310,545$ \\
\hline
\end{tabular}

Monthly Financial Recap:

\begin{tabular}{|c|c|c|c|c|c|c|c|c|c|c|c|c|}
\hline & Jun 96 & Jul 96 & Aug 96 & Sep 96 & Oct 96 & Nov 96 & Dec 96 & $\operatorname{Jan} 97$ & Feb 97 & Mar 97 & Apr 97 & May 97 \\
\hline \multicolumn{13}{|l|}{ Actuals: } \\
\hline Monthly Hours: & 3,099 & 2,743 & 2,528 & 2.026 & 0 & 0 & & & & & & \\
\hline Cumu Hours: & 55,299 & 58,041 & 60,569 & $62, \overline{595}$ & 62,595 & $\overline{62, \overline{595}}$ & & & & & & \\
\hline Monthly Price: & 317,399 & $219, \overline{262}$ & $250, \overline{563}$ & $14 \overline{660}$ & 0 & 0 & & & & & & \\
\hline Cumu Price: & $5,116,646$ & $5,335,908$ & $5,586,471$ & $5,734,130$ & $5, \overline{734,130}$ & $5,734,130$ & & & & & & \\
\hline
\end{tabular}

Budget:

Monthly Hours:

Cumu Hours:

Monthly Price:

Cumu Price:

\begin{tabular}{|c|c|c|}
\hline 5,474 & 5,474 & 5,474 \\
\hline 71,034 & 76,508 & 81,982 \\
\hline 297,160 & 297,160 & 297,160 \\
\hline $4,532,106$ & $4,829,266$ & $5,126,426$ \\
\hline
\end{tabular}

\begin{tabular}{|r|}
\hline 5.474 \\
\hline 87,456 \\
\hline 297.160 \\
\hline 5.423 .585 \\
\hline
\end{tabular}

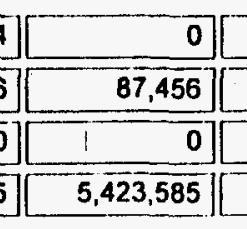

$\begin{array}{r}0] \\ \hline 0] \\ \hline 5,423,585 \\ \hline\end{array}$

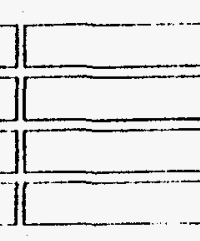

]$_{[}$

$\mid$


$\frac{\infty}{4}$ 
Actuals through Sept 96

WBS: 1043.01.02 Project Management

Manager: Dr. John S. Wilson

Start Date: 6/27/95

End Date: 12/1/96

Task Description: Conduct reviews, analyze and develop strategies for program management systems for integration and control of programs, projects, tasks and documentation.

Cost Performance Summary:

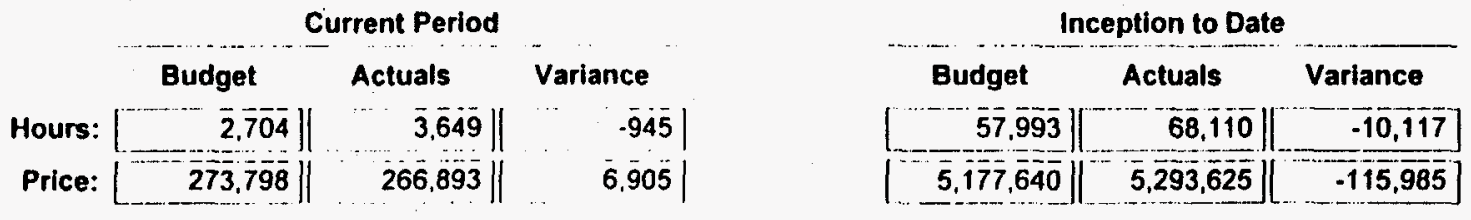

\begin{tabular}{|c|c|c|}
\hline \multicolumn{3}{|c|}{ At Complete } \\
\hline Budget & Estimate & Variance \\
\hline$\overline{57}, \overline{993}$ & $6 \overline{8}, 110$ & $-10,117$ \\
\hline $5,177,640$ & $\overline{5}, 293, \overline{625}$ & $-11 \overline{5}, \overline{985}$ \\
\hline
\end{tabular}

Monthly Financial Recap:

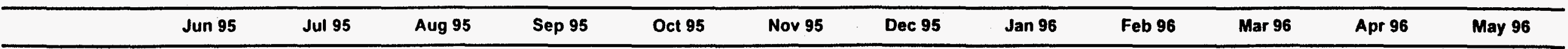

Actuals:

Monthly Hours:

Cumu Hours:

Monthly Price:

\begin{tabular}{|c|c|c|c|c|c|c|c|c|c|c|c|}
\hline 98 & 8,116 & 8.247 & 9,084 & 3,578 & 1.588 & 2,868 & 3,297 & $3, \overline{561}$ & $3,631]$ & $\mathbf{3}, 321$ & $4, \overline{024}$ \\
\hline 98 & 8,214 & 16,462 & 25.545 & 29,123 & 30.711 & 33,578 & 36,875 & 40,436 & 44,067 & 47.388 & 51,412 \\
\hline 5,779 & 599,758 & $566, \overline{591}$ & 719,936 & 341,971 & 108,114 & 275,047 & 255,073 & 319,577 & $306, \overline{69}$ & 269,945 & $315 . \overline{382}$ \\
\hline 5.779 & 605,537 & $1,172,128$ & $1,892,064$ & $2,234,035$ & $2,342,149$ & $2,617,196$ & $2,872,269$ & $3,191,846$ & $3,498,542$ & $3,768,486$ & $4,083,869$ \\
\hline
\end{tabular}

Cumu Price:

Budget:

Monthly Hours:

Cumu Hours:

\begin{tabular}{|r|r|}
\hline 309 & 6.643 \\
\hline 309 & 6,952 \\
\hline 21.034 & 453.804 \\
\hline 21.034 & 474.838 \\
\hline
\end{tabular}

\begin{tabular}{|c|c|}
\hline 8.042 & 10,551 \\
\hline 14,994 & 25,545 \\
\hline
\end{tabular}

$$
2704
$$

\begin{tabular}{|c|c|c|c|c|}
\hline $2, \overline{704}$ & $2, \overline{704}$ & $\overline{2,704}$ & $\overline{2}, \overline{704}$ & $\overline{2}, \overline{704}$ \\
\hline 30,953 & $\overline{33}, \overline{657}$ & 36,361 & $39, \overline{065}$ & 41,769 \\
\hline 273,798 & 273,798 & $273 . \overline{798}$ & 273,798 & 273.798 \\
\hline$\overline{2}, 439, \overline{659}$ & $2,713,457$ & $2,987,25 \overline{5}$ & $\overline{3}, 261,053$ & $3,534,852$ \\
\hline
\end{tabular}

2,7004

2,704

Monthly Price:

Cumu Price:

$\frac{527.559}{1,002,397}$

25,545

28,249


Actuals through Sept 96

WBS: 1043.01 .02 Project Management

Manager: Dr. John S. Wilson

Start Date: 6/27/95

End Date: 12/1/96

Task Description: Conduct reviews, analyze and develop strategies for program management systems for integration and control of programs, projects, tasks and documentation.

\section{Cost Performance Summary:}

\begin{tabular}{|c|c|c|c|}
\hline & \multicolumn{3}{|c|}{ Current Period } \\
\hline & Budget & Actuals & Variance \\
\hline Hours: & 2,704 & 3,649 & .945 \\
\hline Price: & 273,798 & 266.893 & 6.905 \\
\hline
\end{tabular}

\begin{tabular}{|c|c|c|}
\hline \multicolumn{3}{|c|}{ Inception to Date } \\
\hline Budget & Actuals & Variance \\
\hline 57,993 & 68,110 & $-10,117$ \\
\hline $5,177,640$ & $5,293,625$ & $-115,985$ \\
\hline
\end{tabular}

\begin{tabular}{|c|c|c|}
\hline \multicolumn{3}{|c|}{ At Complete } \\
\hline Budget & Estimate & Varlance \\
\hline 57,993 & 68,110 & $-10,117$ \\
\hline $5,177,640$ & $5,293,625$ & $-115,985$ \\
\hline
\end{tabular}

\section{Monthly Financlal Recap:}

\begin{tabular}{|c|c|c|c|c|c|c|c|c|c|c|c|c|}
\hline & Jun 96 & Jul 96 & Aug 96 & Sep 96 & Oct 96 & Nov 96 & Dec 96 & Jan 97 & Feb 97 & Mar 97 & Apr 97 & May 97 \\
\hline \multicolumn{13}{|l|}{ Actuals: } \\
\hline Monthly Hours: & 3,151 & $4 . \overline{572}$ & 5,327 & $\overline{3}, \overline{649}$ & 0] & 0 & & & & & & \\
\hline Cumu Hours: & 54,562 & 59,134 & 64,461 & 68,110 & 68,110 & 68,110 & & & & & & \\
\hline Monthly Price: & 276,057 & 305,344 & 361,463 & 266,893 & - & 0 & & & & & & \\
\hline Cumu Price: & $4,359,925$ & $4,665,270$ & $5,026,733$ & $5,293,625$ & $5,293,625$ & $5,293,625$ & & & & & & \\
\hline
\end{tabular}

Budget:

Monthly Hours:

Cumu Hours:

Monthly Price:

\begin{tabular}{|c|c|c|c|c|c|}
\hline 2.704 & 2,704 & 2,704 & 2.704 & 0 & 0 \\
\hline 49,881 & 52,585 & 55,289 & 57,993 & 57,993 & $57, \overline{93}$ \\
\hline 273,798 & 273,798 & 273,798 & 273,798 & 0 & 0 \\
\hline $4,356,246$ & $4,630,044$ & $4,903,842$ & $5,177,640$ & $5,177,640$ & $5,177, \overline{640}$ \\
\hline
\end{tabular}

(n)

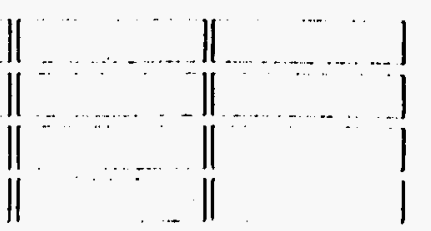


$\frac{0}{4}$ 
Subcontract No. 359636

Actuals through Sept 96

WBS: 1043.01 .03 Technology Integration

Manager: Dr. John S. Wilson

Start Date: 6/27/95

End Date: 12/1/96

Task Description: Provide support in establishing criteria for identifying risks to the public health and safety posed by conditions at the weapons complex facilities, evaluate the extent of these risks, determine the urgency and priorities for eliminating or minimizing the risks, and access the cost of activities required to meet applicable compliance agreements.

Cost Performance Summary:

\begin{tabular}{|c|c|c|c|}
\hline & & Jrrent Period & \\
\hline & Budget & Actuals & Varlance \\
\hline Hours: & $\overline{2}, \overline{32} \overline{8}$ & $\overline{2}, \overline{377}$ & $-4 \overrightarrow{9}$ \\
\hline Price: & 247,120 & 211,294 & $\overline{35}, \overline{8} 2 \overline{6}$ \\
\hline
\end{tabular}

\begin{tabular}{|c|c|c|}
\hline \multicolumn{3}{|c|}{ Inception to Date } \\
\hline Budget & Actuais & Varlance \\
\hline 33,367 & 27,532 & $\overline{5,835}$ \\
\hline $3,393,658$ & $2, \overline{271}, \overline{792}$ & $1,121,866$ \\
\hline
\end{tabular}

\begin{tabular}{|c|c|c|}
\hline \multicolumn{3}{|c|}{ At Complete } \\
\hline Budget & Estimate & Variance \\
\hline 33,367 & 27.532 & 5,835 \\
\hline $3,393,658$ & $2,271,792$ & $1,121,866$ \\
\hline
\end{tabular}

Monthly Financial Recap:

\begin{tabular}{|c|c|c|c|c|c|c|c|c|c|c|c|}
\hline Jun 95 & Jui 95 & Aug 95 & Sep 95 & Oct 95 & Nov 95 & Dec 95 & Jan 96 & Feb 96 & Mar 96 & Apr 96 & May 96 \\
\hline
\end{tabular}

Actuals:

\begin{tabular}{|c|c|c|c|c|c|c|c|c|c|c|c|c|}
\hline Monthly Hours: & 1 & $1, \overline{339}$ & $1, \overline{972}$ & 2,117 & 608 & 450 & 664 & 1,036 & 1,196 & 1,453 & 2,370 & $3,21 \overrightarrow{6}$ \\
\hline Cumu Hours: & 1 & $1, \overline{340}$ & 3,312 & $\overline{5}, \overline{428}$ & $6, \overline{036}$ & 6,486 & 7,150 & 8,185 & 9,381 & $10, \overline{8} \overline{4}$ & 13,203 & 16,419 \\
\hline Monthly Price: & 139 & 106,521 & 151,601 & 169,960 & 73,113 & 41,466 & 82,773 & 75,216 & $11 \overline{7}, \overline{736}$ & 104.335 & $190 . \overline{919}$ & 283,077 \\
\hline Cumu Price: & 139 & 106,660 & 258,261 & 428,221 & 501,334 & 542,800 & $625 . \overline{574}$ & 700,790 & $818, \overline{526}$ & $922, \overline{80}$ & $1,11 \overline{3}, \overline{780}$ & $1, \overline{396}, \overline{85} \overline{7}$ \\
\hline
\end{tabular}

Budget:

Monthly Hours:

Cumu Hours:

Monthly Price:

\begin{tabular}{|r|r|}
\hline 800 & 4,589 \\
\hline 800 & 5,388 \\
\hline 54,170 & 299,639 \\
\hline 54,170 & 353,809 \\
\hline
\end{tabular}

\begin{tabular}{r|r}
5,555 \\
\hline 10,943 \\
\hline 356,729 \\
\hline 710,538 \\
\hline$-282,320$ \\
\hline 428,218 \\
- \\
\hline
\end{tabular}

\begin{tabular}{|c|c|c|c|c|c|}
\hline 2,328 & $\overline{2,328}$ & $2, \overline{328}$ & 2,328 & 2,328 & $2,32 \overline{8}$ \\
\hline 7,756 & 10.085 & 12,413 & 14,741 & 17,069 & 19,398 \\
\hline 247,120 & 247,120 & 247,120 & 247,120 & 247.120 & 247,120 \\
\hline 675,338 & $922, \overline{458}$ & $1,169,578$ & $1,416,69 \overline{8}$ & $1, \overline{6} \overline{3}, \overline{8} 1 \overline{8}$ & $i, 910,938$ \\
\hline
\end{tabular}

$\overline{2}, \mathbf{3 2} \bar{B}|| \overline{\mathbf{3}}, \overline{\mathbf{3}} \overline{\mathrm{B}} \mid$ 21,726 - 24,054 Cumu Price: 
Subcontract No. 359636

Actuals through Sept 96

WBS: 1043.01.03 Technology Integration

Manager: Dr. John S. Wilson

Start Date: 6/27/95

End Date: 12/1/96

Task Description: Provide support in establishing criteria for identifying risks to the public health and safety posed by conditions at the weapons complex facilities, evaluate the extent of these risks, determine the urgency and priorities for eliminating or minimizing the risks, and access the cost of activities required to meet applicable compliance agreements

Cost Performance Summary:

\begin{tabular}{|c|c|c|c|}
\hline & & Irrent Perio & \\
\hline & Budget & Actuals & Varlance \\
\hline ours: & 2,328 & 2.377 & -49 \\
\hline Price: & 247,120 & 211,294 & 35.826 \\
\hline
\end{tabular}

\begin{tabular}{|c|c|c|}
\hline \multicolumn{3}{|c|}{ Inception to Date } \\
\hline Budget & Actuals & Variance \\
\hline 33,367 & 27,532 & 5,835 \\
\hline $3,393,65 \bar{B}$ & $2, \overline{271}, \overline{792}$ & $1,121, \overline{866}$ \\
\hline
\end{tabular}

\begin{tabular}{|c|c|c|}
\hline & At Complete & \\
\hline Budget & Estimate & Variance \\
\hline 33,367 & 27,532 & $5, \overline{8} \overline{5}$ \\
\hline $3,3 \overline{93}, 658$ & $2,271,792$ & $1,121,866$ \\
\hline
\end{tabular}

Monthly Financlal Recap:

\begin{tabular}{|c|c|c|c|c|c|c|c|c|c|c|c|c|}
\hline & Jun 96 & Jul 96 & Aug 96 & Sep 96 & Oct 96 & Nov 96 & Dec 96 & $\operatorname{Jan} 97$ & Feb 97 & Mar 97 & Apr 97 & May 97 \\
\hline \multicolumn{13}{|l|}{ Actuals: } \\
\hline Monthly Hours: & 2,533 & 2,993 & 3.210 & 2,377 & 0 & 0 & & & & & & \\
\hline Cumu Hours: & 18,952 & 21,945 & 25,155 & 27,532 & 27,532 & 27,532 & & & & & & \\
\hline Monthly Price: & 230,149 & 215.115 & 218,378 & 211,294 & 0 & 0 & & & & & & \\
\hline Cumu Price: & $1,627,005$ & $1,842,120$ & $2,060,498$ & $2,271,792$ & $2,271,792$ & $2,271,792$ & & & & & & \\
\hline \multicolumn{13}{|l|}{ Budget: } \\
\hline Monthly Hours: & 2,328 & 2,328 & 2,328 & $2, \overline{328}$ & 0 & 0 & & & & & & r \\
\hline Cumu Hours: & 26,382 & 28,711 & 31,039 & 33,367 & 33,367 & 33,367 & & & & & & \\
\hline Monthly Price: & 247,120 & 247,120 & 247.120 & 247,120 & 0 & 0 & & & & & & \\
\hline Cumu Price: & $2,652,298$ & $2,899,418$ & $3,146,538$ & $3,393,658$ & $3,393,658$ & $3,393,658$ & & & & & & \\
\hline
\end{tabular}


$\frac{2}{5}$ 
Subcontract No. 359636

Actuals through Sept 96

WBS: 1043.01.04 Systems Engineering

Start Date: 2/1/96

End Date: $12 / 1 / 96$

Task Description

Cost Performance Summary:

\begin{tabular}{|c|c|c|c|}
\hline & \multicolumn{3}{|c|}{ Current Period } \\
\hline & Budget & Actuals & Variance \\
\hline Hours: & 162 & 0 & 162 \\
\hline Price: & 21,420 & 4.887 & 16.533 \\
\hline
\end{tabular}

\begin{tabular}{|c|c|c|}
\hline \multicolumn{3}{|c|}{ Inception to Date } \\
\hline Budget & Actuals & Variance \\
\hline 810 & 7 & 803 \\
\hline 107,100 & 16,241 & $\overline{90,859}$ \\
\hline
\end{tabular}

\begin{tabular}{|c|c|c|}
\hline \multicolumn{3}{|c|}{ At Complete } \\
\hline Budget & Estimate & Variance \\
\hline 1,134 & 331 & 803 \\
\hline 149,940 & $\overline{59}, \overline{081}$ & $\overline{90,859}$ \\
\hline
\end{tabular}

Monthly Financial Recap:

\begin{tabular}{|c|c|c|c|c|c|c|c|c|c|c|c|c|}
\hline & Jun 95 & Jul 95 & Aug 95 & Sep 95 & Oct 95 & Nov 95 & Dec 95 & Jan 96 & Feb 96 & Mar 96 & Apr 96 & May 96 \\
\hline \multicolumn{13}{|l|}{ Actuals: } \\
\hline Monthly Hours: & 0 & 0 & 0 & 0 & 0 & 0 & 0 & 0 & 0 & 0 & $\mathbf{0}$ & 0 \\
\hline Cumu Hours: & $\overline{0}$ & 0 & 0 & 0 & 0 & 0 & $\overline{0}$ & 0 & 0 & 0 & $\overline{0}$ & $\overline{0}$ \\
\hline Monthly Price: & 0 & 0 & 0 & 0 & 0 & 0 & 0 & 0 & 0 & 0 & 0 & 51 \\
\hline Cumu Price: & 0 & 0 & 0 & 0 & 0 & 0 & 0 & 0 & $\overline{0}$ & 0 & $\overline{0}$ & 51 \\
\hline
\end{tabular}

Budget:

Monthly Hours:

Cumu Hours:

Monthly Price:

Cumu Price:

\begin{tabular}{|r|r|}
\hline & \\
\hline 0 & 0 \\
\hline 0 & 0 \\
\hline 0 & 0 \\
\hline
\end{tabular}

\begin{tabular}{|l|r|}
\hline 0 & 0 \\
\hline 0 & 0 \\
0 & 0 \\
\hline 0 & 0
\end{tabular}

\begin{tabular}{|l|l|r|r|}
\hline 0 & 0 \\
\hline 0 & 0 & 0 & 0 \\
\hline 0 & 0 & 0 \\
\hline 0 & 0 & 0 \\
\hline 0 & 0 & 0 \\
\hline 0 & 0 & 0 \\
\hline
\end{tabular}

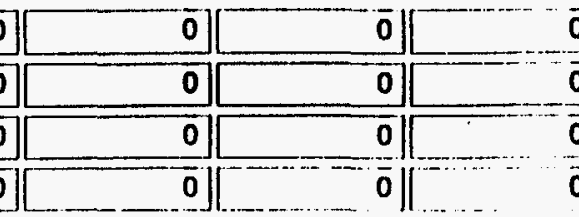

\begin{tabular}{|c|c|c|}
\hline & $\overrightarrow{0}$ & 162 \\
\hline & $\overline{0}$ & 162 \\
\hline & 0 & 21,420 \\
\hline & o) & 21,420 \\
\hline
\end{tabular}


Actuals through Sept 96

WBS: 1043.01 .04 Systems Engineering

Manager: Dr. John S. Wilson

Start Date: 2/1/96

End Date: 12/1/96

Task Description:

Cost Performance Summary:

Current Period Variance

Inception to Date

\begin{tabular}{r|r|r|}
\hline Budget & Actuals & Variance \\
\hline 810 & 7 \\
\hline 107,100 & 803 \\
\hline 16,241 & 90,859 \\
\hline
\end{tabular}

\begin{tabular}{|c|c|c|}
\hline \multicolumn{3}{|c|}{ At Complete } \\
\hline Budget & Estimate & Variance \\
\hline 1.134 & 331 & 803 \\
\hline $14 \overline{9}, \overline{940}$ & $59, \overline{081}$ & $\overline{90}, \overline{859}$ \\
\hline
\end{tabular}

\section{Monthly Financlal Recap:}

\begin{tabular}{|c|c|c|c|c|c|c|c|c|c|c|c|c|}
\hline & Jun 96 & Jul 96 & Aug 96 & Sep 96 & Oct 96 & Nov 96 & Dec 96 & $\operatorname{Jan} 97$ & Feb 97 & Mar 97 & Apr 97 & May 97 \\
\hline Actuals: & & & & & & & & & & & , & \\
\hline Monthly Hours: & 0 & 2 & 5 & 0 & 0 & 0 & & & & & & \\
\hline Cumu Hours: & 0 & 2 & 7 & 7 & 7 & 7 & & & & & & \\
\hline Monthly Price: & 5,648 & 565 & 5,089 & 4,887 & 0 & 0 & & & & & & \\
\hline Cumu Price: & 5.699 & $\overline{6,265}$ & 11,354 & 16,241 & 16,241 & 16,241 & & & & & & \\
\hline
\end{tabular}

Budget:

Monthly Hours:

Cumu Hours:

Monthly Price:

\begin{tabular}{|r|r|r|r|}
\hline 162 & 162 & 162 & 162 \\
\hline 324 & 486 & 648 & 610 \\
\hline 21,420 & 21,420 & 21,420 \\
\hline 42,840 & 64,260 & 21,420 \\
\hline 85,680 & 107,100 \\
\hline
\end{tabular}

\begin{tabular}{|r|r|}
\hline 972 & 162 \\
\hline 21,420 & 1,134 \\
\hline 128,520 & 21,420 \\
\hline 149,940 \\
\hline
\end{tabular}

(2)


X:IFIN14624\&25

(10/80)

1. Program/Project identification Ho.

DE-FC21-94MC31388

4. Name and Addreas
FORM EIA-459E

U.S. DEPARTMENT OF ENERGY

FEDERAL ASSISTANCE MANAGEMENT SUMMARY REPORT

FORM APPROVED

OMB NO. 19000127

Page 1 of 3
2. Program/Project Tide

BM Teak 10 - Technoloay Development integration

Energy \& Environmental Research Center

PO Box 9018, Grand Forks, ND 58202-9018 (701) 777-5000
University of North Dakota
3. Reporting Pariod

211/96 through 9/30/96

5. Progrem Stert Dute $9 / 30 / 94$

6. Complacion Date $9 / 29 / 99$

\begin{tabular}{|l|c|}
\hline $\begin{array}{l}\text { 7. FY } \\
95 / 96\end{array}$ & $\begin{array}{c}\text { 8. Months or Quarters } \\
\text { Quarters }\end{array}$ \\
\hline $\begin{array}{l}\text { 9. Cost } \\
\text { Status }\end{array}$ & a. Dollars Expreseed In \\
Thousends
\end{tabular}

10. Cost Chart

\begin{tabular}{|c|c|c|c|c|c|c|c|}
\hline \multirow{2}{*}{$\begin{array}{l}\text { Fund } \\
\text { Source }\end{array}$} & & \multicolumn{4}{|c|}{ Querter } & \multirow{2}{*}{$\begin{array}{c}\text { Cum. } \\
\text { to } \\
\text { Date } \\
\end{array}$} & \multirow[b]{2}{*}{$\begin{array}{l}\text { Tot. } \\
\text { Pian }\end{array}$} \\
\hline & & \multirow[t]{2}{*}{$18 t$} & \multirow[t]{2}{*}{ 2nd } & \multirow[t]{2}{*}{ 3rd } & \multirow{2}{*}{$\frac{4 \text { th }}{5400}$} & & \\
\hline DOE & $\mathbf{P}$ & & & & & 5400 & 14,481 \\
\hline & $A$ & & & & 1909 & 1909 & \\
\hline & $P$ & & & & & & \\
\hline & $A$ & & & & & & \\
\hline & $\mathbf{P}$ & & & & & & \\
\hline & $A$ & & & & & & \\
\hline & $P$ & & & & & & \\
\hline & $\mathbf{A}$ & & & & & & \\
\hline To & & & & & 5400 & 5400 & 14,481 \\
\hline To & & & & & 1909 & 1909 & \\
\hline Vari & & & & & 3491 & 3491 & \\
\hline
\end{tabular}

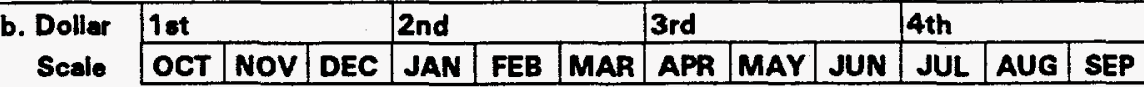

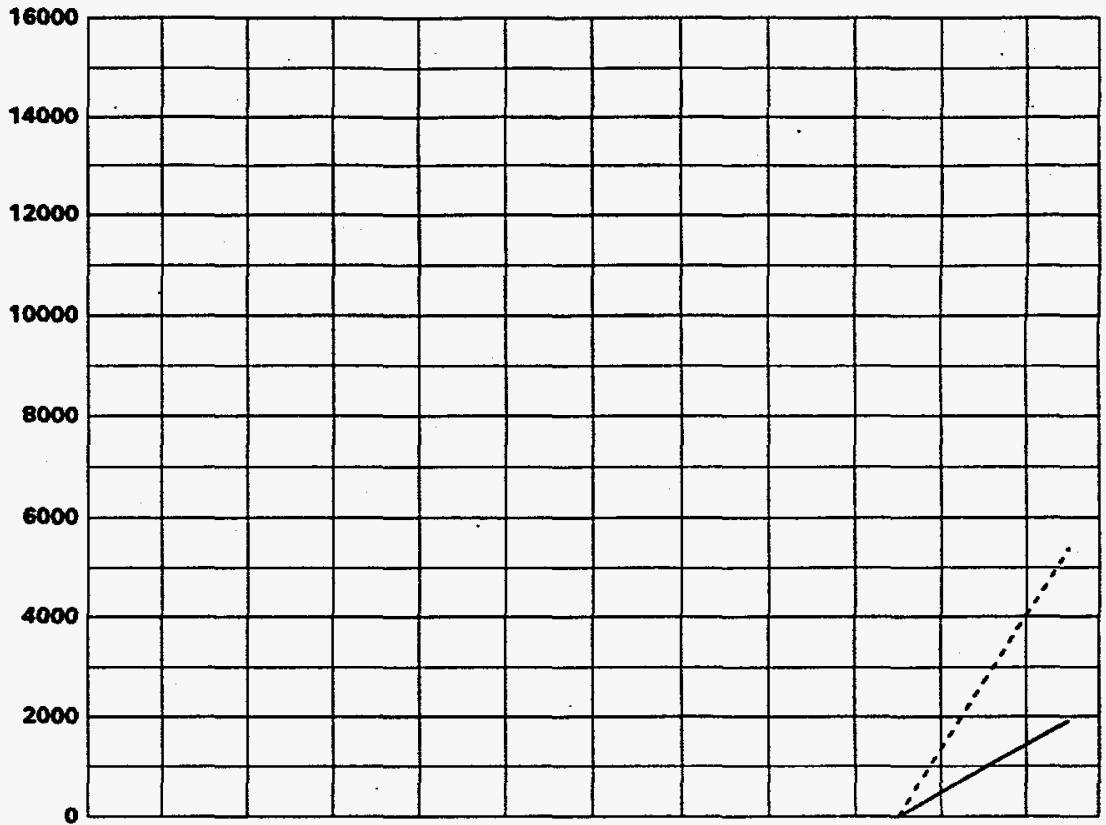

c. Cumulative Accrued Costs

Total Planned Costs for Program/Project $\$ 14,481$

11. Major Milestone Statue

10.1 Technology Management

10.2 Project Mansgement

10.3 Technoiogy Integration

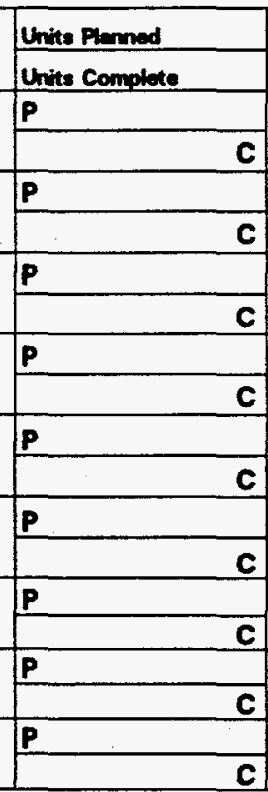

\section{Remarke}

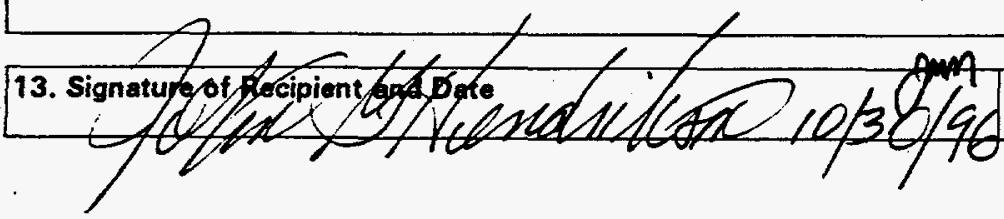

14. Signature of DOE Reviewing Representative and Date 
FORM EIA-459E

(10/80)

1. Program/Project Identificention No. DE-FC21-94MC31388

4. Name and Addrees
U.S DEPARTMENT OF ENERGY FEDERAL ASSISTANCE MANAGEMENT SUMMARY REPORT

FORM APPROVED OMB NO. 19000127

Pere 2 of 3

3. Reporting Period

z1196 throwh 9/30/96

5. Progrmm Sturt Date 9/30/94

University of North Dakote

PO Box 9018, Grand Forks, ND $58202-9018 \quad$ (701) $777-5000$

\section{En Taak 10 - Technology Dovelopinemt Integration}

6. Completion Date 9/29/99

\begin{tabular}{|c|c|}
\hline $\begin{array}{l}\text { 7. FY } \\
96 / 97\end{array}$ & $\begin{array}{c}\text { 8. Monthe or Quarters } \\
\text { Quarters }\end{array}$ \\
\hline Sta & $\begin{array}{l}\text { a. Dollars Expre } \\
\text { Thousands }\end{array}$ \\
\hline
\end{tabular}

10. Cost Chart

\begin{tabular}{|c|c|c|c|c|c|c|c|}
\hline \multirow{2}{*}{$\begin{array}{l}\text { Fund } \\
\text { Source }\end{array}$} & & \multicolumn{4}{|c|}{ Quarter } & \multirow{2}{*}{$\begin{array}{c}\text { Cum. } \\
\text { to } \\
\text { Date }\end{array}$} & \multirow[b]{2}{*}{$\begin{array}{l}\text { Tot. } \\
\text { Plan }\end{array}$} \\
\hline & & $1 \mathrm{st}$ & 2nd & 3rd & 4th & & \\
\hline \multirow[t]{8}{*}{ DOE } & $\mathbf{P}$ & 1000 & 1350 & 3253 & 3478 & 14481 & 14.481 \\
\hline & A & 3227 & 2376 & 3073 & 2708 & 13293 & \\
\hline & $\mathbf{P}$ & & & & & & \\
\hline & A & & & & & & \\
\hline & $\mathbf{P}$ & & & & & & \\
\hline & A & & & & & & \\
\hline & $\mathbf{P}$ & & & & & & \\
\hline & A & & & & & & \\
\hline \multicolumn{2}{|c|}{ Total P } & 1000 & 1350 & 3253 & 3478 & 14481 & 14,481 \\
\hline \multicolumn{2}{|c|}{ Total A } & 3227 & 2376 & 3073 & 2708 & 13293 & \\
\hline \multicolumn{2}{|c|}{ Variance } & $(2,227)$ & $(1,026)$ & 180 & 770 & 1188 & \\
\hline & & $\mathbf{P}=\mathbf{P} \mathbf{I}$ & anned & A & Act & & \\
\hline
\end{tabular}

Total Planned Costs for Program/Project

$\$ 14,481$ \begin{tabular}{|l|l|l|l|l|l|l|l|l|l|l|l|l|}
\hline $\begin{array}{l}\text { b. Dollar } \\
\text { Scale }\end{array}$ & 1st & \multicolumn{3}{|l|}{ 2nd } & \multicolumn{3}{|l|}{ 3rd } & 4th \\
\cline { 2 - 9 } & OCT & NOV & DEC & JAN & FEB & MAR & APR & MAY & JUN & JUL & AUG & SEP \\
\hline
\end{tabular}

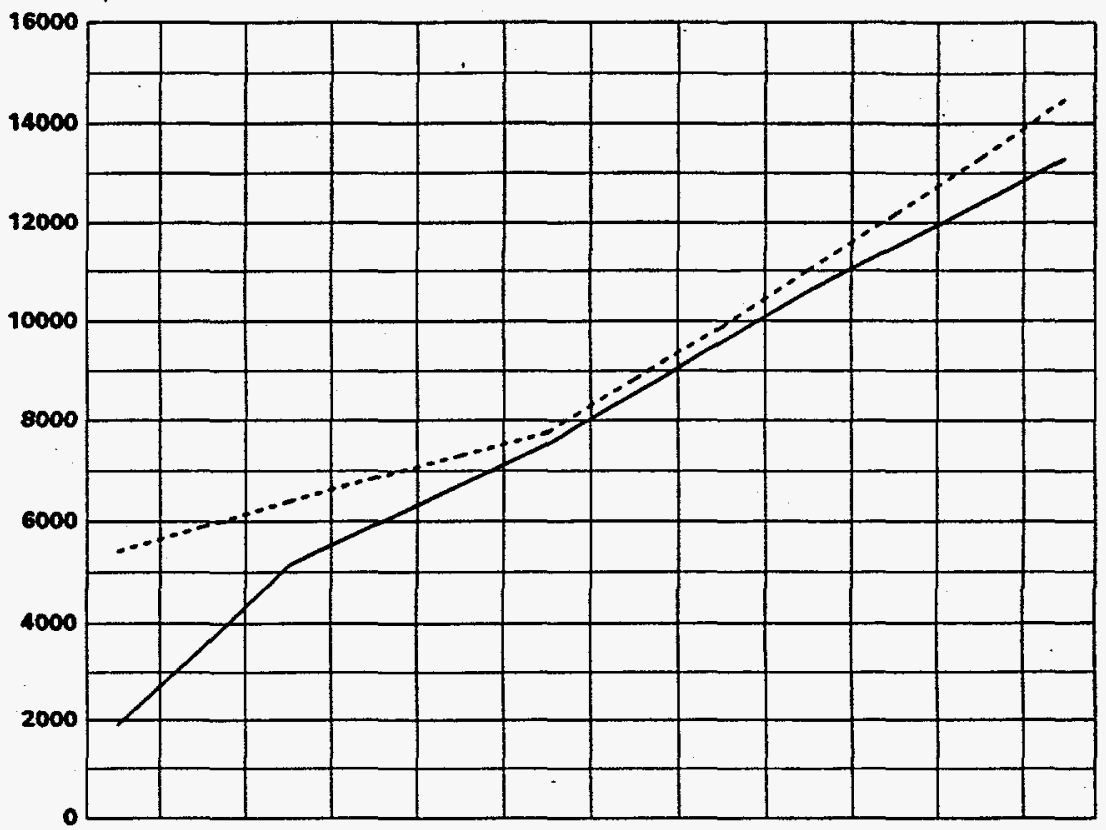

c. Cumulative Accrued Costs

\begin{tabular}{|l|l|l|l|l|l|l|l|l|l|l|l|l|}
\hline Planned & & & 6400 & & & 7750 & & & 11003 & & & 14481 \\
\hline Actual & & & 5136 & & & 7512 & & & 10585 & & & 13293 \\
\hline Variance & & 1.264 & & & 238 & & & 418 & & & 1188 \\
\hline
\end{tabular}

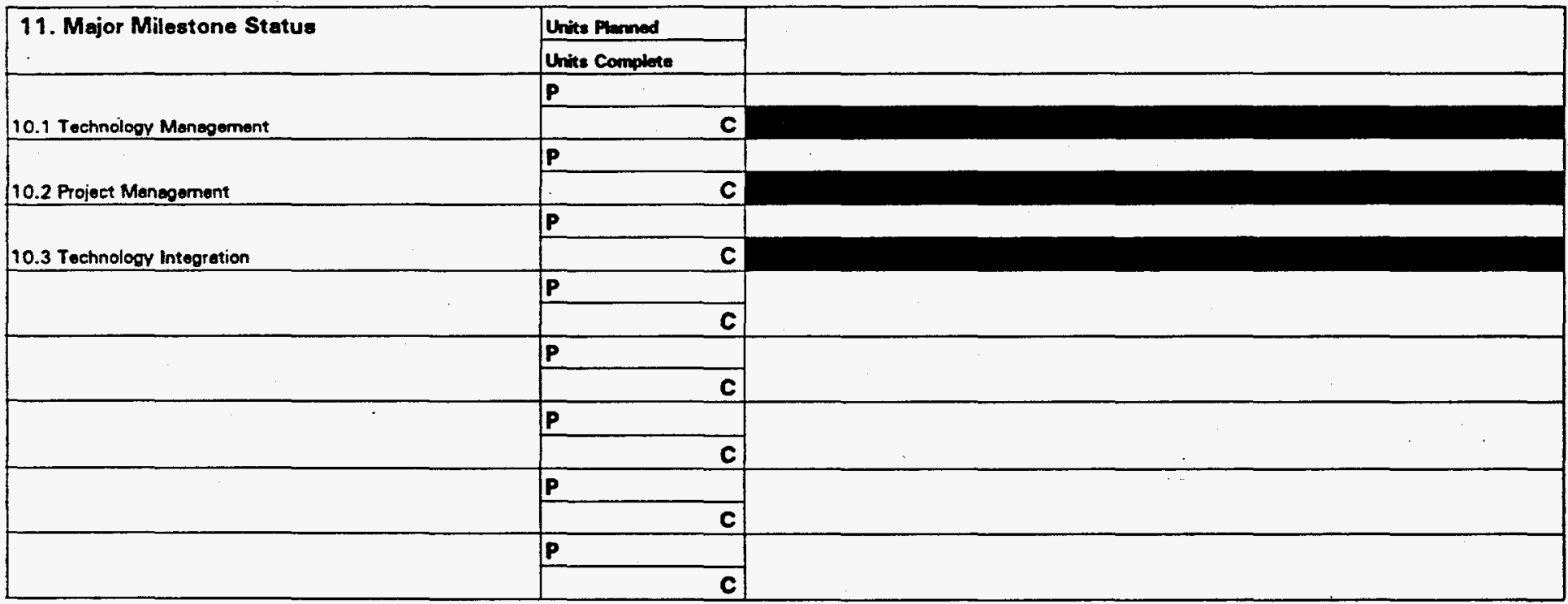

\section{Remarks}


U.S. DEPARTMENT OF ENERGY

FORM EIA-459E

(10/80)
FORM APPROVED

OMB NO. 19000127

Page 3 of 3

1. Prooram/Project Idontifiontion No.

4. Name and Addreas

2. Program/Project Tile

EM Trak 10 - Technology Development integration

Energy \& Environmental Research Center

University of North Dakota

PO Box 9018, Grand Forks, ND $58202-9018$

(701) $777-5000$

3. Reporing Period Z11498 through $9 / 30196$

5. Progrm Stert Date 9/30/94

6. Complation Date DE-FC21-94MC31388 9/29/99

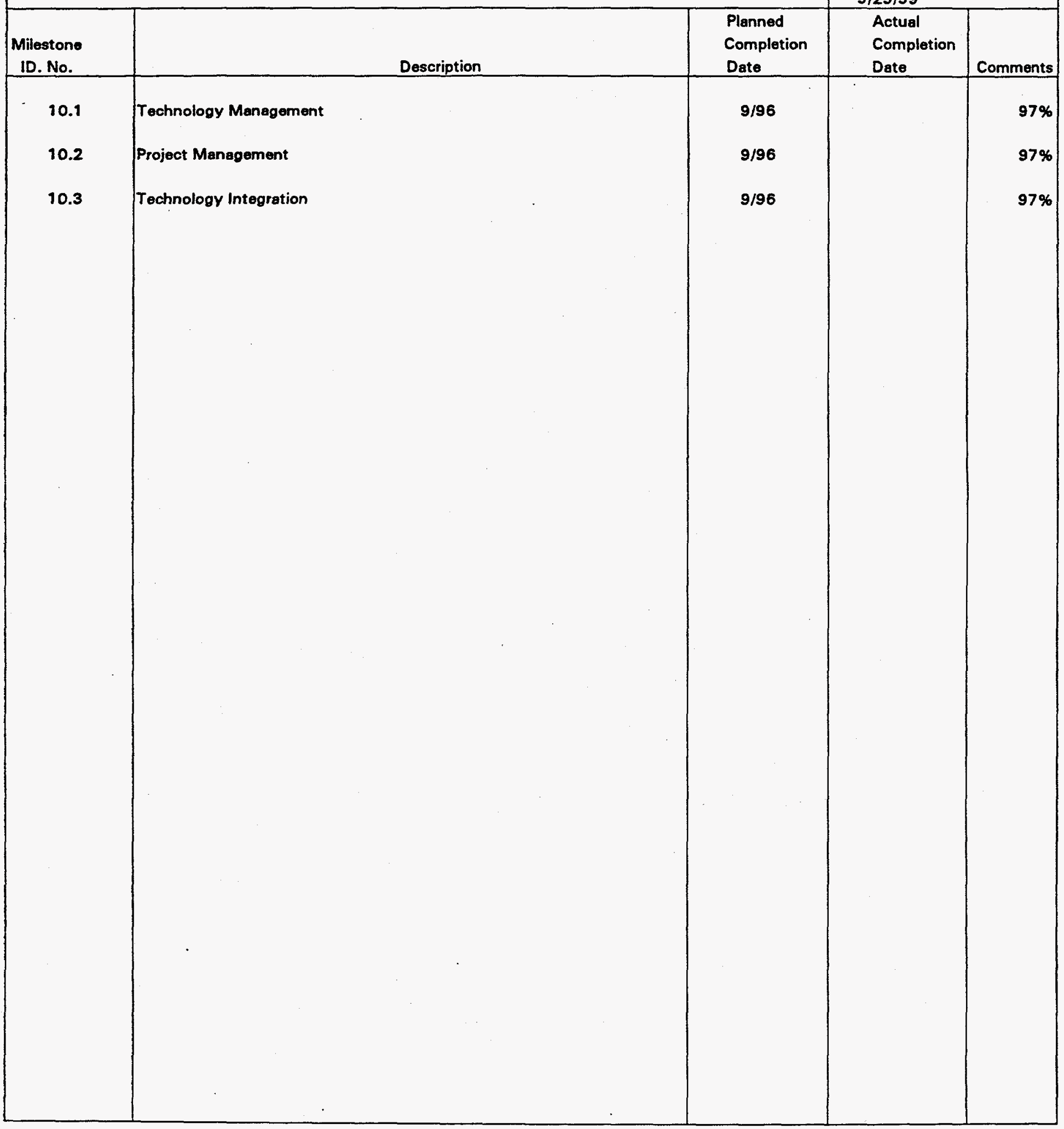

